RAFAEL ALZUGUIR ROSIN

HEURÍSTICA COM BUSCA LOCAL PARA SOLUÇÃO DO PROBLEMA DE COBERTURA DE ROTAS COM CARDINALIDADE RESTRITA 


\section{HEURÍSTICA COM BUSCA LOCAL PARA SOLUÇÃO DO PROBLEMA DE COBERTURA DE ROTAS COM CARDINALIDADE RESTRITA}

Dissertação apresentada à Escola Politécnica da Universidade de São Paulo para obtenção do Título de Mestre em Engenharia.

Área de Concentração:

Engenharia de Sistemas Logísticos

Orientador: Professor Livre-Docente Hugo Tsugunobu Yoshida Yoshizaki 
Este exemplar foi revisado e alterado em relação à versão original, sob responsabilidade única do autor e com a anuência de seu orientador.

São Paulo, 17 de fevereiro de 2012.

Assinatura do autor

Assinatura do orientador

Rosin, Rafael Alzuguir

Heurística com busca local para solução do problema de cobertura de rotas com cardinalidade restrita / R.A. Rosin. -ed.rev. -- São Paulo, 2012.

$107 \mathrm{p}$.

Dissertação (Mestrado) - Escola Politécnica da Universidade de São Paulo. Departamento de Engenharia de Transportes. Sistemas Logísticos.

1. Pesquisa operacional 2. Heurística 3. Logística 4. Administração de materiais I. Universidade de São Paulo. Escola Politécnica. Departamento de Engenharia de Transportes II. t. 
"Queria ter uma bicicleta que me mostrasse o que se esconde na próxima curva, o grau da próxima subida e o local do próximo tombo. Mas então me lembro que uma volta de bicicleta é como nossas próprias vidas, onde existe o prazer de se descobrir o que ainda se esconde, que uma subida é algo necessário para se atingir o topo da montanha, e que depois de cada tombo ainda haverá força para reerguer a bicicleta e continuar"

Rafael Alzuguir Rosin 


\section{AGRADECIMENTOS}

Ao Professor Livre Docente Hugo Yoshizaki pelas orientações e conversas acerca deste mestrado e outros assuntos profissionais.

A todos os professores que tive contato ao longo do mestrado, pelos ensinamentos passados e que hoje fazem parte do meu conhecimento, o maior bem que se pode ter em vida.

Ao Mestre e colega Enrico Ferri por prover os algoritmos utilizados em sua dissertação e pelas valiosas discussões.

Aos meus amigos e colegas de trabalho das salas GOL e GEE, pelas valiosas conversas de logística, heurísticas, programação e etc.

Às empresas Bunge Fertilizantes, DHL e Kimberly-Clark pela experiência profissional e por cederem parte do meu tempo ao longo do meu mestrado.

Aos meus pais Miguel e Vera pelo apoio e por me darem toda a estrutura que me permitiu chegar até aqui.

Aos meus irmãos Gustavo e Fábio pelas conversas e apoio acerca de minhas decisões.

À minha noiva Ana Paula Marchi pelo apoio e por entender que mestrado é algo que demanda tempo e atenção.

Aos meus amigos que por muitas vezes entenderam a minha ausência e que ainda assim se mostraram próximos.

Aos meus avôs e avós que fizeram parte de minha formação e que torcem por $\operatorname{mim}$.

À Deus. 


\section{RESUMO}

A crescente necessidade de buscar operações mais eficientes, com menor custo e mais sustentáveis tem feito com que empresas passassem a procurar oportunidades pelas quais estes objetivos pudessem ser atingidos. $\mathrm{Na}$ área de transportes encontrou-se na colaboração uma oportunidade para tal.

Este trabalho trata o problema de cobertura rotas com cardinalidade restrita (PCRCR), onde empresas que realizam viagens de carga cheia se unem com o objetivo de reduzir o deslocamento vazio de veículos através da formação de ciclos. É chamado de problema de cardinalidade restrita uma vez que limitamos o número de máximo de viagens no ciclo, o que torna este problema NP-Hard.

Existem na literatura duas heurísticas (construtivas) e um modelo por programação linear inteira para a solução deste problema. Este trabalho apresenta uma heurística baseada em um método de busca local que reduziu em média 3,19\% os melhores resultados apresentados na literatura.

Também são apresentados os tempos de execução de cada um dos algoritmos e a importância de escolher de uma boa solução inicial quando se deseja implantar uma Heurística com Busca Local.

Palavras-chave: Heurística, problema de cobertura de rotas, logística colaborativa, busca local. 


\begin{abstract}
The growing need to seek more efficient, lower cost and more sustainable operations has caused industries to seek opportunities in which these objectives could be achieved. In the area of transportation, collaboration is an opportunity for that.
\end{abstract}

This work deals with the cardinality constrained lane covering problem (CCLCP), where companies who uses full truck loads join efforts in order to reduce empty vehicle travel through closed cycle formation. It is known as cardinality constraint problem as the maximum number of trips in the cycle is limited to an integer number, which makes this problem NP-Hard.

There are two heuristics in the literature (constructive) and an integer linear programming model for solving this problem. This work presents a heuristic based on a local search method that reduced an average of $3.19 \%$ the better results in the literature.

It also presents the execution times of each algorithm and the importance of choosing a good initial solution when you want to create a Local Search Heuristic.

Keywords: Heuristics, lane covering problem, collaborative logistics, local search. 


\section{SUMÁRIO}

1 INTRODUÇÃO ......................................................................................

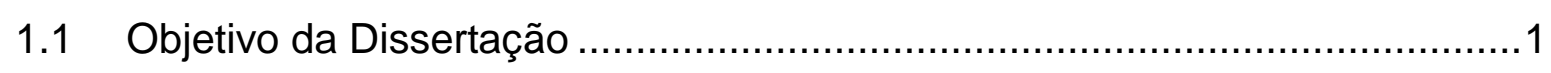

1.2 Relevância do Problema .................................................................

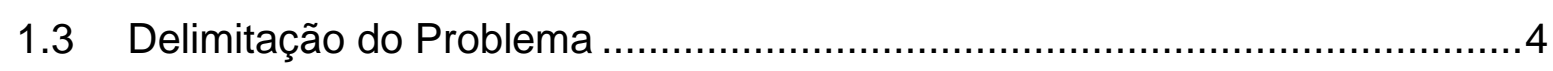

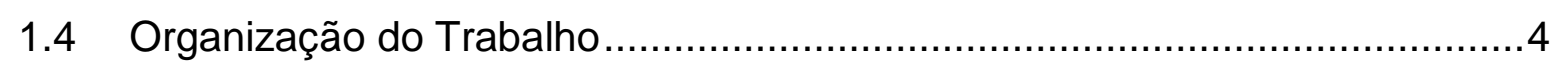

2 REVISÃO DA LITERATURA .......................................................................6

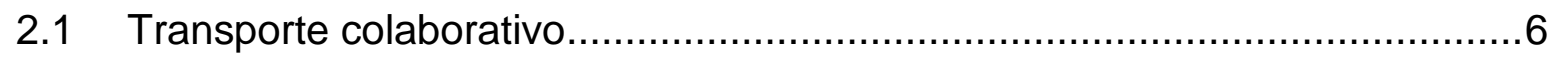

2.2 Problemas de Cobertura de Rotas ...................................................

2.2.1 Problema de Cobertura de Rotas (PCR) ....................................................... 8

2.2.2 Problema de Cobertura de Rotas com Cardinalidade Restrita (PCRCR) ................... 11

2.2.3 Problema de Cobertura de Rotas com Extensão Restrita (PCRER) .......................... 16

2.2.4 Problema de Cobertura de Rotas com Tempo Restrito (PCRTR) .............................. 17

2.2.5 Problema de Cobertura de Rotas com Múltiplos Transportadores (PCRMT) ............. 19

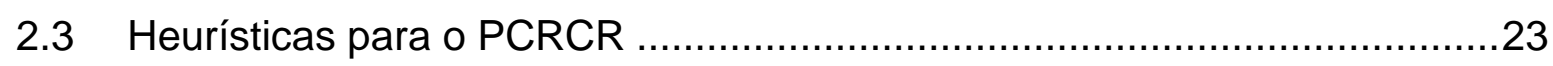

2.3.1 Algoritmo Guloso proposto por Ergun et al. (2007b) .............................................. 23

2.3.2 Heurística Construtivo-Destrutiva proposto por Ferri (2009) ..................................... 23

2.4 Métodos de Busca Local ....................................................... 25

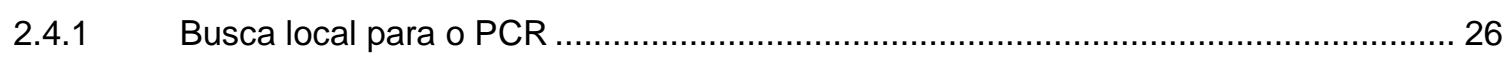

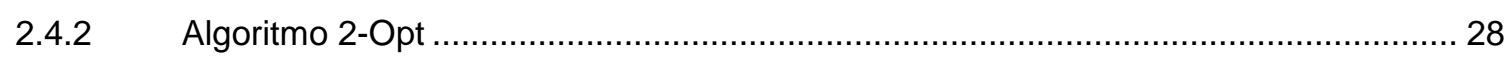

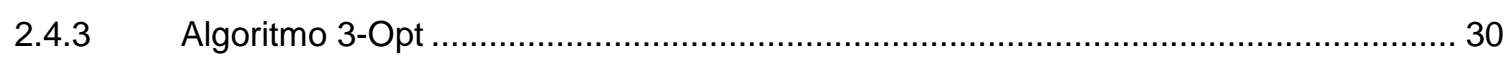

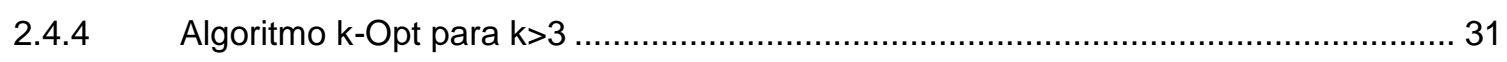

3 MÉTODO DE SOLUÇÃO DO PROBLEMA...................................................33

3.1 Descrição do Problema PCRCR .................................................. 33

3.2 Heurística com Busca Local proposta por este trabalho ............................35

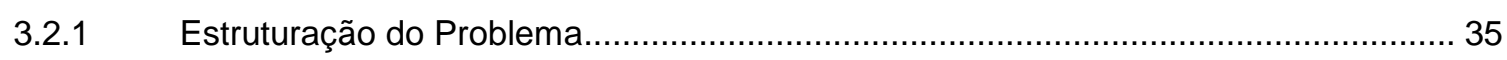

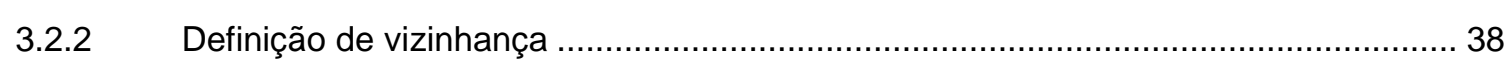

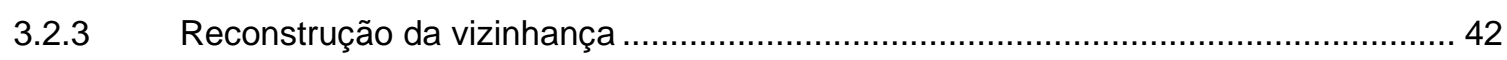

3.2.4 Descrição da Heurística com Busca Local............................................................... 44

3.2.5 Solução Inicial para a Heurística com Busca Local ............................................... 46

4 APLICAÇÃO DOS MÉTODOS ....................................................................48

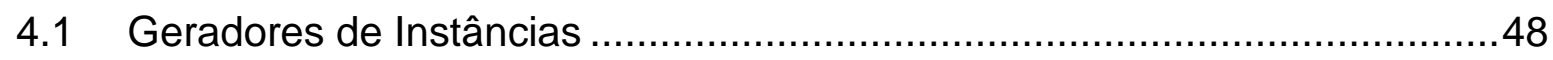

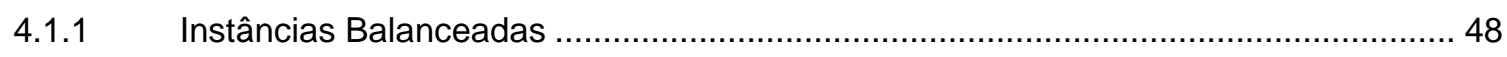

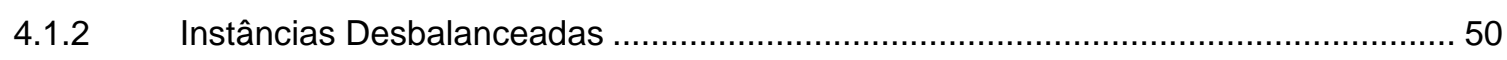

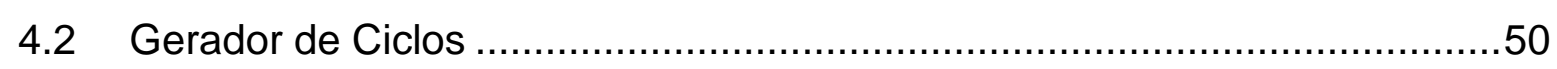


4.3 Aplicação da Programação Linear Inteira (PLI) .......................................52

4.4 Aplicação da Heurística com Busca Local ................................................52

4.5 Leitura da solução inicial com base nos resultados obtidos por GH e CD ...55

4.6 Resumo dos algoritmos apresentados ................................................56

4.7 Comparação e Análise dos resultados .....................................................58

4.7.1 Melhoria realizada pela Heurística com Busca Local (HBL) ..................................59

4.7.2 Comparação dos resultados obtidos pela Heurística com Busca Local ....................71

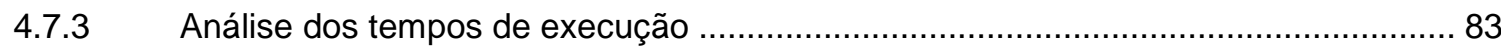

5 CONCLUSÕES E PERSPECTIVAS DE TRABALHOS FUTUROS ................100

5.1 Comentários sobre os resultados obtidos .............................................100

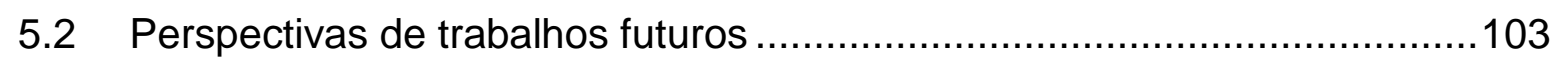

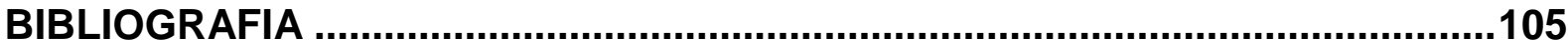




\section{LISTA DE FIGURAS}

Figura 1-1: Exemplo de Transporte Colaborativo .3

Figura 2-1: Exemplo de otimização de uma instância do Problema de Cobertura de Rotas

Figura 2-2: Exemplo de ciclos com $\mathrm{DH}=1$ e $\mathrm{DH}=2$ 12

Figura 2-3: Número de variáveis (em milhões) em função do número de rotas segundo o modelo básico para um problema de 500 vértices. .14

Figura 2-4: Estrutura de vizinhança na busca local para o PCR proposta por Savelsbergh et al. (2004) e Ergun et al. (2004)

Figura 2-5: Estrutura de vizinhança na busca local para o PCR proposta por

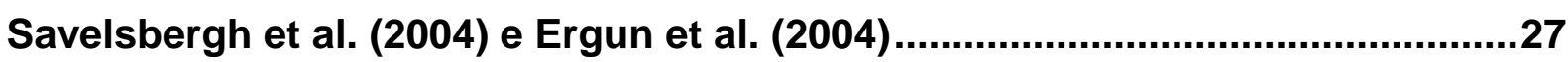

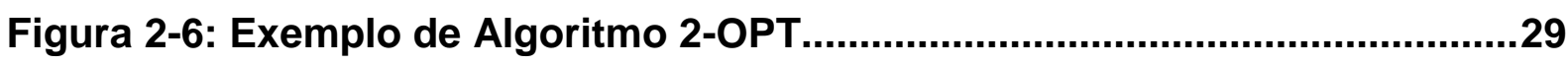

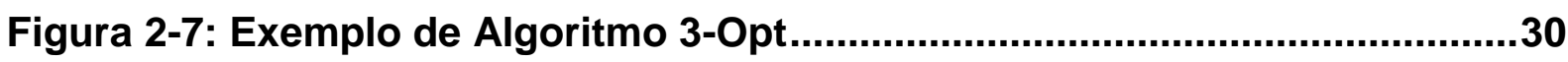

Figura 2-8: Exemplo de movimento 4-Opt "double-bridge"

Figura 2-9: Exemplo de como dois movimentos 2-Opt ilegais (gerando dois ciclos desconexos) é equivalente a um movimento 4-Opt 32

Figura 3-1: Ciclos viáveis por Cardinalidade e Reposicionamentos .34

Figura 3-2: Formação de uma rota simplificada pela união de duas rotas consecutivas. .35

Figura 3-3: Representação de uma solução para implementação do Método de Busca Local .36

Figura 3-4: Representação de uma solução para implementação do Método de Busca Local .

Figura 3-5: Representação das possibilidades de ciclos seguindo a representação simplificada .38

Figura 3-6: Exemplo de duas rotas candidatas a serem combinadas. .39

Figura 3-7: Exemplo de duas rotas candidatas a serem combinadas, sendo que uma delas já pertence a um ciclo 40

Figura 3-8: Exemplo de duas rotas (já alocadas a ciclos) candidatas a serem combinadas

Figura 3-9: Exemplo de soluções possíveis ao se recombinar rotas envolvidas na busca exaustiva 
Figura 4-1: Diferentes Dígrafos gerados para teste dos métodos .49

Figura 4-2 Formação de um ciclo com dois reposicionamentos pela combinação de dois ciclos com um reposicionamento cada. .51

Figura 4-3: Escolha de $n$ para problemas de 100 rotas .53

Figura 4-4: Escolha de $n$ para problemas de 200, 500, 1000, 1500, 3000 e 5000 rotas .54

Figura 4-5: Exemplos de "traduções" da solução inicial gerada por GH ou CD para estrutura a ser utilizada pela Heurística com Busca Local. .55

Figura 4-6: Compilação dos algoritmos utilizados. .56

Figura 4-7: Gráfico dos tempos de execução para problemas balanceados e com um reposicionamento (Dígrafo 1)

Figura 4-8: Gráfico dos tempos de execução para problemas desbalanceados (25\%) e com um reposicionamento (Dígrafo 1 ) .87

Figura 4-9: Gráfico dos tempos de execução para problemas desbalanceados (50\%) e com um reposicionamento (Dígrafo 1) 89

Figura 4-10: Gráfico dos tempos de execução para problemas desbalanceados (75\%) e com um reposicionamento (Dígrafo 1 )

Figura 4-11: Gráfico dos tempos de execução para problemas balanceados e com dois reposicionamentos (Dígrafo 1). .93

Figura 4-12: Gráfico dos tempos de execução para problemas desbalanceados (25\%) e com dois reposicionamentos (Dígrafo 1) .95

Figura 4-13: Gráfico dos tempos de execução para problemas desbalanceados (50\%) e com dois reposicionamentos (Dígrafo 1 )

Figura 4-14: Gráfico dos tempos de execução para problemas desbalanceados (75\%) e com dois reposicionamentos (Dígrafo 1) .99 


\section{LISTA DE TABELAS}

Tabela 2-1: Benefícios do Gerenciamento do Transporte Colaborativo (CTM) ...7 Tabela 4-1: Escolha de $\mathrm{n}$ para cada grupo de problemas .53

Tabela 4-2: Diferença entre as soluções inteiras encontradas e as obtidas por relaxação linear para problemas balanceados e com um reposicionamento....59 Tabela 4-3: Melhoria realizada pela Heurística com Busca Local (HBL) quando aplicada a diferentes soluções iniciais para problemas balanceados e um reposicionamento .60

Tabela 4-4: Diferença entre as soluções inteiras encontradas e as obtidas por relaxação linear para problemas desbalanceados e com um reposicionamento

Tabela 4-5: Melhoria realizada pela Heurística com Busca Local (HBL) quando aplicada a diferentes soluções iniciais para problemas desbalanceados $(25 \%)$ e um reposicionamento .62

Tabela 4-6: Melhoria realizada pela Heurística com Busca Local (HBL) quando aplicada a diferentes soluções iniciais para problemas desbalanceados $(50 \%)$ e um reposicionamento

Tabela 4-7: Melhoria realizada pela Heurística com Busca Local (HBL) quando aplicada a diferentes soluções iniciais para problemas desbalanceados $(75 \%)$ e um reposicionamento 64

Tabela 4-8: Melhoria realizada pela Heurística com Busca Local (HBL) quando aplicada a diferentes soluções iniciais para problemas balanceados e dois reposicionamentos

Tabela 4-9: Melhoria realizada pela Heurística com Busca Local (HBL) quando aplicada a diferentes soluções iniciais para problemas desbalanceados $(25 \%)$ e dois reposicionamentos

Tabela 4-10: Melhoria realizada pela Heurística com Busca Local (HBL) quando aplicada a diferentes soluções iniciais para problemas desbalanceados $(50 \%)$ e dois reposicionamentos 
Tabela 4-11: Melhoria realizada pela Heurística com Busca Local (HBL) quando aplicada a diferentes soluções iniciais para problemas desbalanceados $(75 \%)$ e dois reposicionamentos

Tabela 4-12: Comparação dos diferentes resultados obtidos pela Heurística com Busca Local (HBL) para problemas balanceados e com um reposicionamento .72

Tabela 4-13: Comparação dos diferentes resultados obtidos pela Heurística com Busca Local (HBL) para problemas desbalanceados $(25 \%)$ e com um reposicionamento

Tabela 4-14: Comparação dos diferentes resultados obtidos pela Heurística com Busca Local (HBL) para problemas desbalanceados (50\%) e com um reposicionamento

Tabela 4-15: Comparação dos diferentes resultados obtidos pela Heurística com Busca Local (HBL) para problemas desbalanceados $(75 \%)$ e com um reposicionamento

Tabela 4-16: Comparação dos diferentes resultados obtidos pela Heurística com Busca Local (HBL) para problemas balanceados e com dois reposicionamentos

Tabela 4-17: Comparação dos diferentes resultados obtidos pela Heurística com Busca Local (HBL) para problemas desbalanceados (25\%) e com dois reposicionamentos

Tabela 4-18: Comparação dos diferentes resultados obtidos pela Heurística com Busca Local (HBL) para problemas desbalanceados $(50 \%)$ e com dois reposicionamentos

Tabela 4-19: Comparação dos diferentes resultados obtidos pela Heurística com Busca Local (HBL) para problemas desbalanceados $(75 \%)$ e com dois reposicionamentos

Tabela 4-20: Comparação dos tempos de execução para problemas balanceados e com um reposicionamento

Tabela 4-21: Comparação dos tempos de execução para problemas desbalanceados (25\%) e com um reposicionamento

Tabela 4-22: Comparação dos tempos de execução para problemas desbalanceados (50\%) e com um reposicionamento 
Tabela 4-23: Comparação dos tempos de execução para problemas desbalanceados $(75 \%)$ e com um reposicionamento

Tabela 4-24: Comparação dos tempos de execução para problemas balanceados e com dois reposicionamentos

Tabela 4-25: Comparação dos tempos de execução para problemas desbalanceados (25\%) e com dois reposicionamentos

Tabela 4-26: Comparação dos tempos de execução para problemas desbalanceados $(50 \%)$ e com dois reposicionamentos .96

Tabela 4-27: Comparação dos tempos de execução para problemas desbalanceados $(75 \%)$ e com dois reposicionamentos .98

Tabela 5-1: Resumo da melhoria realizada pela Heurística com Busca Local (HBL) quando aplicada a diferentes soluções iniciais

Tabela 5-2: Resumo da comparação dos diferentes resultados obtidos pela Heurística com Busca Local (HBL) conforme solução inicial utilizada. 101

Tabela 5-3: Tempo médio de execução para instâncias de 5000 rotas 102

Tabela 5-4: Comparação dos resultados obtidos pela HBL aplicada sobre a solução inicial QS com os resultados obtidos pela literatura 


\section{LISTA DE ALGORITMOS}

Algoritmo 3-1: Heurística com Busca Local .45

Algoritmo 3-2: Algoritmo para geração de solução inicial QS (Quick Start)......46 


\section{LISTA DE ABREVIATURAS E SIGLAS}

CD

CPFR

CTM

$\mathrm{DH}$

EDI

$\mathrm{GH}$

HBL

$\mathrm{HBL}_{(\mathrm{CD})}$

$\mathrm{HBL}_{(\mathrm{GH})}$

$\mathrm{HBL}_{(\mathrm{QS})}$

PCR
Heurística construtivo-destrutiva proposta por Ferri (2009) para solucionar o problema PCRCR

Collaboration Planning, Forecasting and Replenishment Sistema Colaborativo de Planejamento, Previsão e Reabastecimento

Collaborative Transportation Management

Gerenciamento do Transporte Colaborativo

Deadhead - Número de reposicionamentos ou viagens vazias com o veículo

Eletronic Data Interchange - Troca eletrônica de dados

Algoritmo guloso proposto por Ergun et al. (2007b) para solucionar o problema PCRCR

Heurística com Busca Local proposta por este trabalho para solucionar o problema PCRCR

Heurística com Busca Local proposta por este trabalho utilizando como solução inicial os resultados obtidos pela Heurística construtivo-destrutiva proposta por Ferri (2009)

Heurística com Busca Local proposta por este trabalho utilizando como solução inicial os resultados obtidos pelo Algoritmo guloso proposto por Ergun et al. (2007b)

Heurística com Busca Local proposta por este trabalho utilizando como solução inicial os resultados obtidos pela heurística (QS) proposta por este trabalho

Problema de Cobertura de Rotas 


$\begin{array}{ll}\text { PCRCR } & \begin{array}{l}\text { Problema de Cobertura de Rotas com Cardinalidade } \\ \text { Restrita }\end{array} \\ \text { PCRER } & \text { Problema de Cobertura de Rotas com Extensão Restrita } \\ \text { PCRMT } & \begin{array}{l}\text { Problema de Cobertura de Rotas com Múltiplos } \\ \text { Transportadores }\end{array} \\ \text { PCRTR } & \text { Problema de Cobertura de Rotas com Tempo Restrito } \\ \text { PLI } & \text { Programação Linear Inteira } \\ \text { QS } & \text { Quick Start - Solução inicial rápida proposta por este } \\ & \text { trabalho } \\ \text { TL } & \text { Truckload - Transporte de carga cheia } \\ \text { VICS } & \text { Voluntary Interindustry Commerce Solutions - Comitê } \\ & \text { Voluntário de Padronização do Comércio entre Indústrias }\end{array}$




\section{INTRODUÇÃO}

\subsection{Objetivo da Dissertação}

O objetivo deste trabalho é desenvolver uma heurística com busca local que resolva um problema específico da área de Transporte Colaborativo chamado Problema de Cobertura de Rotas com Cardinalidade Restrita.

\subsection{Relevância do Problema}

O crescente interesse na área de logística colaborativa é alimentado por uma crescente pressão sobre as empresas para que estas operem de maneira mais eficiente, devido à percepção de que os fornecedores, consumidores e até mesmo competidores podem ser potenciais parceiros de logística colaborativa (ERGUN et al, 2004).

Botter et al. (2006) citam que a colaboração entre empresas pode torná-las mais fortes e competitivas no mercado, mas que para isso é necessário um entrosamento entre elas nos níveis estratégico, tático e operacional.

Vieira et al. (2010) também mostram como o maior nível de colaboração contribui para um melhor desempenho logístico, e aponta o relacionamento interpessoal ou comportamental como elemento essencial e mais importante na construção do relacionamento colaborativo.

Segundo Ballou (2006), apesar do potencial da colaboração logística ser muito elevada, esta é pouco adotada principalmente pelo fator confiança. Ainda segundo Ballou (2006), as empresas relutam em compartilhar dados com outros agentes do mercado, sendo que estas barreiras podem ser reduzidas através de acordos formais.

Apesar do estado atual da Tecnologia da Informação já permitir com que empresas compartilhem informações por diversos sistemas de comunicação (ex. 
EDI, Sistemas na Internet), Bourlakis et al. (2005) também citam a capacidade tecnológica como um empecilho para se realizar a colaboração entre empresas.

O termo Transporte Colaborativo também vai ao encontro da atual tendência do mercado em buscar operações mais eficientes e ecologicamente corretas, uma vez que, ao compartilhar um veículo ou serviço com outra empresa, está sendo reduzida a emissão de gases poluentes ao meio ambiente.

Este trabalho enfocará somente o transporte de carga cheia ou de lotação (TL - truckload), que, segundo Chopra et al. (2003), corresponde a viagens cobradas de acordo com a origem e destino do veículo, independente do peso carregado. Nesse caso, o tempo ocioso e a distância da viagem entre os sucessivos carregamentos adicionam custo à operação. Ainda segundo Chopra et al. (2003), as transportadoras tentam agendar as entregas para atender às exigências de serviço e, ao mesmo tempo, minimizar o tempo ocioso dos caminhões e o tempo de viagem com caminhões vazios.

Para os efeitos deste trabalho, denominam-se rotas as viagens de carga cheia entre pontos origens-destino (ponto a ponto).

Para a indústria de transporte de carga cheia, Ergun et al. (2004) demonstraram uma forma de se reduzir estes deslocamentos vazios através do Transporte Colaborativo, como ilustrado na Figura 1-1.

A Figura 1-1 mostra o exemplo de duas empresas (A e B) realizando diferentes viagens com e sem colaboração. No Caso 1 a Empresa $A$ realiza sua rota e retorna para a origem (1) com o veículo vazio e a Empresa $B$ também realiza a sua rota retornando com o veículo vazio para a sua origem (3). Para este deslocamento do veículo vazio é dado o nome de reposicionamento. 


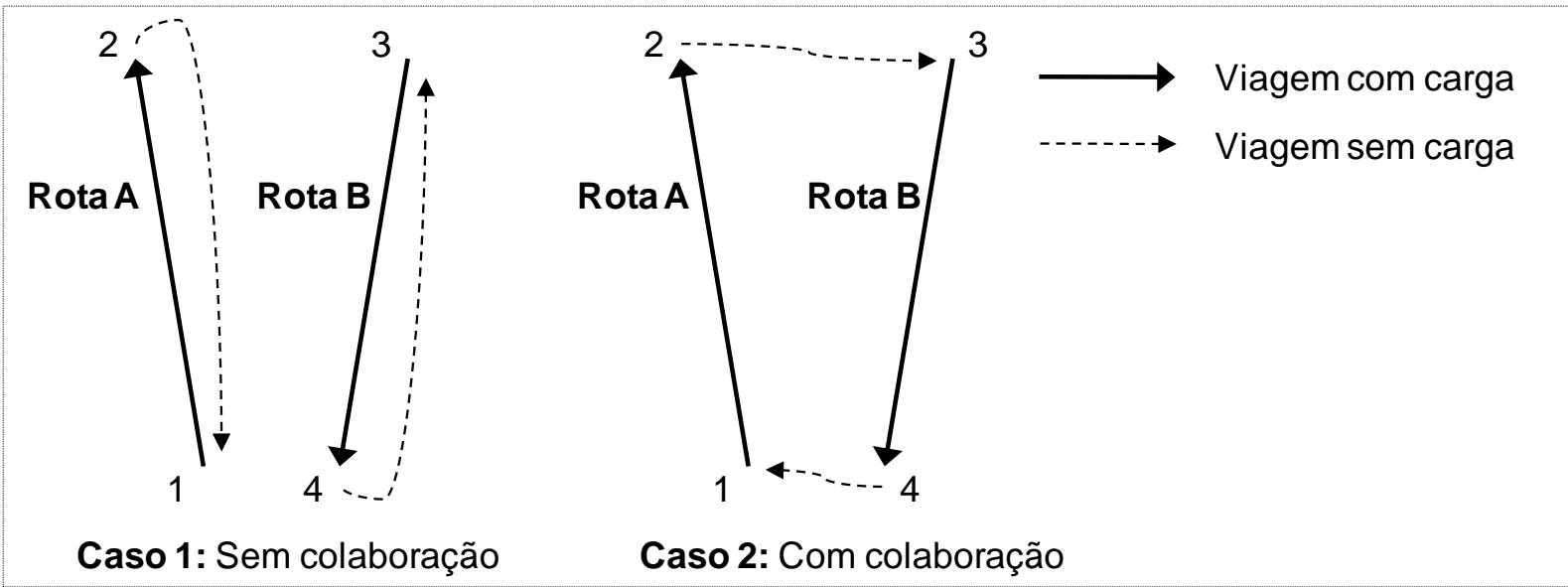

Figura 1-1: Exemplo de Transporte Colaborativo

Já no Caso 2, quando existe colaboração entre as empresas, a Empresa $\mathrm{A}$ realiza sua viagem e então desloca o veículo vazio até a origem da viagem $B$ (3), que ao atender tal viagem retorna para a origem da viagem $A$ (1), formando um ciclo fechado 1, 2, 3, 4.

Comparando os dois casos apresentados pode-se notar que, no Caso 2 (com colaboração), houve uma redução na distância total percorrida com o veículo vazio, podendo então refletir em uma redução de custo para o transportador, uma vez que são embutidos no custo da viagem os custos referentes aos deslocamentos dos veículos vazios.

Ergun et al. (2004) apresentaram o Problema de Cobertura de Rotas (PCR) onde, dado um conjunto de rotas, deve-se encontrar um conjunto de ciclos que cubram estas rotas de tal forma que o custo total dos ciclos seja minimizado

$\mathrm{Na}$ prática, segundo Ergun et al. (2004), existem diversas restrições que podem limitar a geração de ciclos viáveis, tais como o número máximo de rotas pertencentes a um ciclo, distância ou tempo máximo de um ciclo. Assim, vão-se listar neste trabalho algumas variações com restrições do PCR, o que tornam este problema mais complexo, enfocando o Problema de Cobertura de Rotas com Cardinalidade Restrita (PCRCR), onde se limita o número máximo de viagens e reposicionamentos do veículo. 


\subsection{Delimitação do Problema}

Será estudado o Problema de Cobertura de Rotas com Cardinalidade Restrita (PCRCR), onde, dado um conjunto de rotas, o objetivo é cobri-las com ciclos de tal forma que o número de rotas e de reposicionamentos seja limitado, minimizando a distância total percorrida.

Neste problema não é tratada a ocupação do veículo e, sendo assim, considera-se a demanda de veículos independente da ocupação final dos mesmos, tal como ocorre para cargas do tipo lotação.

Também não serão consideradas restrições como tipo de veículo, distância total percorrida, tempo de viagem e janelas de tempo.

A heurística proposta será testada para problemas balanceados e desbalanceados, como propostos por Ferri (2009), de forma a representar fluxos de materiais mais adequados quando comparados às economias reais, onde existe um desbalanceamento no fluxo entre diferentes regiões.

\subsection{Organização do Trabalho}

A dissertação é composta por cinco capítulos, descritos a seguir.

No Capítulo 1 é feita uma introdução do problema, onde é mostrado o objetivo do trabalho, a relevância do assunto a ser estudado e quais as suas delimitações.

No Capítulo 2 é feita uma revisão da literatura sobre as principais referências da área de transporte colaborativo, é apresentado o problema de cobertura de rotas e suas variações, as heurísticas encontradas na literatura para solução do problema de cobertura de rotas com cardinalidade restrita (PCRCR) em específico e outras referências relacionadas à busca local que podem ser utilizadas por este trabalho.

No Capítulo 3 é descrito detalhadamente o PCRCR e a Heurística desenvolvida por este trabalho para solução do mesmo. 
No Capítulo 4 são apresentados os resultados da heurística comparados com resultados obtidos pela literatura.

No Capítulo 5 é feita uma conclusão sobre o trabalho apresentando os principais pontos abordados, resultados obtidos, conclusões finais e propostas de estudos futuros. 


\section{REVISÃO DA LITERATURA}

Neste capítulo é feita uma revisão na literatura acerca dos temas mais importantes para o desenvolvimento e conclusão deste trabalho.

Inicialmente é feita uma revisão sobre transporte colaborativo mostrando as principais referências e conceitos acerca deste tema. Posteriormente apresenta-se uma revisão sobre o Problema de Cobertura de Rotas (PCR) e suas variações.

Como parte do objetivo deste trabalho é implantar uma heurística com busca local, também é feita uma revisão sobre os métodos de busca local para problemas similares.

\subsection{Transporte colaborativo}

Segundo Esper et al. (2003), o conceito de colaboração tem se tornado cada vez mais importante nos campos do gerenciamento da cadeia de suprimentos, transportes e logística. Um dos principais processos associados à colaboração na Cadeia de Suprimentos é o CPFR (Collaboration Planning, Forecasting and Replenishment), comitê este criado pelo Comitê Voluntário de Padronização do Comércio entre Indústrias - VICS (Voluntary Inter-Industry Commerce Standards Association).

Ainda segundo Esper et al. (2003), uma extensão do CPFR pode ser encontrada no Gerenciamento do Transporte Colaborativo - CTM (Collaborative Transportation Management), cujo objetivo, segundo Browning et al. (2004), é reduzir ou eliminar as ineficiências no processo de transporte através da colaboração, trazendo benefícios como aumento da visibilidade, redução de custos e um melhor atendimento ao cliente.

Tyan et al. (2003) citam que o CTM visa reduzir os tempos de trânsito e os custos totais através de uma melhor utilização dos ativos da empresa, mas que isso só é possível através do envolvimento de todos os agentes da cadeia, como clientes, fornecedores e transportadores. 
Esper et al. (2003) citam diversos benefícios que podem ser obtidos para estes agentes da cadeia através do CTM, como representados na Tabela 2-1.

Tabela 2-1: Benefícios do Gerenciamento do Transporte Colaborativo (CTM)

\begin{tabular}{|c|c|c|}
\hline Benefício & Exemplos & A quem beneficia \\
\hline $\begin{array}{l}\text { Redução do custo de } \\
\text { transportes }\end{array}$ & $\begin{array}{l}\text { Reduzir o número de } \\
\text { retornos de veículos vazios e } \\
\text { tempo ocioso no cliente }\end{array}$ & $\begin{array}{l}\text { Cliente, } \\
\text { Transportador }\end{array}$ \\
\hline $\begin{array}{l}\text { Melhor utilização dos } \\
\text { ativos }\end{array}$ & $\begin{array}{l}\text { Reduzir distância percorrida } \\
\text { vazia pelo veículo que não } \\
\text { são pagas diretamente para } \\
\text { o transportador }\end{array}$ & Transportador \\
\hline $\begin{array}{l}\text { Melhora no nível de } \\
\text { serviço }\end{array}$ & $\begin{array}{l}\text { Maior assertividade do } \\
\text { tempo de entrega }\end{array}$ & Cliente, Fornecedor \\
\hline Aumento da visibilidade & $\begin{array}{l}\text { Localização de produtos e } \\
\text { veículos na cadeia de } \\
\text { suprimentos }\end{array}$ & $\begin{array}{l}\text { Cliente, } \\
\text { Transportador, } \\
\text { Fornecedor }\end{array}$ \\
\hline $\begin{array}{l}\text { Aumento da satisfação do } \\
\text { consumidor final }\end{array}$ & $\begin{array}{l}\text { Aumento de pedidos } \\
\text { atendidos de maneira } \\
\text { "perfeita" }\end{array}$ & Cliente, Fornecedor \\
\hline Aumento da Receita & $\begin{array}{l}\text { Conseqüência de um melhor } \\
\text { nível de serviço ao cliente e } \\
\text { melhor qualidade da entrega. }\end{array}$ & $\begin{array}{l}\text { Cliente, } \\
\text { Transportador, } \\
\text { Fornecedor }\end{array}$ \\
\hline
\end{tabular}

Botter et al. (2006) ressaltam que o entrosamento e colaboração entre as empresas nos níveis estratégico, tático e operacional as torna mais competitivas através da troca de informações, redução de custos, maior poder de negociação com fornecedores, maior capilaridade na distribuição e como conseqüência a possibilidade de alcançar novos mercados.

Botter et al. (2006) destacam ainda que o maior beneficiário da colaboração é o transportador, pela redução de número de viagens vazias e menor tempo de espera no cliente, e que como conseqüência todo o sistema ganha.

Chan et al. (2010) mostraram como o CTM pode reduzir custos e aumentar o nível de serviço. 
Pan et al. (2009) e Ballot et al. (2010) mostraram como o aumento do custo da energia e as mudanças climáticas passaram a chamar mais a atenção nas últimas décadas. O setor de transportes, como um dos principais agentes de emissão de gases do efeito estufa, neste contexto, passou a chamar atenção especial. Como conseqüência, estudos relacionados ao aumento da eficiência logística (tal como o PCR) passaram a receber um maior destaque.

\subsection{Problemas de Cobertura de Rotas}

Nesta seção é apresentado de forma mais detalhada o Problema de Cobertura de Rotas em sua forma original, seguido de algumas variações do problema, que diferem principalmente em relação a restrições adicionadas a eles.

\subsubsection{Problema de Cobertura de Rotas (PCR)}

Segundo Ergun et al. (2007b), o Problema de Cobertura de Rotas é um problema que representa o transporte colaborativo. O problema pode ser descrito como: dado um grafo euclidiano direcionado $D=(V, A)$, com conjunto de vértices $V$, $\operatorname{arcos} A$, custo dos arcos $c(a)$ para $a \in A$ e conjunto de rotas $L$ tal que $L \subseteq A$ encontre o custo mínimo de ciclos fechados que cubram $L$.

O Problema de Cobertura de Rotas pode representar um problema de transporte colaborativo, uma vez que podemos tratar uma rota como sendo uma viagem do tipo TL (truckload - transporte de carga cheia) a ser coberta por um transportador.

A Figura 2-1 mostra dois exemplos de soluções viáveis, onde a Rotas ( $A, B$ e C) são cobertas por ciclos fechados. Na solução inicial temos três ciclos fechados, onde cada ciclo é composto por uma rota com seu respectivo retorno. Na solução otimizada temos apenas um ciclo cobrindo todas as rotas, onde o retorno de cada rota foi substituído por um reposicionamento para o início da rota seguinte. 


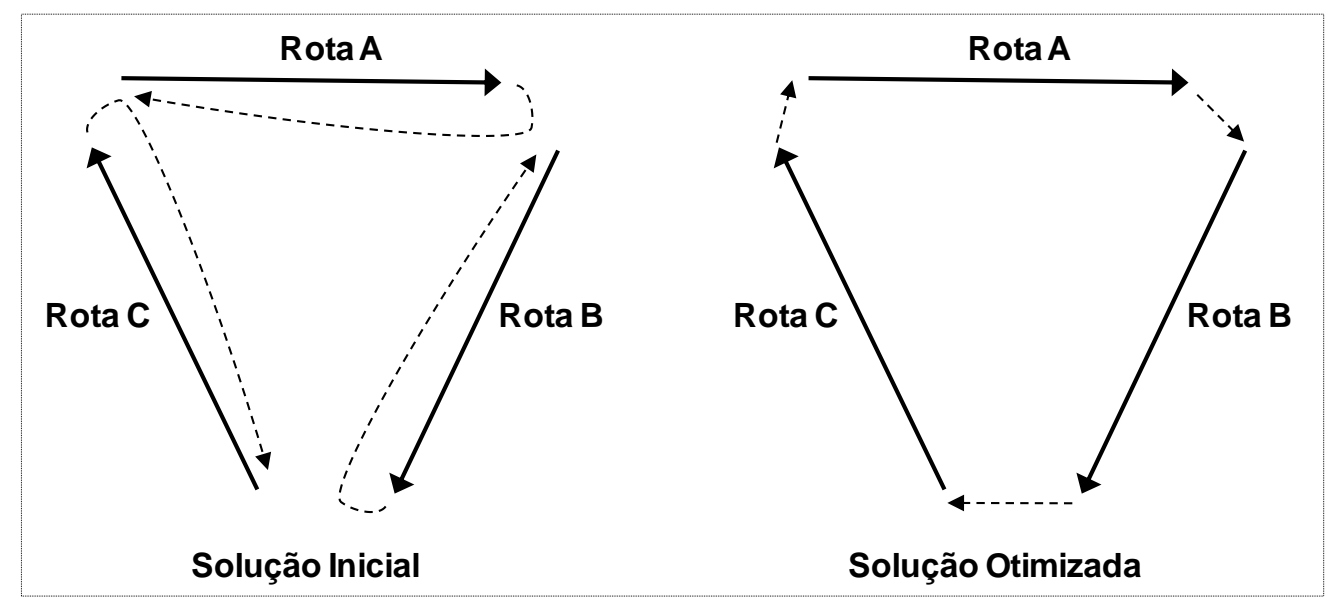

Figura 2-1: Exemplo de otimização de uma instância do Problema de Cobertura de Rotas

No problema de transporte colaborativo podemos tratar um retorno ou mesmo um reposicionamento de uma rota (representados por linhas tracejadas na Figura 2-1) como sendo uma viagem vazia de um veículo. Desta forma, ao se minimizar o custo dos ciclos fechados que cobrem tais rotas, estamos minimizando a distância total percorrida pelos veículos vazios.

$\mathrm{Na}$ formulação matemática do problema de PCR, Ergun et al. (2004) associam o custo do arco ao seu comprimento $\left(l_{i j}\right)$ da forma como está descrito a seguir, onde $A$ corresponde ao conjunto de arcos, $V$ o conjunto de vértices e $L o$ conjunto de rotas.

\section{ÍNDICES:}

$i \in V:$ vértices de origem

$j \in V:$ vértices de destino

\section{PARÂMETROS:}

$l_{i j}$ : comprimento do arco $(i, j)$.

\section{VARIÁVEIS:}

$x_{i j}$ : variável inteira que indica quantas vezes o arco $(i, j)$ é atravessado. 


\section{FUNÇÃO OBJETIVO:}

$$
\min \sum_{(i, j) \in A} l_{i j} x_{i j}
$$

\section{RESTRIÇÕES:}

$$
\begin{aligned}
& \sum_{j \in N} x_{i j}-\sum_{j \in N} x_{j i}=0 \forall i \in N \\
& x_{i j} \geq 1, \forall(i, j) \in L \\
& x_{i j} \geq 0, \forall(i, j) \in A \backslash L
\end{aligned}
$$

Nesta formulação, a função objetivo (2.1) consiste em minimizar a distância total percorrida. A restrição (2.2) garante o balanço do nó, ou seja, se um veículo entra em um nó, ele deve deixar este nó. A restrição (2.3) garante que toda rota deve pertencer a um ciclo. A restrição (2.4) determina o domínio das variáveis.

Ergun et al. (2007b) mostraram que o Problema de Cobertura de Rotas (PCR) pode ser resolvido em tempo polinomial, apresentando dois algoritmos que resolvem este problema desta forma:

1. Considere o grafo euclidiano direcionado $D$ como descrito anteriormente. Atribuir um limite superior igual a infinito para todos os arcos em $A$, um limite inferior igual a um para todos os arcos em $L$ e zero para todos os arcos em $A \backslash L$. Seja $C$ o custo mínimo de circulação neste grafo. $O$ subgrafo $D$ ' de $D$ induzido por todos os arcos com fluxo positivo em $C$ é um grafo Euleriano (ciclo em $D$ que contenha todas as suas arestas). Além disso, uma vez que todos os arcos em $L$ têm um fluxo positivo em $C$, o subgrafo $D^{\prime}$ inclui todas as Rotas. Assim, o fluxo $C$ em $D^{\prime}$ pode ser decomposto em um fluxo unitário no ciclo direcionado abrangendo todos os arcos em $L$, provendo assim um custo mínimo para a cobertura das rotas. 
2. Ergun et al. (2007b) descrevem outro algoritmo que se assemelha ao algoritmo para o Problema do Carteiro Chinês, o qual pode ser resolvido em tempo polinomial (EIZENT et al, 1995).

Caris et al. (2011) mostraram como o PCR poderia ser aplicado ao transporte intermodal de barcaças. Já Stringher (2004) tratou o problema de formação de ciclos para cargas do tipo lotação aplicado a um caso real de distribuição de linha branca (eletrodomésticos como lavadoras, fogões, refrigeradores e condicionadores de ar). A principal diferença de Ergun et al. (2004) é que Stringher (2004) considerou também os custos fixos associados ao veículo.

Dai et al. (2009) apresentaram uma generalização do PCR para cargas do tipo fracionada, onde além de representar o número de vezes que cada arco é percorrido por veículos, o modelo também possui variáveis que representam a quantidade de produto transportada em cada arco.

\subsubsection{Problema de Cobertura de Rotas com Cardinalidade Restrita (PCRCR)}

O PCRCR foi inicialmente proposto por Ergun et al. (2004), sendo que este difere do problema original PCR por ser limitado o número de arcos que podem fazer parte de um ciclo.

Ergun et al. (2004) trataram este problema limitando não apenas a cardinalidade máxima do ciclo, mas também o número máximo de reposicionamentos (DH - Deadhead).

Chamamos de cardinalidade o número de arcos presentes em um ciclo. Os arcos podem servir para cobrir uma rota ou para representar um reposicionamento do veículo

A Figura 2-2 mostra o exemplo de dois ciclos de cardinalidade cinco com um e dois reposicionamentos respectivamente. 


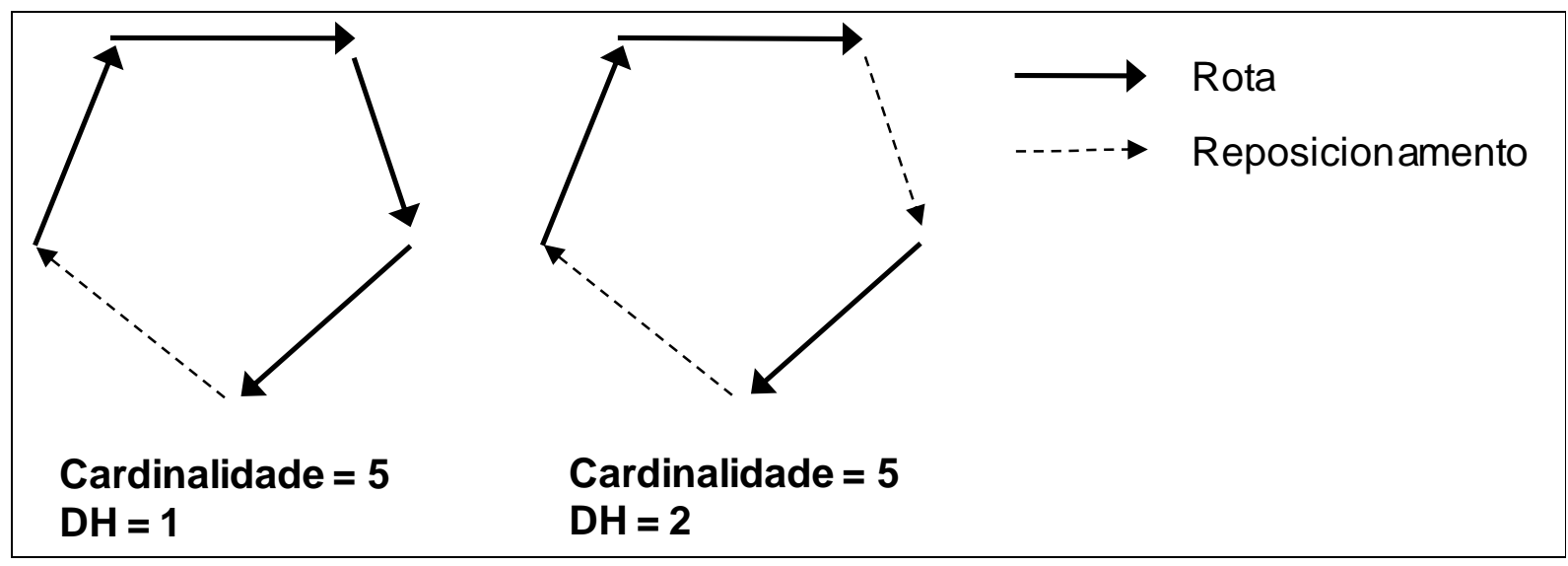

Figura 2-2: Exemplo de ciclos com $\mathrm{DH}=1$ e $\mathrm{DH}=2$

O principal motivo para que seja limitado o número de arcos em um ciclo é que para cada arco que representa a viagem de um veículo estão associadas operações de carga ou descarga em seus extremos (vértices). Assim, quando se aumenta o número de viagens em um mesmo ciclo, torna-se cada vez mais difícil coordenar a operação dos diversos vértices (pontos de carga ou descarga).

Para o PCRCR foram encontradas duas formulações, sendo uma por cobertura de rotas e outra por cobertura de conjuntos. A seguir são apresentadas estas duas formulações.

\section{- Formulação por Cobertura de Rotas}

A formulação por cobertura de rotas foi proposta por Ferri (2009), que adicionou três restrições $(2.8,2.9$ e 2.10) à formulação do problema de PCR proposta por Ergun et al. (2004) para torná-la restrita em relação à cardinalidade e reposicionamentos possíveis. Nesta formulação, $C$ corresponde ao conjunto de ciclos viáveis e $V$ o conjunto de vértices do problema.

\section{ÍNDICES:}

$i \in V:$ vértices de origem

$j \in V$ : vértices de destino

$c \in C:$ ciclos 


\section{PARÂMETROS:}

k: cardinalidade máxima do ciclo.

$l_{i j}$ : indica se o arco $(i, j)$ é ou não percorrido por uma rota. $l_{i j}=1$ se $l_{i j} \in \operatorname{L}$ e $l_{i j}=$ 0 caso contrário.

$c_{i j:}$ custo associado ao arco (i, j).

$d h$ : número de reposicionamentos permissíveis

\section{VARIÁVEIS:}

$x_{i j}^{c}$ : indica se o arco $(i, j)$ pertence ao ciclo $c$.

\section{FUNÇÃO OBJETIVO:}

$\min \sum_{i} \sum_{j} c_{i j} x_{i j}^{c}$

\section{RESTRIÇÕES:}

$\sum_{c} x_{i j}^{c} \geq l_{i j}, \forall i \in V, \forall j \in V$

$\sum_{i^{\prime}} x_{i^{\prime} i}^{c}-\sum_{j^{\prime}} x_{i j^{\prime}}^{c}=0, \forall c \in C, \forall i \in V$

$\sum_{i} \sum_{j} x_{i j}^{c} \leq k, \forall c \in C$

$\sum_{i} \sum_{j} x_{i j}^{c}-\sum_{i} \sum_{j} x_{i j}^{c} * l_{i j} \leq d h, \forall c \in C$

$\sum_{i} x_{i i}^{c}=0, \forall c \in C$

$x_{i j}^{c} \in\{0,1\}, \forall i \in V, \forall j \in V, \forall c \in C$ 
A função objetivo (2.5) consiste em minimizar o custo total dos ciclos gerados. A restrição (2.6) garante que todas as rotas pertençam a um ciclo. A restrição (2.7) garante o fechamento de cada um dos ciclos através do balanço de nós, ou seja, se um veículo entra em um nó, ele deve deixar este nó. A restrição (2.8) restringe o ciclo em relação ao seu limite de cardinalidade. A restrição (2.9) restringe o ciclo em relação ao limite de reposicionamentos permissíveis. A restrição (2.10) garante que cada ciclo tenha origem e destino em vértices distintos. A restrição (2.11) determina o domínio das variáveis.

A formulação por Cobertura de Rotas apresenta um número de variáveis que cresce exponencialmente com o número de rotas. Para problemas com 500 vértices, este crescimento é ilustrado na Figura 2-3.

As menores instâncias, com apenas 100 rotas, já gerariam aproximadamente 25 milhões de variáveis, enquanto que as instâncias maiores com 5000 rotas gerariam aproximadamente 1,25 bilhões de variáveis. Isso porque na formulação por cobertura de rotas, a variável $x_{i j}^{c}$ se refere ao arco entre os vértices $i$ e $j$ (que podem variar de 1 a 500) e que pertence ao ciclo c (que no pior dos casos é igual ao número de rotas).

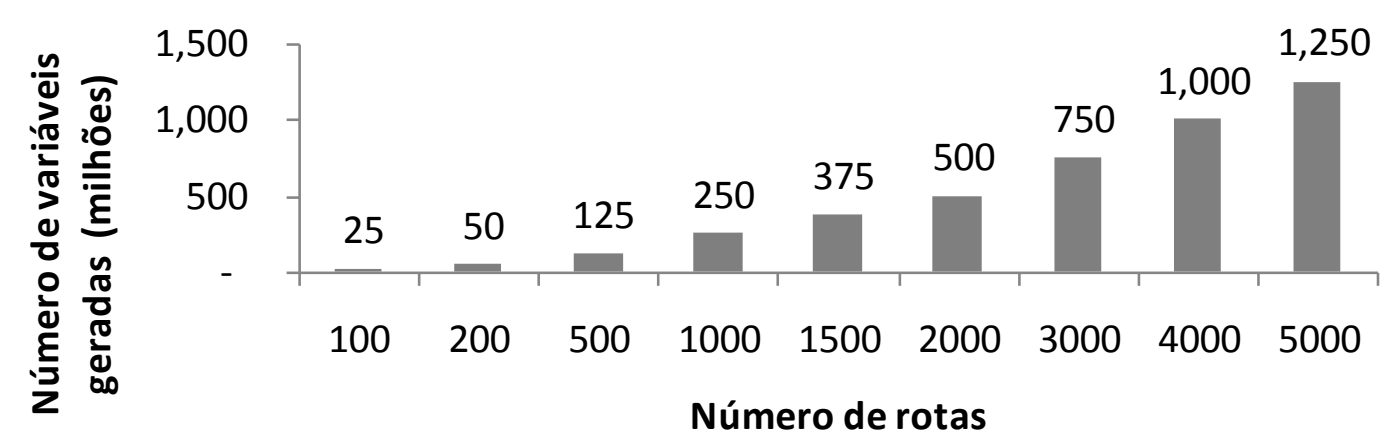

Figura 2-3: Número de variáveis (em milhões) em função do número de rotas segundo o modelo básico para um problema de 500 vértices 


\section{- Formulação por Cobertura de Conjuntos}

Devido à grande quantidade de variáveis que são geradas no problema anterior, Ergun et al. (2007b) propuseram um modelo por cobertura de conjuntos. Para este modelo, são geradas previamente todas as combinações de ciclos $c$ viáveis que respeitem os limites de cardinalidade, reposicionamentos e que cubram pelo menos uma rota (conjunto $C_{k}$ ).

Feito isso, deve-se escolher um subconjunto de ciclos $c \in C_{k}$ de forma a minimizar o custo total dos ciclos e cobrir todas as rotas de modo que $c \cap L \neq \emptyset$.

\section{ÍNDICES:}

$c \in C_{k}$ : cada um dos ciclos viáveis.

\section{PARÂMETROS}

$c_{c}$ : custo associado ao ciclo $c$.

$l_{c}$ : indica se a rota $l \in L$ pertence ao ciclo $c \in C_{k} . l_{c}=1$ se $l_{c}$ pertence ao ciclo ce $l_{c}=0$ caso contrário.

\section{VARIÁVEIS}

$x_{c}$ : indica se o ciclo $c \in C_{k}$ faz ou não parte da solução.

\section{FUNÇÃO OBJETIVO:}

$\min \sum_{c \in c_{k}} c_{c} x_{c}$

\section{RESTRIÇÕES:}

$$
\begin{aligned}
& \sum_{c \in C_{k}} l_{c} x_{c} \geq 1, \forall l \in L \\
& x_{c} \in\{0,1\}, \forall c \in C_{k}
\end{aligned}
$$


A função objetivo (2.12) consiste em minimizar o custo total dos ciclos selecionados. A restrição (2.13) garante que toda rota pertencerá a um ciclo. A restrição (2.14) determina o domínio das variáveis.

Este método, utilizado por Ergun et al. (2007b), exige que a solução seja dividida em duas partes:

1. Inicialmente é executado um algoritmo recursivo proposto por Ergun et al. (2004) para a geração de todos os ciclos viáveis.

2. Posteriormente é feita a otimização do problema utilizando o conjunto de ciclos gerados anteriormente.

Ergun et al. (2004) mostraram que este problema é NP-Hard, o que o torna cada vez mais difícil de se resolver conforme se aumenta o tamanho das instâncias tratadas. Desta forma, faz-se necessário a criação de heurísticas capazes de resolver este problema de maneira eficiente e em um tempo hábil.

\subsubsection{Problema de Cobertura de Rotas com Extensão Restrita (PCRER)}

Ergun et al. (2004) estudaram duas variações do Problema de Cobertura de Rotas, sendo elas:

1. Problema de Cobertura de Rotas com Cardinalidade Restrita (PCRCR) tratado na seção anterior, onde o número de arcos em um ciclo deve ser igual ou inferior à $K$.

2. Problema de Cobertura de Rotas com Extensão Restrita (PCRER), onde o comprimento de um ciclo deve ser igual ou inferior a uma constante $B$.

Como apontado por Ergun et al. (2004), todas as técnicas utilizadas para a solução do PCRCR podem ser estendidas para o PCRER. 


\section{- Formulação por Cobertura de Rotas}

A formulação por Cobertura de Rotas poderia ser facilmente obtida substituindo-se as equações de cardinalidade e reposicionamento (2.8 e 2.9 respectivamente) do PCRCR pela equação abaixo, onde $d_{i j}$ representa 0 comprimento do arco (i, j) e B representa a extensão máxima de um ciclo.

$$
\sum_{i} \sum_{j} x_{i j}^{c} d_{i j} \leq B, \forall c \in C
$$

\section{- Formulação por Cobertura de Conjuntos}

$\mathrm{Na}$ formulação por Cobertura de Conjuntos, de maneira similar ao PCRCR, devemos gerar previamente todas as combinações de ciclos $c$ viáveis e que cubram pelo menos uma rota. Entretanto, para o problema PCRER, um ciclo viável é aquele cujo comprimento é igual ou menor a constante $B$ anteriormente apresentada.

\subsubsection{Problema de Cobertura de Rotas com Tempo Restrito (PCRTR)}

Ergun et al. (2007a) apresentaram o Problema de Cobertura de Rotas com Tempo Restrito, onde a duração de um ciclo deve ser igual ou inferior a um limite pré determinado.

Segundo Ergun et al. (2007a), a incorporação de restrições temporais ao Problema de Cobertura de Rotas aumenta a viabilidade deste problema ser implementado na prática, isso porque cargas do tipo carga cheia ou lotação são usualmente definidas como rotas com uma origem, destino e uma janela de tempo. Existem dois tipos principais de restrições temporais:

1. Janela de tempo para carregamento ou descarregamento do veículo.

2. Regulamentações quanto ao tempo máximo que um motorista pode permanecer dirigindo. 
A Janela de tempo neste contexto indica o período no qual o veículo deve ser expedido, como por exemplo, na segunda-feira entre 8 e 14 horas. Esta restrição é usada em geral para garantir que o veículo chegue a seu destino final em um horário específico ou por restrições do local de expedição. Como exemplo, ao não se considerar esta restrição, o modelo pode dar como resposta um ciclo onde a saída de um veículo de uma determinada unidade ocorrerá em um período em que não terá pessoal responsável para emissão de documentos ou para o carregamento / descarregamento do veículo.

A restrição quanto ao tempo máximo que um motorista pode permanecer dirigindo pode variar de país para país conforme sua respectiva legislação. Esta restrição interfere diretamente nos tempos de chegada do veículo em cada um dos destinos. No Brasil, conforme Constituição Federal de 1988, a duração do trabalho não pode ser superior a 8 horas diárias ou 44 horas semanais. A Consolidação das Leis do Trabalho limita ainda em 6 horas o tempo máximo de trabalho interrupto, devendo ser concedido então para o motorista um intervalo de no mínimo uma hora para repouso ou alimentação.

O PCRTR pode ser definido da seguinte forma: dado um conjunto de rotas, encontre ciclos que cubram estas rotas minimizando o tempo total dos ciclos respeitando-se as janelas de tempo e o tempo total de viagem para cada ciclo. Formalmente, dado um grafo euclidiano direcionado $D=(V, A)$, com conjunto de vértices $V$, arcos $A$, tempo de viagem $t_{a}$ para cada $a \in A$, período $T$ e conjunto de rotas $L$ onde cada rota $l \in L$ é definida por um arco $a \in A$ e uma janela de tempo $\left[e_{l}, l_{l}\right]\left(e_{l}, l_{l} \leq T\right)$, encontre o conjunto de ciclos viáveis direcionados que cubram as rotas em $L$ minimizando a somatória do tempo de todas as viagens.

Um ciclo $C$ é viável se podemos identificar um primeiro arco no ciclo e atribuir um horário de saída $d_{a}$ para a origem de cada arco $a \in C$ de tal forma que $d_{a}+t_{a} \leq$ $d_{\text {suc (a) }}$ para todos os arcos no ciclo, exceto para o último arco, onde suc(a) denota o sucessor imediato do arco a no ciclo.

O horário de saída $d_{a}$ para a origem de cada arco $a \in C$ deve sempre pertencer à janela de tempo de cada rota $l$, ou seja, $e_{l} \leq d_{a} \leq l_{l}$. Para que a duração do ciclo seja menor ou igual a $T$, o tempo passado entre a partida da origem do 
primeiro arco e o retorno até a origem do primeiro arco deve ser menor ou igual a $T$, ou seja, $e_{l}+T \leq d_{a} \leq l_{l}+T$. Esta última condição garante que o ciclo pode ser repetido.

Ergun et al. (2007a) apresentaram para este problema uma formulação por cobertura de conjuntos, onde $C_{k}$ representa o conjunto de ciclos viáveis definidos anteriormente e $c_{c}$ o custo associado ao ciclo $C$, que neste caso é associado ao tempo total de cada ciclo viável.

Ergun et al. (2007a) afirmaram que da mesma forma que os demais Problemas de Cobertura de Rotas restritos, este problema também é NP-Hard.

\subsubsection{Problema de Cobertura de Rotas com Múltiplos Transportadores (PCRMT)}

Özener (2008) apresentou o Problema de Cobertura de Rotas para o caso que existe mais de um transportador para uma determinada rota. Neste problema existe o objetivo de se atribuir um transportador par cada rota de forma a minimizar o custo total dos ciclos realizados.

Neste problema, o custo total pode ser dividido em dois componentes principais:

1. Custo de cobertura da rota, que depende unicamente de qual transportador foi designado para aquela rota. $O$ custo de cobertura da rota pode ser diferente conforme o transportador escolhido.

2. Custo de reposicionamento, o qual depende de qual transportador foi designado e qual a configuração da rota. 
Neste problema existem dois conjuntos de rotas: rotas que devem ser executadas por um transportador específico e rotas que podem ser executadas por qualquer transportador.

Foi assumido que o custo de se atravessar um arco é indiferente da direção no mesmo, e que o custo de reposicionamento é um percentual do custo de realizar a rota. Estes custos podem ser diferentes conforme o transportador escolhido.

Özener (2008) definiu o problema em um grafo $D=(V, A)$, onde $V$ é o conjunto de vértices e $A$ é o conjunto de arcos. O conjunto de rotas que pode ser atendidas por qualquer transportador é dado por $L \subseteq A$ enquanto que as rotas que podem ser atendidas apenas pelo transportador $d$ são dadas por $I^{d} \subseteq A$. Seja $B$ o conjunto de transportadores e $c_{i j}^{b}$ o custo para realizar o arco $(i, j)$ pelo transportador $b(b \in B)$. O objetivo é cobrir todas as rotas com o mínimo custo.

Özener (2008) então formulou o PCRMT como um modelo de programação linear inteira (PLI) da seguinte forma:

\author{
ÍNDICES: \\ $i \in V:$ vértices de origem \\ $j \in V:$ vértices de destino \\ $b \in B:$ transportador
}

\title{
PARÂMETROS:
}

$c_{i j}^{b}$ : custo para realizar o arco $(i, j)$ pelo transportador $b(b \in B)$.

$\theta^{b}(b \in B)$ : coeficiente do custo de reposicionamento do transportador $b$, onde $0<\theta^{b} \leq 1$. Assim, o custo de reposicionamento através de um arco $(i, j)$ pode ser dado por $\theta^{b} c_{i j}^{b}$ caso atendido pelo transportador $b$. 
$I_{i j}^{b}$ : representa o número de vezes que a rota $(i, j) \in L$ deve ser atendida pelo transportador $b$. Esta variável representa o caso em que existe um contrato que dá ao transportador $b$ o direito de realizar determinada rota $I_{i j}^{b}$ vezes.

$r_{i j}$ : número de vezes que a rota $(i, j) \in L$ deve ser atendida por qualquer transportador.

\section{VARIÁVEIS:}

$x_{i j}^{b}$ : número de vezes que a rota $(i, j) \in L$ é atendida pelo transportador $b$.

$z_{i j}^{b}$ : número de vezes que o arco $(i, j) \in A$ é atendido vazio (reposicionamento) pelo transportador $b$.

\section{FUNÇÃO OBJETIVO:}

$\min \sum_{b \in B} \sum_{(i, j) \in L} c_{i j}^{b} x_{i j}^{b}+\sum_{b \in B} \theta^{b} \sum_{(i, j) \in A} c_{i j}^{b} z_{i j}^{b}$

\section{RESTRIÇÕES:}

$$
\begin{aligned}
& \sum_{j \in N} x_{i j}^{b}-\sum_{j \in N} x_{j i}^{b}+\sum_{j \in N} z_{i j}^{b}-\sum_{j \in N} z_{j i}^{b}=0, \forall i \in N, \forall b \in B \\
& \sum_{b \in B} x_{i j}^{b} \geq r_{i j}+\sum_{b \in B} I_{i j}^{b}, \forall(i, j) \in L \\
& x_{i j}^{b} \geq I_{i j}^{b}, \forall(i, j) \in I^{b}, \forall b \in B \\
& z_{i j}^{b} \geq 0, \forall(i, j) \in A, \forall b \in B \\
& x_{i j}^{b}, z_{i j}^{b} \in Z
\end{aligned}
$$

A função objetivo (2.16) consiste em minimizar o custo total de cobertura das rotas pelos transportadores mais seus respectivos custos de reposicionamento. A restrição (2.17) garante o fechamento de cada um dos ciclos através do balanço de nós, ou seja, se um veículo entra em um nó, ele deve deixar este nó. A restrição 
(2.18) garante que todas as rotas sejam atendidas levando-se em consideração se a rota pode ser atendida por qualquer ou por determinado transportador $d$. A restrição (2.19) garante que rotas designadas pra um determinado transportador $d$ devem obrigatoriamente ser atendidas por este. As restrições (2.20) e (2.21) determinam o domínio das variáveis.

Özener (2008) também mostrou que quando os transportadores não diferem quanto às rotas que atendem e estrutura de custos, este problema equivale ao problema padrão de cobertura de rotas (PCR) e pode então ser resolvido em tempo polinomial, enquanto que no caso de haver três ou mais transportadores com diferentes estruturas de custos, este problema se torna NP-hard.

Além de múltiplos transportadores (quem realiza o serviço de transporte), podem existir também múltiplos embarcadores (quem contrata o serviço de transporte) no problema anteriormente apresentado. Desta forma, Özener et al. (2008) e Özener (2008) apresentaram também uma metodologia para designação do custo total entre os embarcadores.

Ao contrário desses estudos, Özener et al. (2011) estudaram o problema quando as transportadoras não colaboram operacionalmente para alcançar os objetivos comuns e, em seguida, partilhar os benefícios resultantes. Em vez disso, os transportadores colaboram definindo regras para realizar trocas de rotas de tal forma que seus lucros individuais sejam maximizados. Neste problema os transportadores não estão tentando estabelecer uma parceria de longo prazo e não estão tentando desenvolver mecanismos para sustentar uma colaboração, pois eles estão apenas tentando identificar trocas de rotas que irão beneficiar ambas as partes.

Berger et al. (2010) também propuseram um modelo para maximização do lucro total de transportadores (sem que o lucro individual de cada uma seja reduzido) através de uma realocação de rotas. 


\subsection{Heurísticas para o PCRCR}

Nesta seção são apresentadas as duas heurísticas encontradas na literatura para o Problema de Cobertura de Rotas com Cardinalidade Restrita (PCRCR).

\subsubsection{Algoritmo Guloso proposto por Ergun et al. (2007b)}

O Algoritmo Guloso (GH) proposto por Ergun et al. (2007b) exige que sejam geradas todas as combinações de ciclos viáveis.

Uma vez gerados todos os ciclos viáveis, é calculado o fator $f$ para cada ciclo dado por:

$$
f=\frac{\text { custo das rotas presentes no ciclo }}{\text { custo total do ciclo }}
$$

No pior caso em que uma rota tem seu retorno vazio, teremos $f=0.5$, enquanto que no melhor caso em que rotas se unem de tal forma que não haja reposicionamentos, $f=1$.

Uma vez calculado $f$ para cada um dos ciclos viáveis, seleciona-se o ciclo com o maior fator $f$ e retira-se da lista todos os ciclos viáveis que possuem alguma das rotas presentes no ciclo anterior. Seleciona-se então o próximo ciclo com o maior fator $f$, repetindo-se este processo até que todas as rotas tenham sido atribuídas a um ciclo.

Uma grande desvantagem deste algoritmo é a necessidade de se gerar todos os ciclos viáveis antes de sua execução.

\subsubsection{Heurística Construtivo-Destrutiva proposto por Ferri (2009)}

A Heurística Construtivo-Destrutiva (CD) foi proposta por Ferri (2009) como alternativa ao PLI e ao método proposto por Ergun et al. (2007b). O objetivo deste algoritmo é a geração de soluções sem que seja necessária a geração de todos os ciclos viáveis, o que é necessário nos métodos anteriormente propostos. 
A heurística inicia através da criação do conjunto $U$ de rotas em ordem decrescente de tamanho, isso porque a heurística dá prioridade às rotas mais longas para serem alocadas. Escolhe-se então a rota de maior tamanho que será chamada de rota base.

Sobre a rota base inicia-se então a construção do ciclo $C_{j}$, adicionando-se ao final deste ciclo a rota do conjunto $U$ que possui vértice inicial mais próximo do vértice final de $C_{j}$. Uma vez utilizada, a rota é retirada do conjunto $U$.

Repete-se o processo adicionando-se ao início do ciclo $C_{j}$ a rota do conjunto $U$ que possui vértice final mais próximo do vértice inicial de $C_{j}$.

Entretanto, sobre a rota base são criados diversos ciclos em paralelo com 0 objetivo de se reduzir a "miopia" da heurística. Ao final da construção dos ciclos, escolhe-se aquele que respeita os devidos limites de cardinalidade, reposicionamentos e que possua o melhor fator de qualidade dado por:

$$
p=\frac{\text { custo dos reposicionamentos }}{\text { custo total do ciclo }}
$$

Rotas que foram utilizadas nas construções e que não foram selecionadas são devolvidas ao conjunto $U$. Repete-se então o processo selecionando a próxima rota base.

A heurística Construtivo-Destrutiva permite que sejam alterados alguns parâmetros como:

- $\quad p_{\text {min: }}$ menor proporção $p$ que o ciclo deve ter. Caso não seja atingido $p_{\min , 0}$ ciclo não é construído e parte para a próxima rota do conjunto $U$.

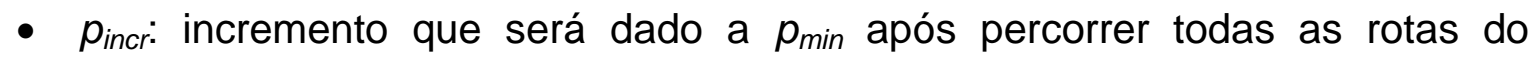
conjunto $U$.

- $j_{\max }$ : número máximo de ciclos que serão construídos em paralelo sobre a mesma rota base com o objetivo de se reduzir a "miopia" da heurística. Ao final da construção seleciona-se o ciclo com melhor fator de qualidade $p$ e devolvem-se as rotas que pertenciam a ciclos não selecionados ao conjunto $U$. 
Um grande diferencial da heurística Construtivo-Destrutiva em relação aos demais métodos é a possibilidade desta resolver problemas de grande porte, uma vez que não exige a geração de todos os ciclos viáveis.

\subsection{Métodos de Busca Local}

Segundo Aarts et al. (1997), existem muitos problemas de otimização combinatória NP-Hard. Acredita-se que grande parte desses problemas não pode ser resolvida em tempo polinomial, tornando inviável a busca por soluções ótimas para grandes instâncias. Desta forma, existe grande interesse no desenvolvimento de algoritmos que nos dê soluções de boa qualidade em tempos aceitáveis.

A literatura, ainda segundo Aarts et al. (1997), distingue tais algoritmos aproximados em duas classes principais: construtivos e baseados em busca local.

Um algoritmo baseado em busca local, que será abordado neste trabalho, exige que seja definida uma vizinhança para uma solução do problema e de que forma iremos explorar esta vizinhança.

A definição de vizinhança depende do problema que está sendo estudado, e sua definição é o ponto crucial para que seja criado um algoritmo eficiente que nos leve a uma solução de boa qualidade.

Não existe na literatura referências que tenham tratado o PCRCR através de uma heurística baseada em busca local. Desta forma foi feita uma revisão na literatura dos principais métodos de Busca Local para o PCR não restrito ou outros problemas similares.

Chamamos aqui de problemas similares qualquer problema que envolva grafos, geração de roteiros ou qualquer outro problema de transporte, tal como o Problema do Caixeiro Viajante. 


\subsubsection{Busca local para o PCR}

Savelsbergh et al. (2004) e Ergun et al. (2004) propuseram uma estrutura de vizinhança que permite gerar soluções com dois reposicionamentos $(\mathrm{DH}=2)$ a partir de dois ciclos com um reposicionamento $(\mathrm{DH}=1)$.

A Figura 2-4 mostra como o Ciclo $C_{1}$ (formado pelas Rotas $A$ e B) foi mesclado ao Ciclo $\mathrm{C}_{2}$ (formado pelas Rotas $\mathrm{C}$ e D) formando o Ciclo $\mathrm{C}_{12}$.

Esta operação só pode ser realizada quando houver uma redução do custo $c$ total dos ciclos envolvidos, ou seja, sendo $c_{1}$ o custo de se realizar o ciclo $\mathrm{C}_{1}, c_{2} \mathrm{O}$ custo de se realizar o ciclo $\mathrm{C}_{2}$ e $c_{12}$ o custo de se realizar o ciclo mesclado $\mathrm{C}_{12}$, é necessário que seja satisfeita a inequação:

$$
c_{1}+c_{2}>c_{12}
$$

No exemplo acima, os ciclos $\mathrm{C}_{1}$ e $\mathrm{C}_{2}$ possuem apenas duas rotas, sendo que a mesma regra vale para qualquer tentativa de união de ciclos, devendo-se atentar apenas ao número máximo de ciclos e reposicionamentos permissíveis no ciclo $\mathrm{C}_{12}$ final. Como exemplo, a Figura 2-5 mostra a união de dois ciclos (com três rotas e um reposicionamento cada) que resultaram no ciclo final com seis rotas e dois reposicionamentos (cardinalidade oito).

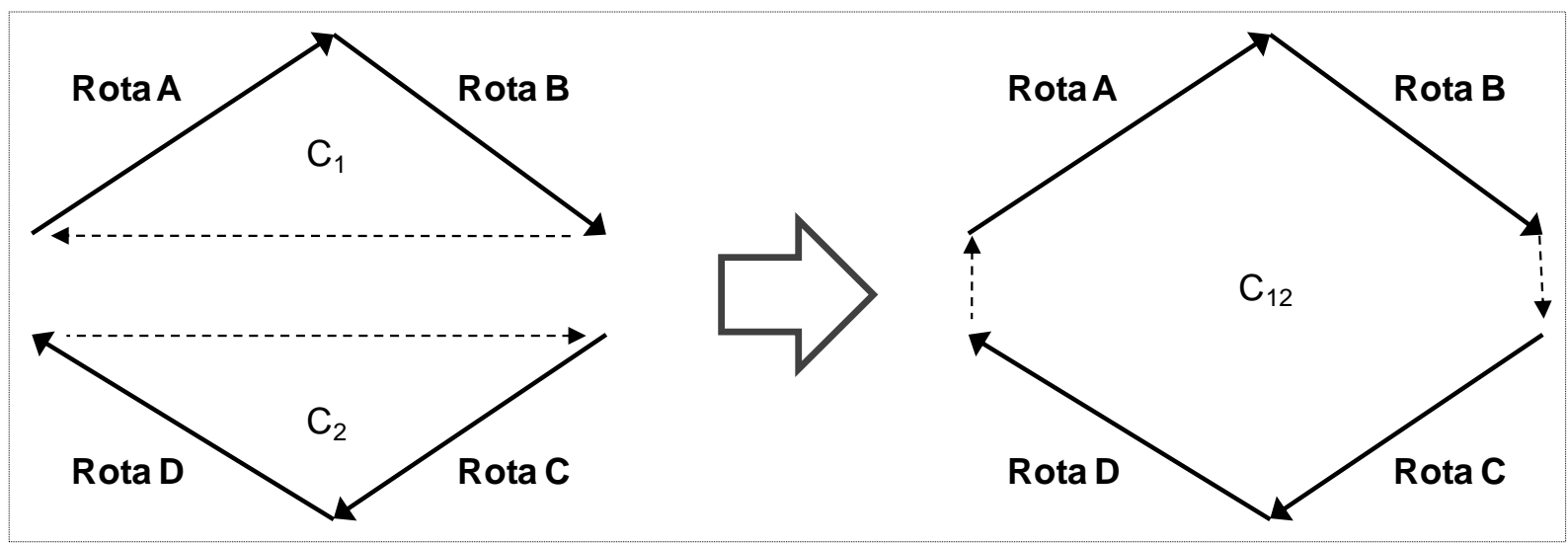

Figura 2-4: Estrutura de vizinhança na busca local para o PCR proposta por Savelsbergh et al. (2004) e Ergun et al. (2004) 


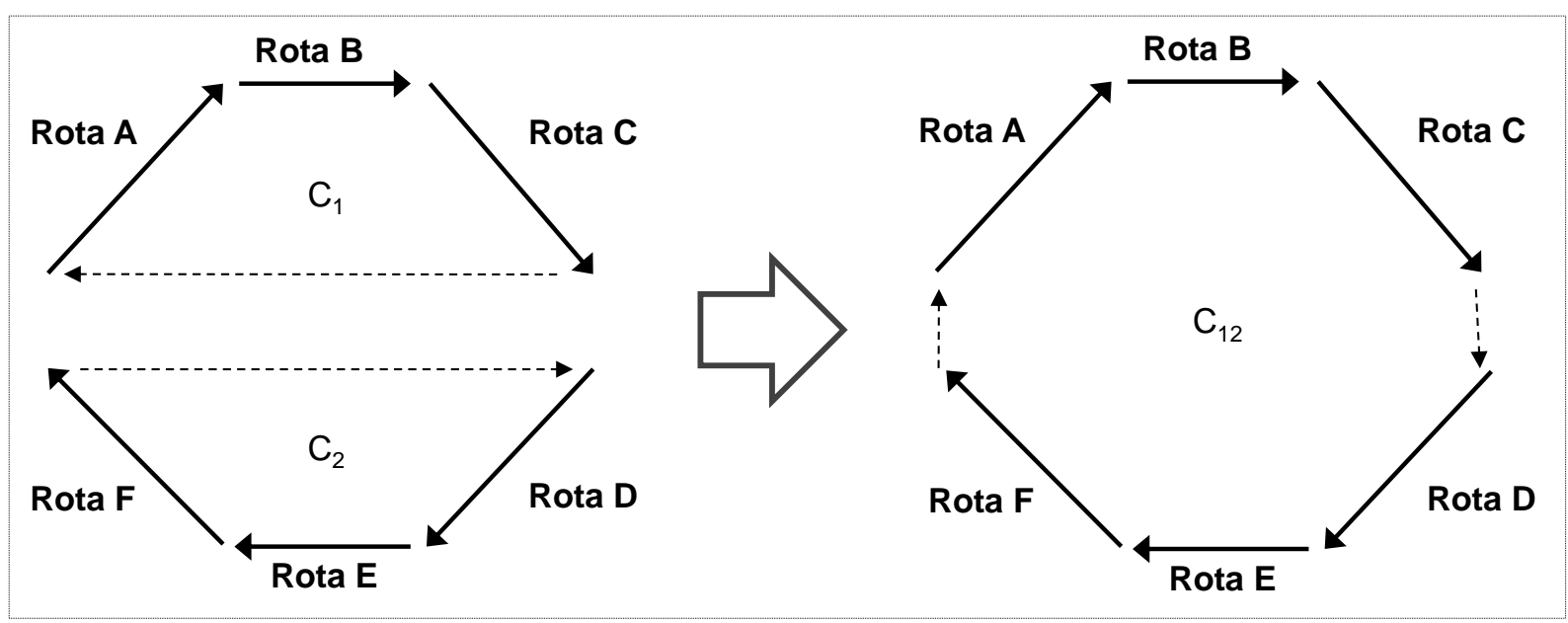

Figura 2-5: Estrutura de vizinhança na busca local para o PCR proposta por Savelsbergh et al. (2004) e Ergun et al. (2004)

Caso deseje ciclos finais com apenas dois reposicionamentos permissíveis, uma opção é gerar previamente uma solução com ciclos de apenas um reposicionamento e então buscar em alguma ordem todas as combinações de ciclos dois a dois até que alguma economia seja encontrada. Uma vez encontrada uma economia, mescla-se os ciclos e continua-se a busca combinando-se os ciclos restantes. Esta heurística verifica cada combinação no máximo uma vez, sendo, portanto, bem eficiente, mas com pouco potencial de economia.

Ergun et al. (2004) propuseram então uma heurística que segue as seguintes etapas:

1. Geração de uma solução inicial para $\mathrm{DH}=1$.

2. Identificação das combinações de ciclos viáveis (quando existe redução de custo).

3. Encontra o ciclo que traz a maior redução de custo $c_{12}-\left(c_{1}+c_{2}\right)$.

4. Gera-se o ciclo e repete-se a operação para os próximos ciclos viáveis em ordem de maior redução de custo.

A eficiência da heurística acima foi melhorada explorando-se a seguinte hipótese: 
Hipótese 1: Se mesclar os ciclos $C_{1}$ e $C_{2}$ nos leva a uma redução de custo, então pelo menos uma das condições abaixo devem ser satisfeitas:

1. $d_{\text {(fim de C1,Início C1) }}>d_{(\text {fim de C1,Início de C2) }}$

2. $d_{\text {(fim de C2,Início C2) }}>d_{\text {(fim de C2,Início de C1) }}$

Onde $d_{i j}$ é o custo associado ao arco $(i, \jmath)$.

Prova: Assumimos que nenhuma das hipóteses seja verdadeira, ou seja:

3. $d_{\text {(fim de C1,Início C1) }}<d_{\text {(fim de C1,Início de C2) }}$

4. $d_{\text {(fim de C2,Início C2) }}<d_{\text {(fim de C2,Início de C1) }}$

Neste caso,

$d_{\text {(fim de C1,Iń́cio C1) }}+d_{\text {(fim de C2,Iń́cio C2) }}<d_{\text {(fim de C1,Início C2) }}+d_{\text {(fim de C2,Início C1) }}$

O que gera uma contradição com a premissa de que $c_{1}+c_{2}>c_{12}$.

Desta forma, foi significativamente reduzido o número combinações de ciclos a serem verificados, uma vez que ao menos uma condição das que foram apresentadas na Hipótese 1 teria que ser satisfeita.

\subsubsection{Algoritmo 2-Opt}

Entre os métodos de busca local, um dos mais populares é o algoritmo 2-Opt, proposto inicialmente por Croes (1958) para o Problema do Caixeiro Viajante. A idéia principal deste algoritmo consiste em eliminar um par de arestas e reconectar os nós de tal forma que seja obtido um novo roteiro. A Figura 2-6 mostra como o algoritmo 2-Opt funciona eliminando-se as arestas que ligam os pares de nós ( $B, E$ ) e $(D, C)$ e inserindo as novas arestas ligando os pares de nós $(B, D)$ e $(E, C)$. Caso a troca leve a um menor custo, mantemos a troca, caso contrário, escolhemos outro par de arestas para realizar novo teste. 


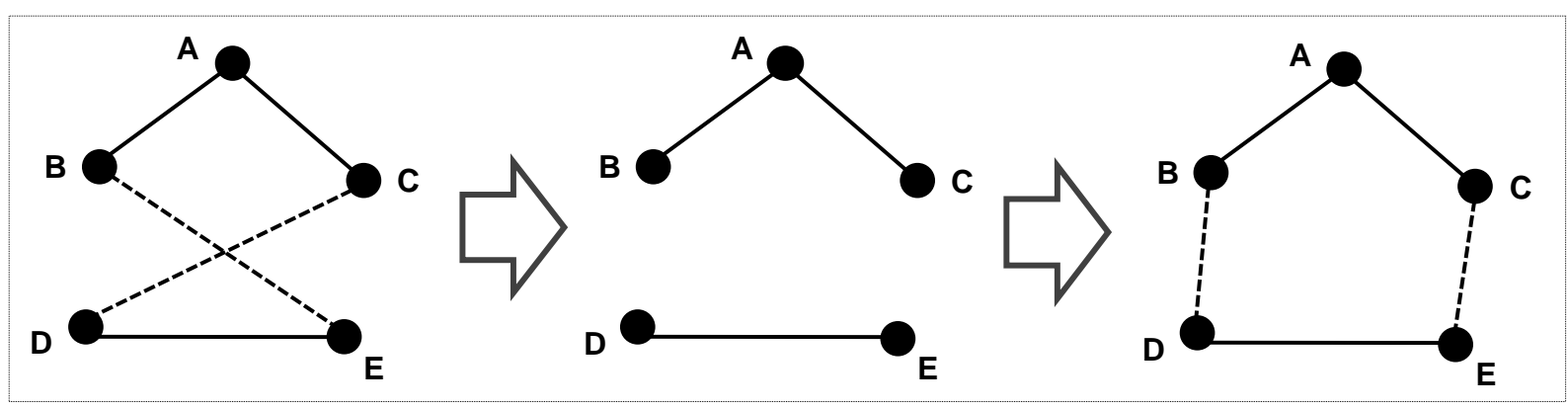

Figura 2-6: Exemplo de Algoritmo 2-OPT

Para problema com $n$ nós e que haja simetria na distância de uma cidade $i$ a outra $j$, ou seja, $d_{i j}=d_{j i}$, existem $\mathrm{n}(\mathrm{n}-3) / 2$ movimentos possíveis.

Aarts et al. (1997) também apresentaram uma forma de aumentarmos a eficiência de um algoritmo 2-Opt limitando-se o espaço de busca. Podemos verificar esta propriedade observando a Figura 2-6 e explorando a seguinte hipótese:

Hipótese 2: Se realizar um movimento 2-Opt nos arcos (C,D) e (E,B) nos leva a uma redução de custo, então pelo menos uma das condições abaixo devem ser satisfeitas:

1. $\mathrm{d}_{(\mathrm{C}, \mathrm{D})}>\mathrm{d}_{(\mathrm{D}, \mathrm{B})}$

2. $\mathrm{d}_{(\mathrm{E}, \mathrm{B})}>\mathrm{d}_{(\mathrm{C}, \mathrm{E})}$

Onde $d_{i j}$ é a distância associada ao arco $(i, j)$.

Prova: Assumimos que nenhuma das hipóteses seja verdadeira, ou seja:

3. $\mathrm{d}_{(\mathrm{C}, \mathrm{D})}<\mathrm{d}_{(\mathrm{D}, \mathrm{B})}$

4. $\mathrm{d}_{(\mathrm{E}, \mathrm{B})}<\mathrm{d}_{(\mathrm{C}, \mathrm{E})}$

Neste caso,

$\mathrm{d}_{(\mathrm{C}, \mathrm{D})}+\mathrm{d}_{(\mathrm{E}, \mathrm{B})}<\mathrm{d}_{(\mathrm{D}, \mathrm{B})}+\mathrm{d}_{(\mathrm{C}, \mathrm{E})}$ 
O que gera uma contradição com a premissa de que houve redução de custo.

Podemos verificar que esta propriedade é muito próxima da propriedade apresentada por Ergun et al. (2004) para a Busca Local aplicada ao PCR (Hipótese 1), o que reforça a importância de estudarmos propriedades não aplicadas diretamente ao Problema de Cobertura de Rotas, mas que podem ser úteis para o desenvolvimento deste trabalho.

\subsubsection{Algoritmo 3-Opt}

O algoritmo 3-Opt foi proposto inicialmente por Lin (1965) também para o Problema do Caixeiro Viajante. De forma similar ao algoritmo 2-Opt, eliminam-se 3 arestas e logo após conecta-se novamente o ciclo com o objetivo de se encontrar um novo ciclo de menor custo como mostrado na Figura 2-7.

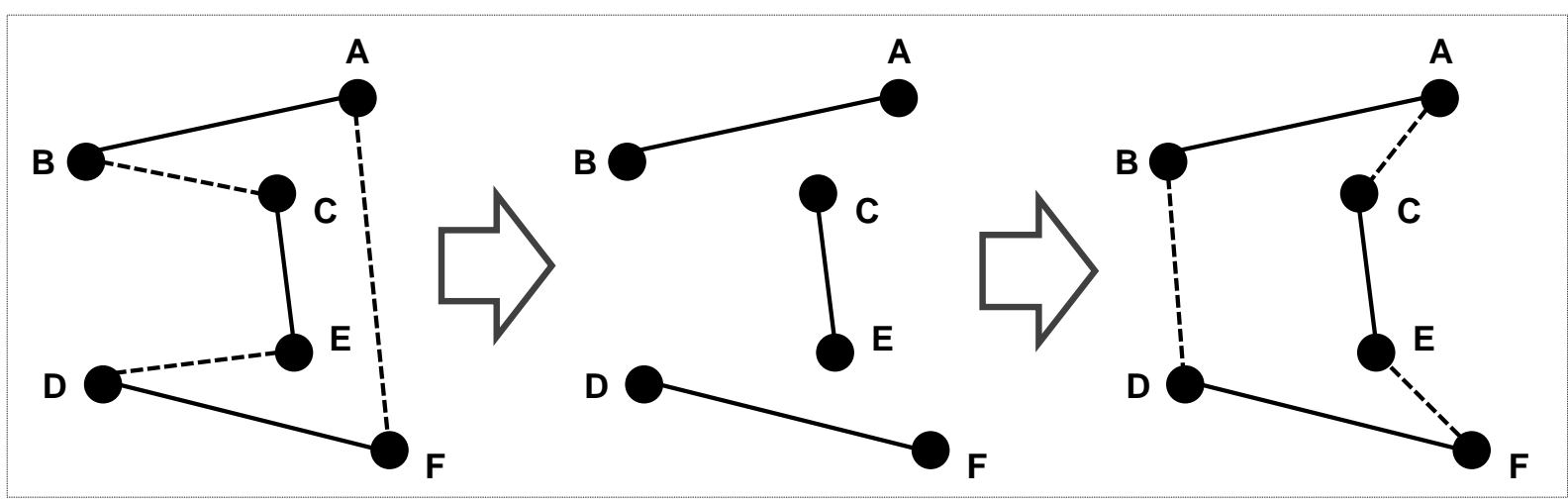

Figura 2-7: Exemplo de Algoritmo 3-Opt

Como apontado por Cunha et al. (2002), o aumento de $k$ melhora o resultado do modelo mas também causa um grande aumento no esforço computacional. Ainda segundo Cunha et al. (2002), podemos obter bons resultados em tempos aceitáveis combinando-se o algoritmo 2-Opt (até que não haja mais melhorias no modelo) com o algoritmo 3-Opt.

Cunha et al. (2002) também demonstraram a importância da solução inicial na qualidade das soluções seja pelo método 2-Opt ou 3-Opt. 


\subsubsection{Algoritmo k-Opt para k>3}

O Algoritmo k-Opt é uma generalização dos Algoritmos 2-Opt e 3-Opt proposta inicialmente por Lin et al. (1973), onde se destroem $k$ arcos e reconstroemse $k$ arcos para restaurar o ciclo.

Um exemplo de movimento k-Opt para k>3 é o movimento 4-Opt conhecido como "double-bridge", utilizado muitas vezes para causar uma perturbação na solução corrente. A Figura 2-8 apresenta este movimento.

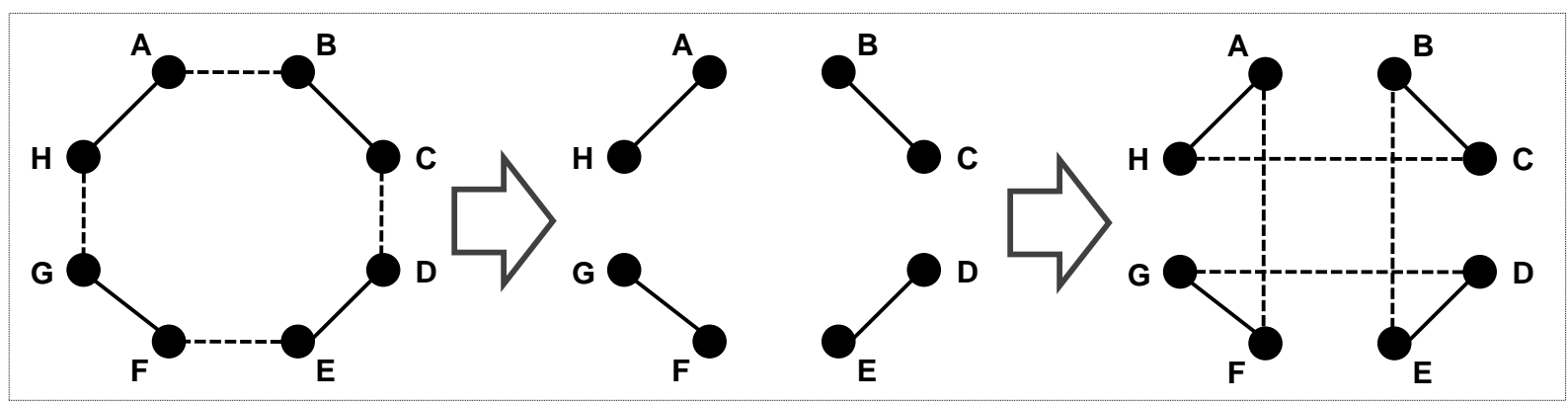

Figura 2-8: Exemplo de movimento 4-Opt "double-bridge"

Este movimento foi inicialmente mencionado por Lin et al. (1973), onde ele foi usado como um simples exemplo de movimento, que não poderia ser obtido diretamente por movimentos 2-Opt ou 3-Opt. Este movimento pode ser visto como uma seqüência de dois movimentos 2-Opt ilegais, onde cada um geraria dois ciclos independentes, mas que de maneira conjunta uniria novamente os vértices em questão.

A Figura 2-9 mostra como dois movimentos 2-Opt ilegais é equivalente ao movimento 4-Opt apresentado na Figura 2-8. Isso porque o primeiro movimento 2Opt geraria dois ciclos desconexos, que são unidos apenas após o segundo movimento 2-Opt. 


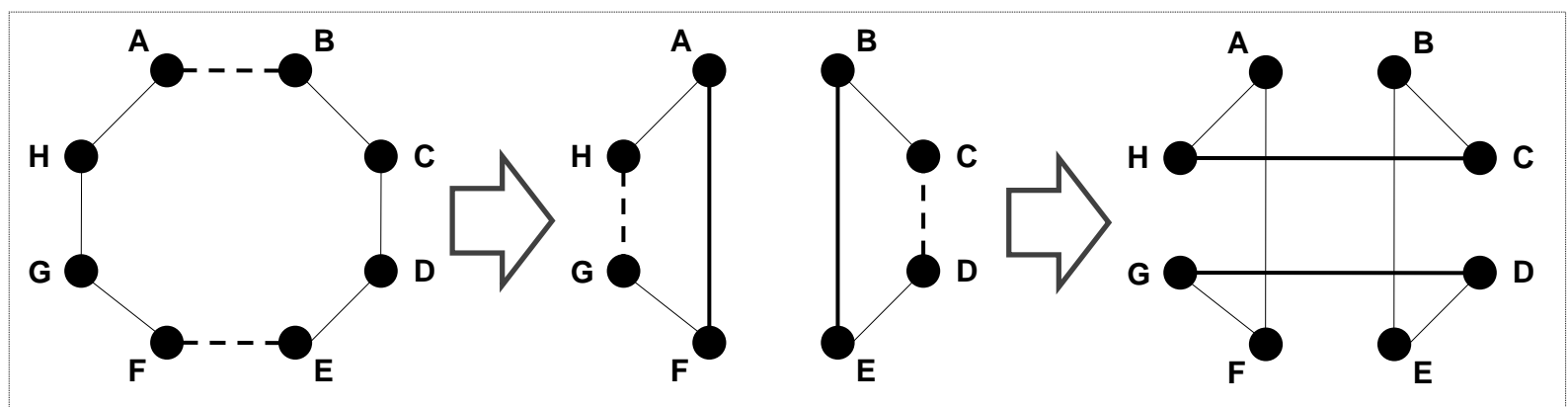

Figura 2-9: Exemplo de como dois movimentos 2-Opt ilegais (gerando dois ciclos desconexos) é equivalente a um movimento 4-Opt

Em geral, o alto custo computacional para k>3 não compensa os resultados obtidos, desta forma são aplicadas em geral as heurísticas 2-Opt e 3-Opt.

Neste capítulo foi feita uma revisão do Problema de Cobertura de Rotas com Cardinalidade Restrita associado a diversos conceitos existentes na literatura que podem vir a servir no desenvolvimento da Heurística com Busca Local proposta por este trabalho. No capítulo seguinte é feita uma descrição mais detalhada do problema e a forma como este foi modelado e estruturado. 


\section{MÉTODO DE SOLUÇÃO DO PROBLEMA}

Neste capítulo é apresentado de forma mais detalhada o problema de cobertura de rotas com cardinalidade restrita (PCRCR). Também será detalhada a heurística desenvolvida por este trabalho que é a Heurística com Busca Local.

\subsection{Descrição do Problema PCRCR}

Conforme descrito no Capítulo 2, o Problema de Cobertura de Rotas é um problema que representa o transporte colaborativo. O problema pode ser descrito como: dado um grafo euclidiano direcionado $D=(N, A)$, com conjunto de nós $N$, $\operatorname{arcos} A$, custo dos arcos $c($ a) para $a \in A$ e conjunto de rotas $L$ tal que $L \subseteq A$ encontre o custo mínimo de ciclos fechados que cubram $L$ de tal forma que a cardinalidade do ciclo seja menor ou igual à $\mathrm{k}$.

Da mesma forma que Ergun et al. (2007b) e Ferri (2009), são tratados problemas com limite de cardinalidade cinco com limitações de um ou dois reposicionamentos $(\mathrm{DH})$.

Como mencionado no Capítulo 2, o principal motivo de se limitar a cardinalidade de um ciclo é que, na prática, para cada arco que representa a viagem de um veículo estão associadas operações de carga ou descarga em seus extremos (vértices). Assim, quando aumentamos o número de viagem em um mesmo ciclo, torna-se cada vez mais difícil alinhar a operação dos diversos vértices (pontos de carga ou descarga).

A Figura 3-1 mostra todas as combinações de ciclos viáveis para cada cardinalidade e número de reposicionamentos. 


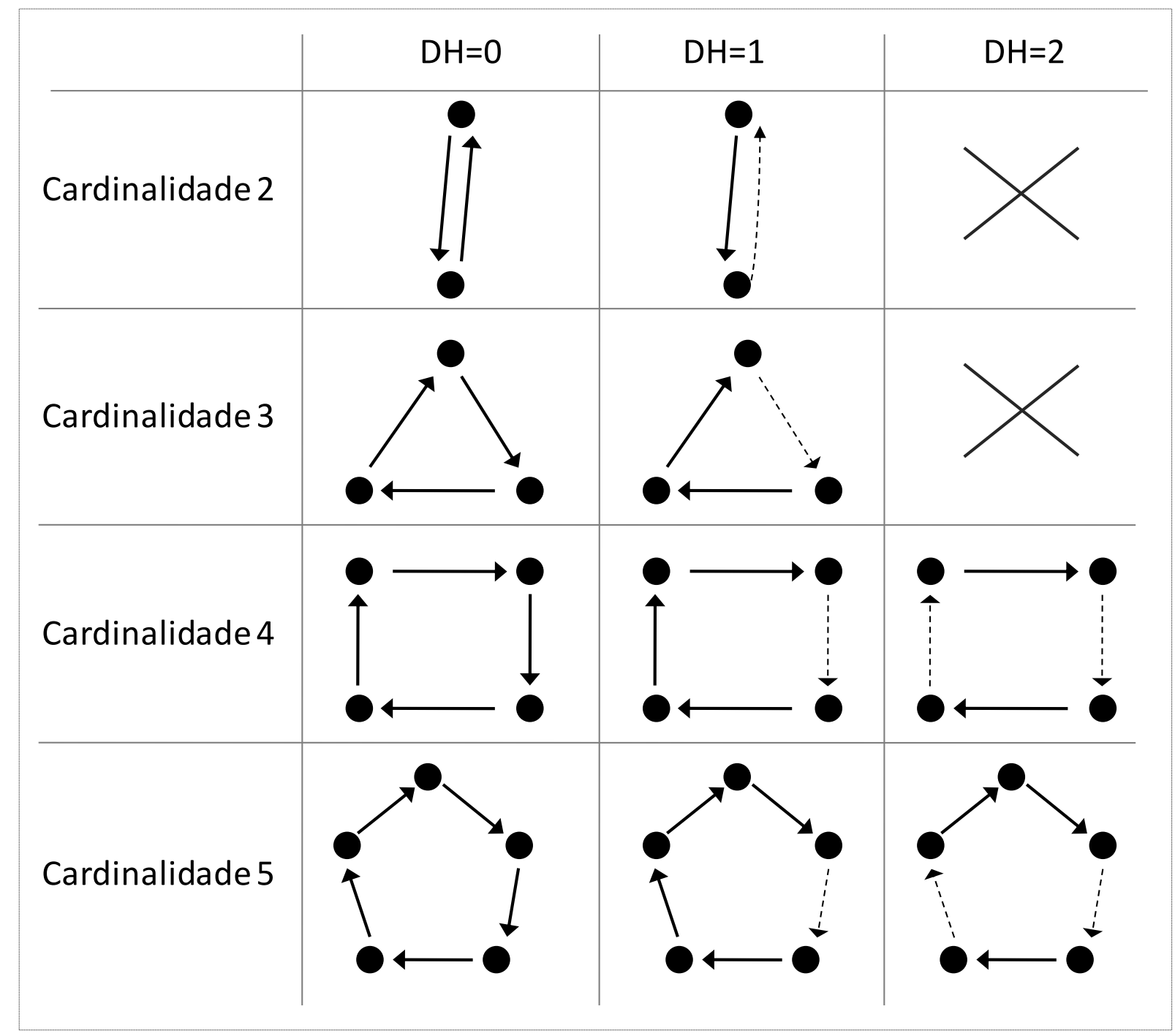

Figura 3-1: Ciclos viáveis por Cardinalidade e Reposicionamentos

Uma primeira observação é que não existe uma solução viável com Cardinalidade igual a um, uma vez que uma condição necessária para este problema é que todos os ciclos sejam fechados, tendo portando cardinalidade mínima igual a dois.

Também não existe solução viável para Cardinalidade 2 e 3 com dois reposicionamentos. 


\subsection{Heurística com Busca Local proposta por este trabalho}

Como já mencionado anteriormente, o objetivo central deste trabalho é desenvolver uma heurística com Busca Local para a solução do Problema de Cobertura de Rotas com Cardinalidade Restrita.

Um método de Busca Local depende basicamente de como que é definida uma vizinhança para uma solução qualquer do problema, sendo que esta depende de como o problema foi estruturado.

\subsubsection{Estruturação do Problema}

Com o objetivo de simplificar a representação de uma solução do problema bem como percorrer a vizinhança de uma solução, um ciclo foi representado seguindo-se as definições apresentadas a seguir.

- Duas rotas consecutivas podem ser representadas por meio de uma rota simplificada

Rotas consecutivas são unidas e representadas por meio de uma única rota simplificada. A Figura 3-2 mostra como as rotas 1 e 2 foram substituídas pela rota 1'.

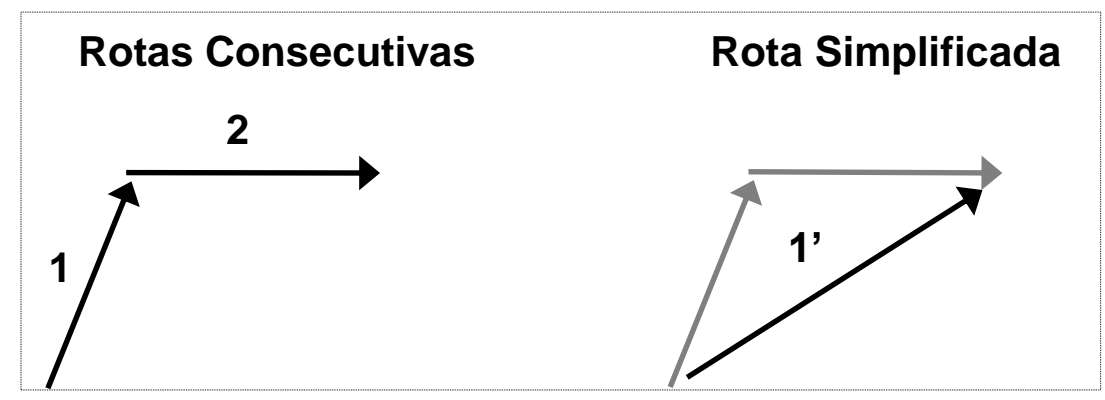

Figura 3-2: Formação de uma rota simplificada pela união de duas rotas consecutivas 
- Representação de um ciclo através da união de duas rotas simplificadas

Uma vez formadas as rotas simplificadas, estas são então combinadas (em pares) para a formação de um ciclo.

A Figura 3-3 mostra como um ciclo de cardinalidade cinco (quatro rotas e um reposicionamento) foi representado pela união de duas rotas simplificadas.

$\mathrm{Na}$ Figura 3-3, as Rotas 1 e 2 foram substituídas por uma única rota simplificada (rota 1'), enquanto que as Rotas 3 e 4 foram substituídas pela rota simplificada 3'.

Pode existir o caso em que sejam combinadas duas rotas, sendo uma delas simplificada e outra não, como mostrado na Figura 3-4.

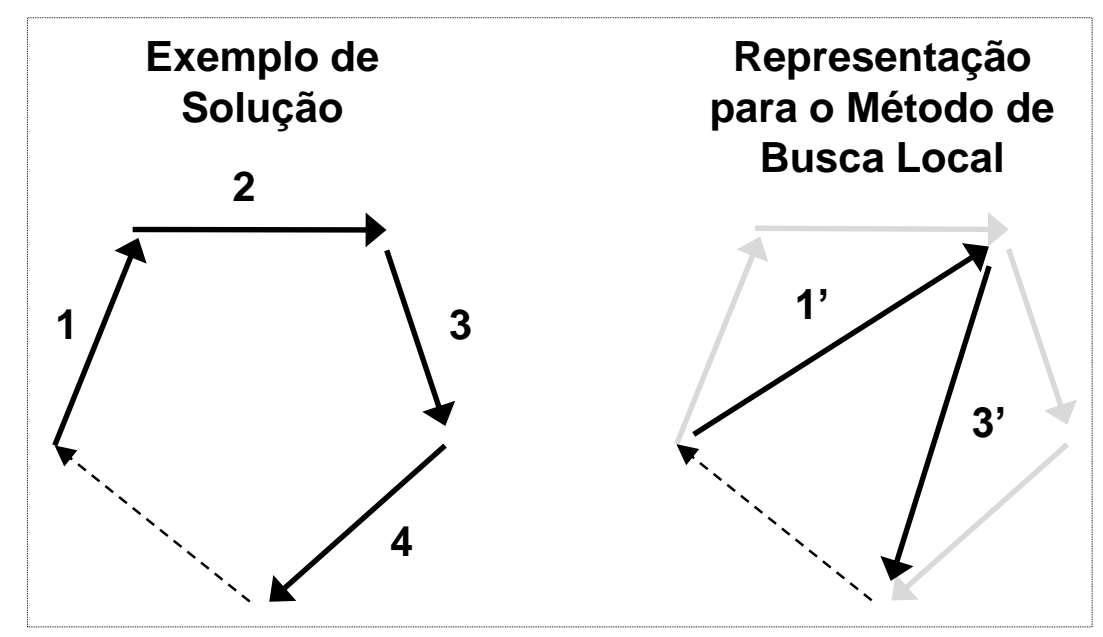

Figura 3-3: Representação de uma solução para implementação do Método de Busca Local 


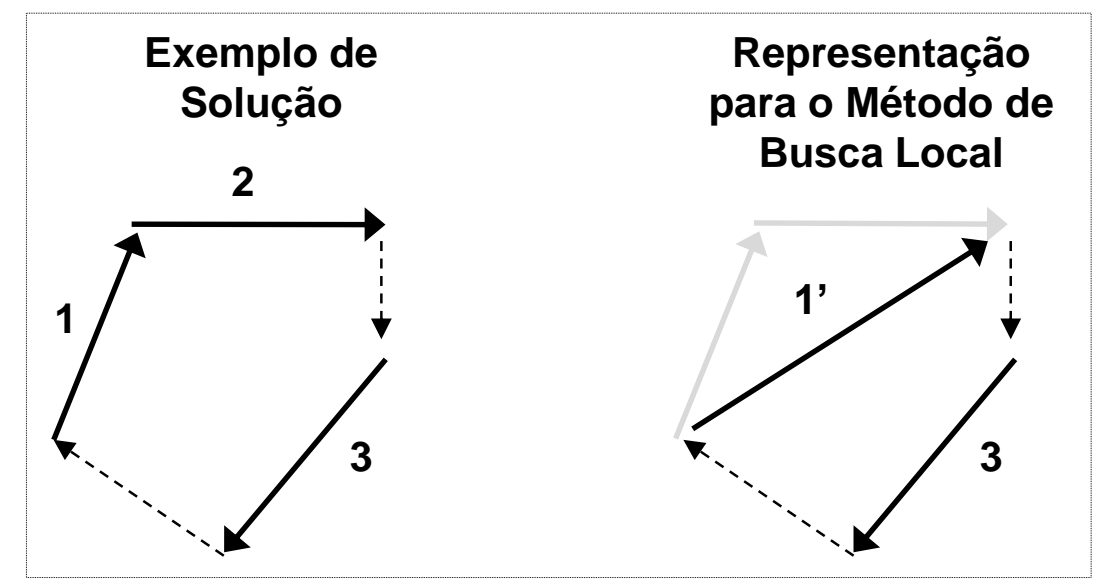

Figura 3-4: Representação de uma solução para implementação do Método de Busca Local

Estruturando o problema desta forma, o mesmo deixa de ser formar ciclos e passa a ser combinar pares de rotas, podendo ser uma ou duas delas rotas simplificadas.

Entretanto, estruturar o problema desta forma nos leva a uma limitação com relação à cardinalidade máxima de um ciclo, isso porque a combinação de um par de rotas simplificadas nos leva a um ciclo com quatro rotas. Caso o objetivo seja gerar um ciclo de cardinalidade cinco sem reposicionamentos (cinco rotas), esta nova estrutura não cobriria tal necessidade.

A Figura 3-5 mostra ciclos com diferentes cardinalidades e diferentes números de reposicionamentos permissíveis $(\mathrm{DH})$, e para cada ciclo a forma como este poderia ser tratado seguindo a nova estrutura.

O único ciclo que não pode ser tratado seguindo a nova estrutura é o ciclo de cardinalidade cinco sem reposicionamentos, isso porque este exigiria duas rotas simplificadas (quatro rotas) mais uma rota não simplificada, o que não é possível seguindo a nova estrutura. 


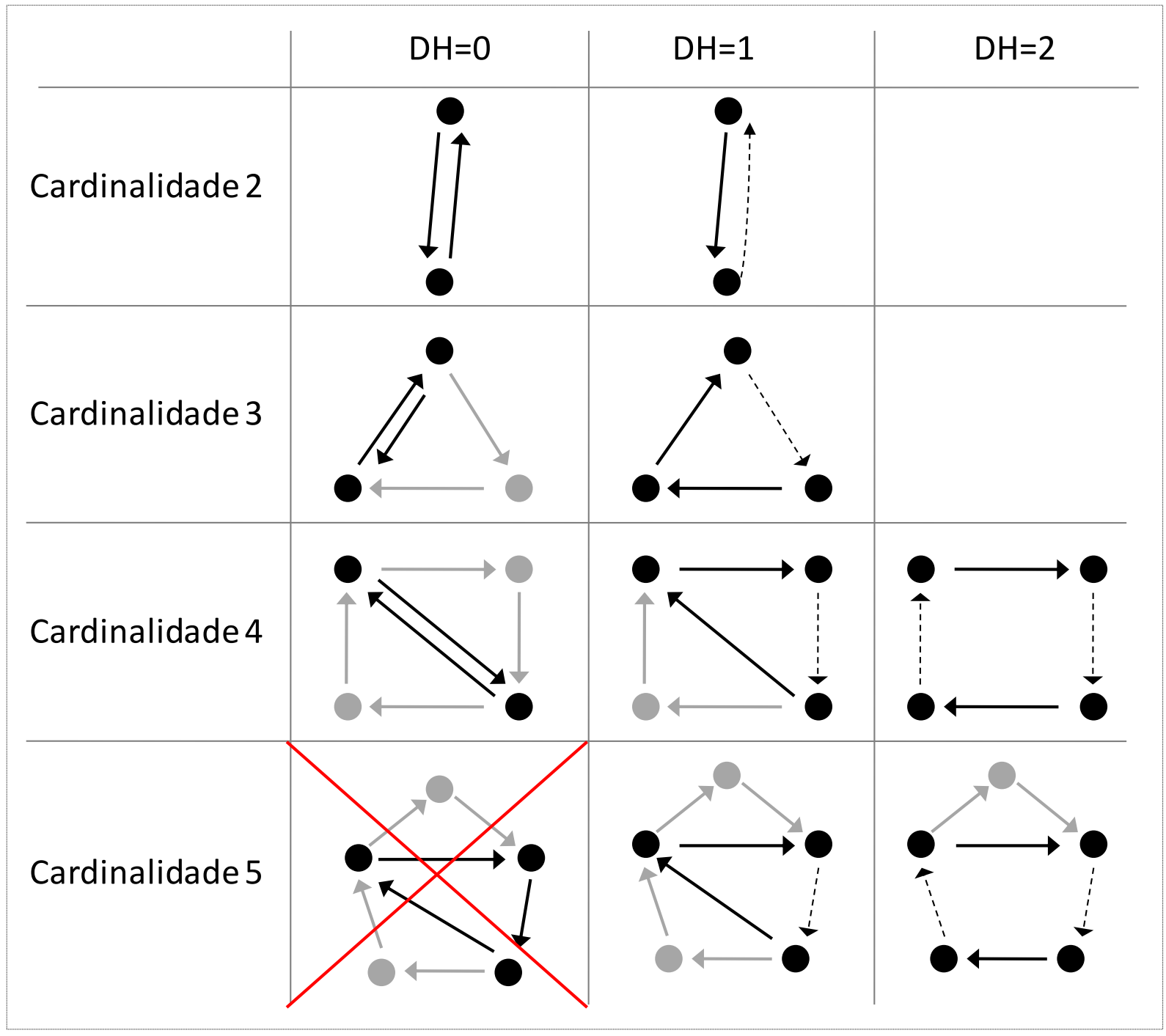

Figura 3-5: Representação das possibilidades de ciclos seguindo a representação simplificada

Análises preliminares das soluções obtidas pela literatura ou por Programação Linear Inteira (PLI) mostraram que soluções de Cardinalidade cinco e $\mathrm{DH}=0$ são extremamente raras, e sendo assim, a inviabilidade de representar esta solução através da simplificação proposta não afetaria significativamente a qualidade dos resultados obtidos.

\subsubsection{Definição de vizinhança}

A Figura 3-6 mostra o exemplo de duas rotas (sendo uma delas simplificada, ou seja, composta por outras duas rotas) candidatas a serem combinadas. 


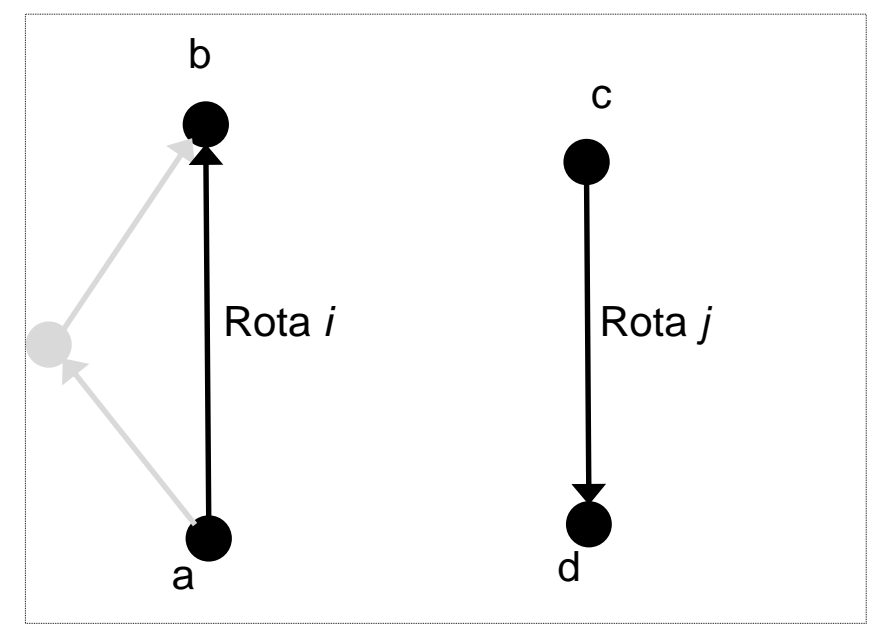

Figura 3-6: Exemplo de duas rotas candidatas a serem combinadas

Para cada par de rotas (simplificadas ou não) foi criado um fator $q_{i j}$ definido pela somatória dos custos das rotas dividida pela somatória dos reposicionamentos que a união destas geraria.

Para efeitos de cálculo do fator $q_{i j}$, caso a rota a ser combinada seja uma rota simplificada, consideramos o seu custo como sendo a distância entre o nó de origem da primeira rota até o nó de destino da segunda rota.

Sendo $d_{y z}$ a distância entre os nós y e $z$, no exemplo da Figura 3-6 teríamos:

$$
q_{i j}=\frac{\left(d_{a b}+d_{c d}\right)}{\left(d_{d a}+d_{b c}+e\right)}
$$

Foi adicionado o parâmetro e no denominador da equação para o caso de candidatos onde não há reposicionamentos, o que levaria a uma divisão por zero. Para execução dos cenários foi atribuído para este parâmetro o valor de uma unidade, sendo que a variação deste entre o intervalo $[0.1,10]$ não causou alterações nos resultados obtidos.

Ao procurarmos pares de rotas candidatas a serem combinadas, o valor de $q_{i j}$ se comporta da seguinte forma:

- Alto valor de $q_{i j}$ : rotas a serem combinadas são rotas grandes e que quando unidas irão gerar baixos reposicionamentos. 
- Baixo valor de $q_{i j}$ : rotas a serem combinadas são rotas pequenas e que quando unidas irão gerar altos reposicionamentos.

Desta forma, o interesse é combinar rotas com altos valores de $q_{i j}$, o que geraria ciclos com rotas grandes e baixos reposicionamentos.

No exemplo da Figura 3-6, poderia ocorrer o caso em que a Rota $j$ (a ser combinada com a Rota l) já estivesse inserida em um ciclo com baixo reposicionamento, não sendo então interessante para o modelo explorar esta vizinhança. Este caso está representado na Figura 3-7.

É então utilizado o conceito de "qualidade" de um ciclo definido por Ferri (2009), como sendo a proporção do custo dos reposicionamentos em relação ao custo total do ciclo.

Seja $\mathrm{C}_{\mathrm{k}} \mathrm{O}$ ciclo onde a rota $i$ está inserida, a "qualidade" do ciclo é dada por:

$p_{i}=\frac{\text { custo dos reposicionamentos de } C_{k}}{\text { custo total do ciclo } C_{k}}$

Dessa forma, quanto menor for o $p$ de um ciclo, mais "qualidade" ele terá.

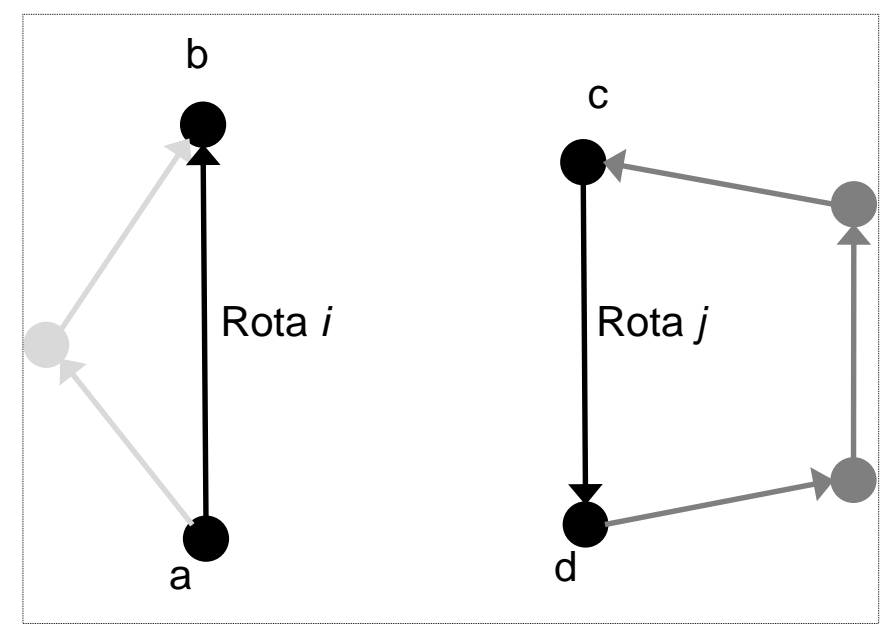

Figura 3-7: Exemplo de duas rotas candidatas a serem combinadas, sendo que uma delas já pertence a um ciclo 
O valor de $p_{i}$ pode ser então interpretado da seguinte forma:

- Alto valor de $p_{i}$ : rota a ser combinada pertence a um ciclo com altos reposicionamentos.

- Baixo valor de $p_{i}$ : rota a ser combinada pertence a um ciclo com baixos reposicionamentos.

Desta forma, o interesse é combinar rotas com altos valores de $p_{i}$, o que indica que a rota pertence a um ciclo pouco interessante para o sistema (altos reposicionamentos) e que, portanto, poderia ser recombinada com outra rota.

Assim, dadas duas rotas ( $i$ e $\jmath$ ) a serem combinadas, vimos anteriormente que estas rotas são boas candidatas a serem combinadas quanto maior for:

- $\mathrm{q}_{\mathrm{ij}}$ : indica que são rotas de grandes dimensões e que quando unidas irá gerar baixos reposicionamentos.

- $\mathrm{p}_{\mathrm{i}}$ : indica que a rota $i$ ainda pertence a um ciclo com altos reposicionamentos.

- $\mathrm{p}_{\mathrm{j}}$ : indica que a rota $j$ ainda pertence a um ciclo com altos reposicionamentos.

Definimos então o fator $f_{i j}$ que une os fatores $q_{i j}, p_{i}$ e $p_{j}$ através da equação (3.3):

$f_{i j}=q_{i j} * p_{i} * p_{\mathrm{j}}$

O objetivo desta equação é dizer para dois pares de rotas ( $i$ e $J$ ) qual a "proximidade" entre elas, ou seja, com quais rotas devo tentar uma recombinação com o objetivo de se obter uma nova configuração de menor custo com as rotas envolvidas.

Foram testadas outras variações para a equação (3.3), sendo que esta foi a que apresentou melhor desempenho conforme se alteravam os parâmetros $q_{i j}, p_{i} \mathrm{e}$ $p_{j}$. 
Foram testadas outras equações para como:

$$
\begin{gathered}
f_{i j}=q_{i j}+p_{i}+p_{\mathrm{j}} \\
f_{i j}=q_{i j}{ }^{2}+p_{i}+p_{\mathrm{j}} \\
f_{i j}=q_{i j}{ }^{2} * p_{i} * p_{\mathrm{j}}
\end{gathered}
$$

Dado um conjunto de rotas $L$, dizemos então que uma rota $j$ é a vizinha mais próxima de uma rota $i$ se:

$$
f_{i j}>f_{i k} \forall k \in L
$$

\subsubsection{Reconstrução da vizinhança}

Uma vez definido o fator $f$ que nos dirá qual a rota mais "próxima" de uma determinada rota, é apresentada a forma como será feita a reconstrução dos ciclos envolvidos.

Suponha que se deseje verificar se existe alguma possibilidade de ganho ao se combinarem as Rotas $i$ e $j$ apresentadas na Figura 3-8 e que por sua vez já estão associadas a ciclos. 


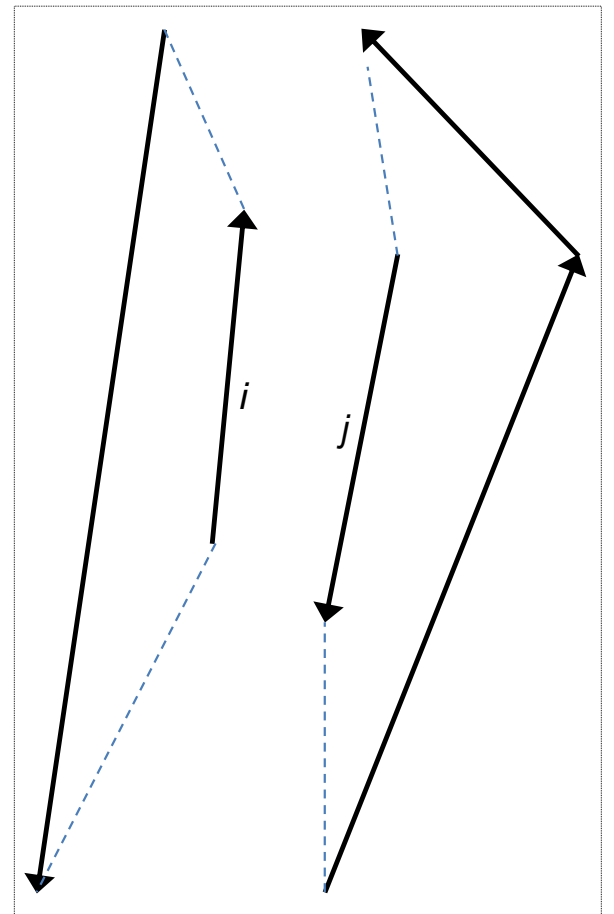

Figura 3-8: Exemplo de duas rotas (já alocadas a ciclos) candidatas a serem combinadas

O que o algoritmo faz é uma busca exaustiva envolvendo o conjunto de rotas que incluem as rotas vizinhas e as rotas anteriormente associadas a estas através dos ciclos. Escolhe-se então a opção que apresentar um menor custo e que respeite os devidos limites de cardinalidade e reposicionamentos permissíveis.

A Figura 3-9 mostra duas das opções possíveis de reconstrução. Note que na Opção 2 foi desconectada uma das rotas do sistema (destacada em vermelho). 


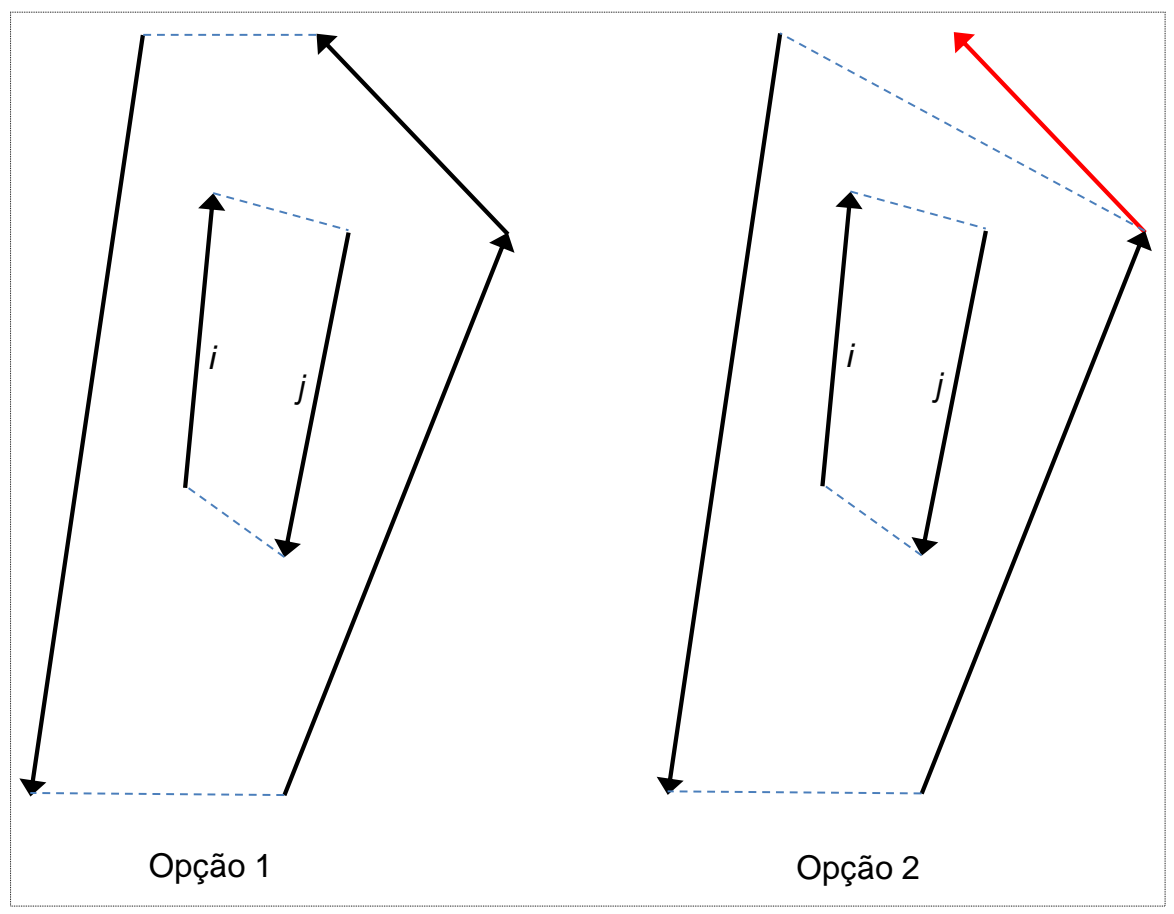

Figura 3-9: Exemplo de soluções possíveis ao se recombinar rotas envolvidas na busca exaustiva

\subsubsection{Descrição da Heurística com Busca Local}

Dado as definições de vizinhança apresentadas anteriormente, iremos aqui descrever o funcionamento da Heurística com Busca Local.

Etapa 1: Primeiramente deve-se criar uma solução inicial do problema

Etapa 2: Cria-se o conjunto $V$ de pares de rotas. Calcular o fator $f_{i j}$ para cada par de rotas $i$ e $j$, sendo que a rota $i$ ou $j$ podem ser rotas sozinhas ou rotas simplificadas.

Etapa 3: Ordena-se o conjunto $V$ em ordem decrescente de valores de $f_{i j}$.

Etapa 4: Percorre-se o conjunto $V$ até a linha $n$. Para cada par do conjunto, realizar reconstrução caso esta leve a uma redução de custo, respeitando-se os devidos limites de cardinalidade e reposicionamento. 
Limita-se a busca até a linha $n$ (valor que será parametrizado na Seção 4.4) para que a busca não seja realizada em pares "pouco interessantes" (baixo valor de $f_{i j}$ ) demandando um alto esforço computacional.

Etapa 5: Caso seja alterada a solução do problema na Etapa 4, retorna-se a Etapa 2 com o objetivo de recalcular $f_{i j}$ (visto que na Etapa 4 foi alterada a solução do problema). Caso não seja alterada a solução do problema na Etapa 4, interrompe-se o algoritmo.

A heurística com busca local é então representada da seguinte forma:

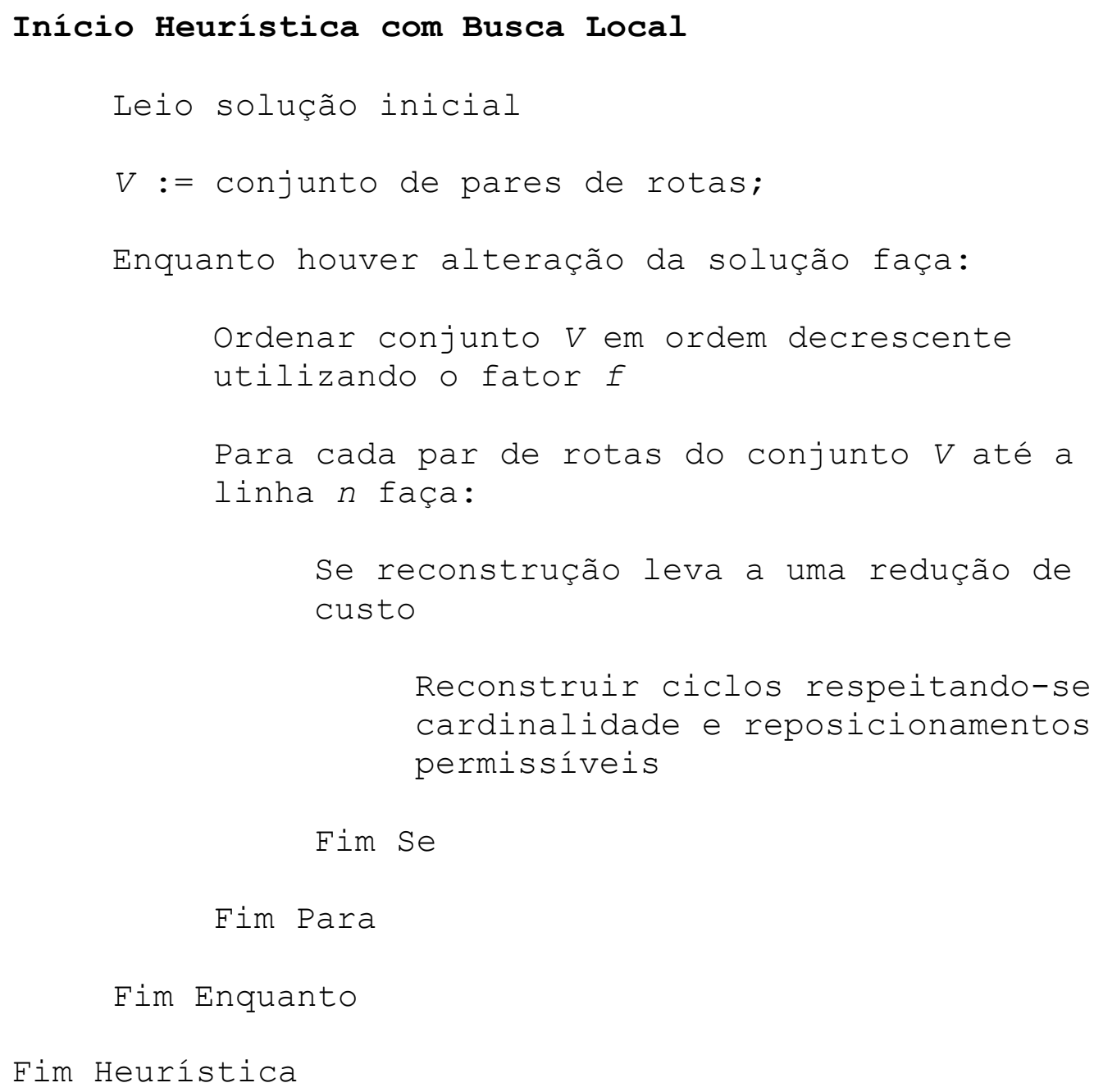

Algoritmo 3-1: Heurística com Busca Local 


\subsubsection{Solução Inicial para a Heurística com Busca Local}

Como mencionado por Cunha et al. (2002), a obtenção de uma boa solução através da implementação de um método de busca local depende fundamentalmente de qual solução inicial partimos.

Assim, foram testadas três soluções iniciais, sendo elas:

a. Solução inicial com base nos resultados obtidos pelo Algoritmo Guloso (GH) proposto por Ergun et al. (2007b).

b. Solução inicial com base nos resultados obtidos pela Heurística Construtivo-Destrutiva (CD) proposta por Ferri (2009).

c. Solução inicial Quick Start (QS) proposta por este trabalho, a qual será explicada a seguir.

A solução inicial proposta por este trabalho (Quick Start - QS) tem como objetivo criar uma primeira solução rápida (mesmo que de qualidade ruim) para que então seja aplicada a Heurística com Busca Local.

A heurística consiste em ordenar as rotas em ordem decrescente de valor e a seguir percorrer este vetor buscando rotas consecutivas, de forma a criar o primeiro conjunto de rotas simplificadas dando preferência àquelas de maior tamanho.

O Algoritmo 3-2 representa esta geração.

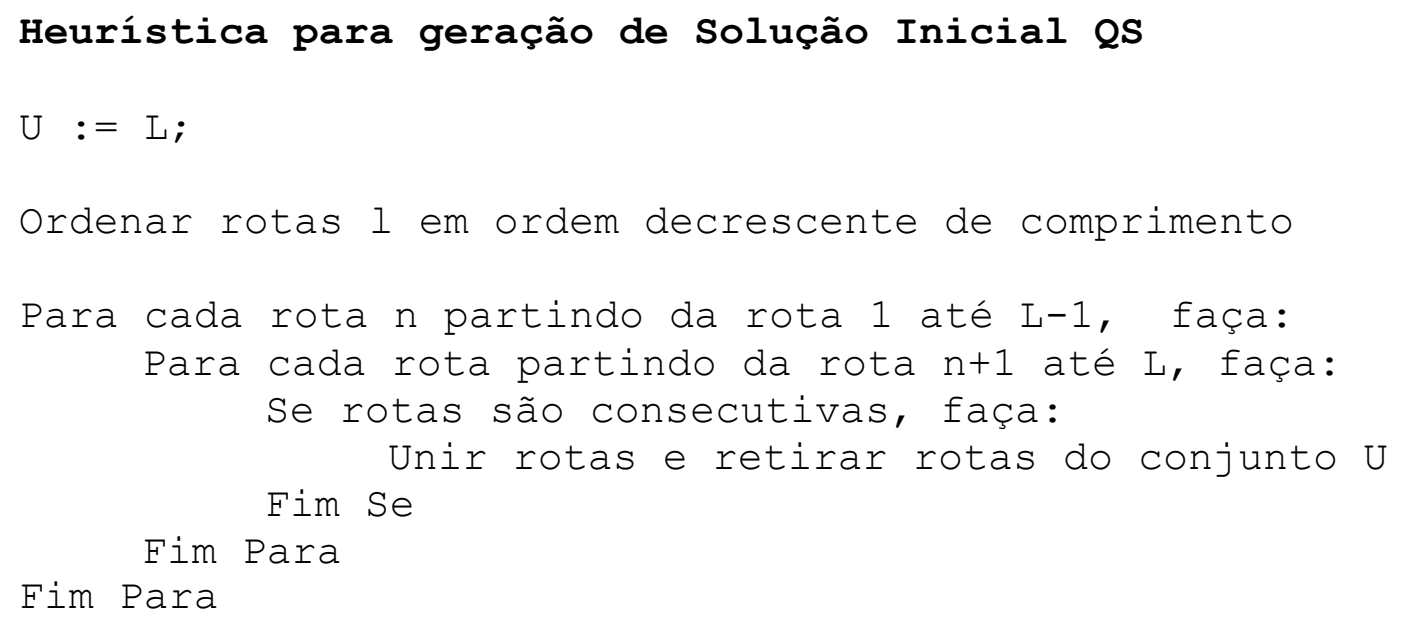


O resultado desta heurística é apenas a junção de rotas consecutivas, formando então rotas simplificadas como descrito na seção 3.2.1.

Neste capítulo foi apresentada a Heurística com Busca Local proposta por este trabalho e as diferentes soluções iniciais utilizadas. No capítulo seguinte é feita a aplicação dos métodos utilizando instâncias obtidas através de geradores de instâncias também propostos pela literatura. 


\section{APLICAÇÃO DOS MÉTODOS}

Neste capítulo é apresentada a forma como foi aplicado o método HBL utilizando as diferentes soluções iniciais propostas pela literatura e por este trabalho. Para comparação dos métodos são utilizados geradores de instâncias também propostos pela literatura.

Feito isso são comparados os resultados conforme os resultados e tempos de processamento obtidos.

\subsection{Geradores de Instâncias}

Ergun et al. (2007b) e Ferri (2009) propuseram geradores de instâncias com o objetivo de avaliar suas heurísticas.

Ergun et al. (2007b) desenvolveram um gerador de instâncias onde as rotas são distribuídas de forma balanceada sobre o dígrafo, enquanto que Ferri (2009) fez uma alteração neste gerador com o objetivo de criar cenários desbalanceados, seguindo assim cenários mais próximos da realidade onde regiões têm tendências maiores do que outras para a geração de cargas.

A seguir são descritos cada um destes geradores.

\subsubsection{Instâncias Balanceadas}

Um gerador de instâncias balanceadas foi desenvolvido por Ergun et al. (2007b) com o objetivo de criar os dígrafos, ou seja, grafos direcionados de instâncias teste que podem receber os seguintes parâmetros de entrada:

- Dimensão do dígrafo: altura e largura do dígrafo representado pelas variáveis $\mathrm{H}_{\max }$ e $\mathrm{V}_{\text {max }}$ 
- Número de regiões de agrupamento: agrupamentos de vértices que simulam regiões metropolitanas, onde existe a concentração de pontos de origem e destino de rotas. Representado pela variável $\mathrm{n}_{\text {agroup }}$.

- Fator de dispersão do agrupamento: representado pela variável $f_{\text {agroup, }}$ indica qual a relação entre o raio da região de agrupamento em relação a dimensão do dígrafo. Como exemplo, se tiverrmos um dígrafo com $\mathrm{H}_{\max }=1.000 \mathrm{~km}, \mathrm{~V}_{\max }$ $=1.000 \mathrm{~km}$ e $f_{\text {agroup }}=10 \%$, isso indica que a região de agrupamento terá um raio de $100 \mathrm{~km}$.

- Número de vértices: representado pela variável $n_{v}$.

- Número de rotas: número de rotas no problema representado pela variável n.

Da mesma forma que Ergun et al. (2007b) e Ferri (2009), foram gerados três dígrafos para avaliação das heurísticas, com as seguintes características:

- Dígrafo 1: 20 regiões de agrupamento e fator de dispersão (f $f_{\text {agroup }}$ ) de 5\%.

- Dígrafo 2: 10 regiões de agrupamento e fator de dispersão ( $f_{\text {agroup }}$ ) de 10\%.

- Dígrafo 3: 5 regiões de agrupamento e fator de dispersão ( $f_{\text {agroup }}$ ) de $10 \%$.

Para todos os dígrafos foram utilizada as dimensões de $\mathrm{H}_{\max }=1.000$ e $\mathrm{V}_{\max }=$ 1.000 e um total de 500 vértices (independente do número de rotas da instância).

A Figura 4-1 mostra os exemplos de três tipos de dígrafos gerados.

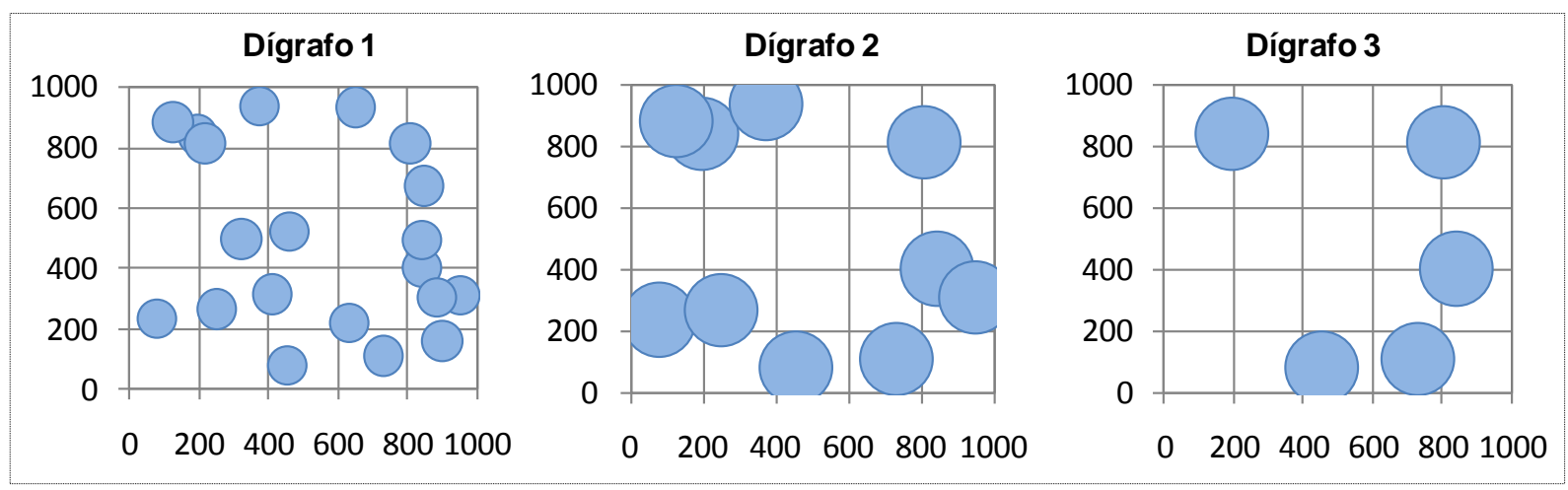

Figura 4-1: Diferentes Dígrafos gerados para teste dos métodos 


\subsubsection{Instâncias Desbalanceadas}

Um gerador de instâncias desbalanceadas foi proposto em Ferri (2009) com o objetivo de representar cenários que mais se assemelhassem com a realidade, onde regiões têm tendências de terem mais origens de carga (produtoras) ou destinos (consumidoras).

Assim, o gerador de instâncias desbalanceadas foi criado a partir do gerador de instâncias balanceadas adicionando-se as seguintes características:

- Tipo de agrupamento: ao ser gerado um agrupamento, este tem igual probabilidade de ter vocação de origem ou destino de rotas.

- Tipo de vértice: ao ser gerado o vértice, ele tem uma probabilidade igual a $p_{\text {desb }}$ de ter a mesma característica de seu agrupamento e $\left(1-p_{\text {desb }}\right)$ de poder ser tanto origem quanto destino de rota. Como exemplo, se estivermos gerando uma instância desbalanceada com $p_{\text {desb }}=25 \%$ e um vértice foi criado no interior de uma região com vocação de origem, então este vértice possui a probabilidade de $25 \%$ de ser uma origem exclusiva (ou seja, não poderá receber destinos de rotas) e $75 \%$ de chance de poder ser tanto origem quanto destino de rota.

Assim como Ferri (2009), serão geradas instâncias balanceadas ( $p_{\text {desb }}=0 \%$ ) e desbalanceadas com $p_{\text {desb }}=25 \%, 50 \%$ e $75 \%$.

\subsection{Gerador de Ciclos}

A formulação por cobertura de conjuntos para o PCRCR, conforme proposto por Ergun et al. (2007b), exige que sejam geradas todas as combinações de ciclos $c$ viáveis que respeitem os limites de cardinalidade, reposicionamentos e que cubram pelo menos uma rota.

O mesmo autor propôs uma heurística que também exige a geração de todas as combinações de ciclos. 
Como foram tratados problemas com um e dois reposicionamentos, a geração dos ciclos viáveis foi dividida em duas etapas principais:

1) Geração de todos os ciclos viáveis com um ou nenhum reposicionamento

2) Geração de todos os ciclos viáveis com dois reposicionamentos a partir dos ciclos gerados anteriormente.

A Figura 4-2 mostra como um ciclo com dois reposicionamentos pode ser gerado pela combinação de dois ciclos com um reposicionamento.

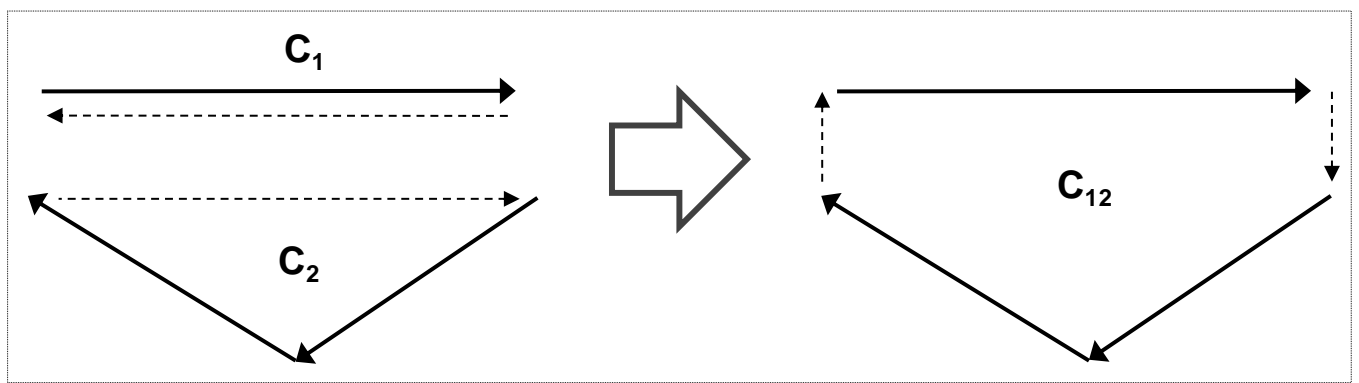

Figura 4-2 Formação de um ciclo com dois reposicionamentos pela combinação de dois ciclos com um reposicionamento cada.

De forma similar o que foi apresentado na seção 2.4.1, a união dos ciclos só é feita se isso levar a uma redução de custos. Ou seja:

$$
\text { Custo }\left(\mathrm{C}_{12}\right)<\text { Custo }\left(\mathrm{C}_{1}\right)+\text { Custo }\left(\mathrm{C}_{2}\right)
$$

Se mesclar os ciclos $\mathrm{C}_{1}$ e $\mathrm{C}_{2}$ nos leva a uma redução de custo, então pelo menos uma das condições abaixo deve ser satisfeitas:

$$
\begin{aligned}
& \text { 1. } \text { Custo }_{(\text {fim de C1,Início C1) }}>\text { Custo }_{(\text {fim de C1,Início de C2) }} \\
& \text { 2. } \text { Custo }_{(\text {fim de C2,Início C2) }}>\text { Custo }_{(\text {fim de C2,Início de C1) }}
\end{aligned}
$$

As condições acima reduzem significativamente o número de ciclos a ser combinado, o que torna o algoritmo de geração de ciclos altamente eficiente. 


\subsection{Aplicação da Programação Linear Inteira (PLI)}

A aplicação da Programação Linear Inteira (PLI) foi feita utilizando o modelo de cobertura de conjuntos utilizando para isso o software GAMS/CPLEX.

Da mesma forma que Ergun et al. (2007b) e Ferri (2009), o sistema foi configurado para devolver a primeira solução viável, utilizando como limite superior a resposta dada pelo Algoritmo $\mathrm{GH}$. Também configurou-se um tempo limite de execução de 8 horas.

\subsection{Aplicação da Heurística com Busca Local}

A aplicação da Heurística com Busca Local demanda que seja definido o parâmetro $n$ apresentado na Seção 3.2.4.

Este parâmetro indica até qual linha do conjunto $V$ (conjunto de pares de rotas) será explorada a vizinhança de rotas antes que seja feito o recálculo de $f$.

Para um problema com I rotas, existem $\frac{l^{2}-l}{2}$ pares de rotas possíveis. Os gráficos apresentados na Figura 4-3 e Figura 4-4 mostram o comportamento do custo à medida que "caminhamos" pelo conjunto $V$.

Assim, para cada conjunto de problemas (100, 200, 500, 1000, 1500, 3000, 4000 e 5000 rotas) define-se empiricamente qual o valor de $n$ para o qual o método deixa de ter uma redução considerável de custo e passa a apresentar um comportamento assintótico.

A Figura 4-3 mostra o comportamento do custo em função do número de iterações em $V$ para problemas com 100 rotas.

A Figura 4-4 mostra o comportamento do custo em função do número de iterações em $V$ para problemas com 200, 500, 1000, 1500, 3000 e 5000 rotas.

A Tabela 4-1 mostra o valor de $n$ escolhido para cada conjunto de problemas. 


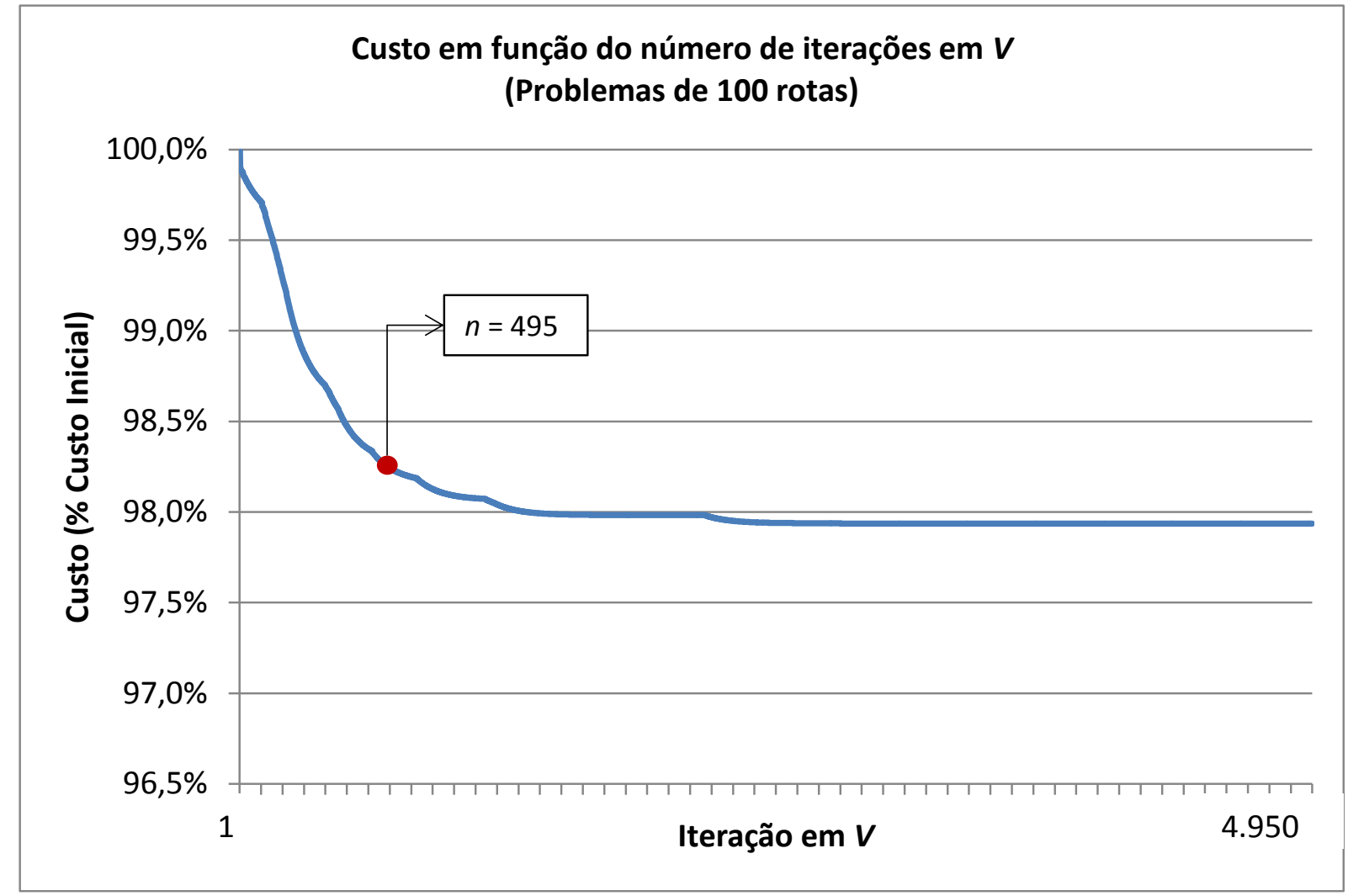

Figura 4-3: Escolha de $n$ para problemas de 100 rotas

Tabela 4-1: Escolha de $n$ para cada grupo de problemas Número de rotas

\begin{tabular}{cc}
100 & 495 \\
200 & 1.590 \\
500 & 7.485 \\
1.000 & 16.980 \\
1.500 & 26.980 \\
3.000 & 80.973 \\
5.000 & 124.975 \\
\hline
\end{tabular}




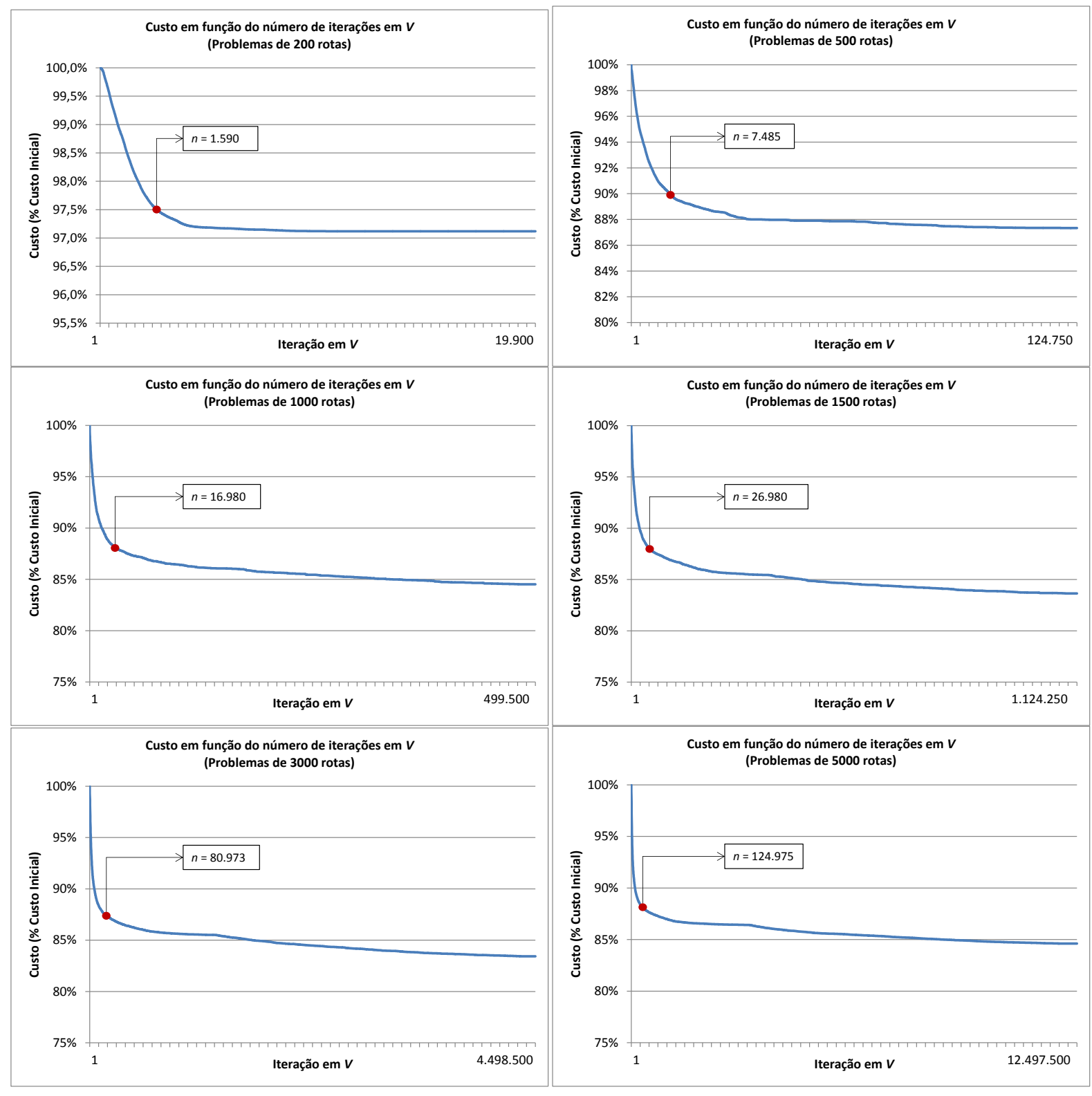

Figura 4-4: Escolha de $n$ para problemas de $200,500,1000,1500,3000$ e 5000 rotas 


\subsection{Leitura da solução inicial com base nos resultados obtidos por GH e CD}

Como apontado na seção anterior, a Heurística com Busca Local pode ser aplicada sobre a solução inicial QS proposta por este trabalho, ou sobre os resultados obtidos por $\mathrm{GH}$ e $\mathrm{CD}$.

Entretanto, a Heurística com Busca Local é estruturada de forma a combinar rotas simplificadas como apresentado na seção 3.2.1.

Assim, ao obter os resultados por GH ou CD, é feita uma "tradução" do ciclo de forma a transformar a solução inicial em uma combinação de pares de rotas (podendo uma ou duas delas serem simplificadas).

A Figura 4-5 mostra alguns exemplos de "tradução".

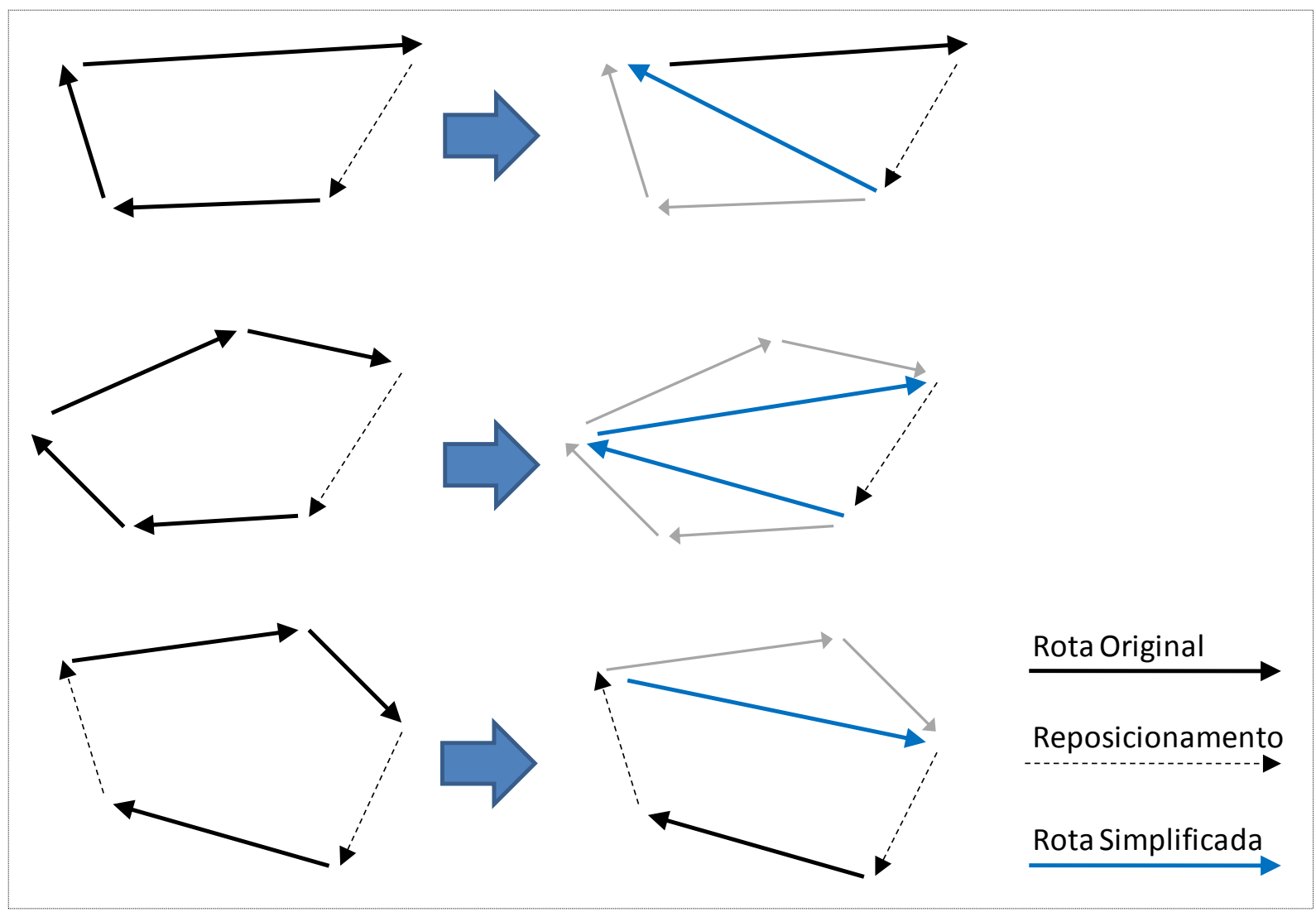

Figura 4-5: Exemplos de "traduções" da solução inicial gerada por GH ou CD para estrutura a ser utilizada pela Heurística com Busca Local 
A Figura 3-5 apresentada na seção 3.2.1 mostra como um ciclo com determinada cardinalidade e reposicionamentos pode ser "traduzido" para a aplicação da Heurística com Busca Local.

\subsection{Resumo dos algoritmos apresentados}

A Figura 4-6 mostra os principais algoritmos aqui apresentados e de que forma estes estão dependentes.

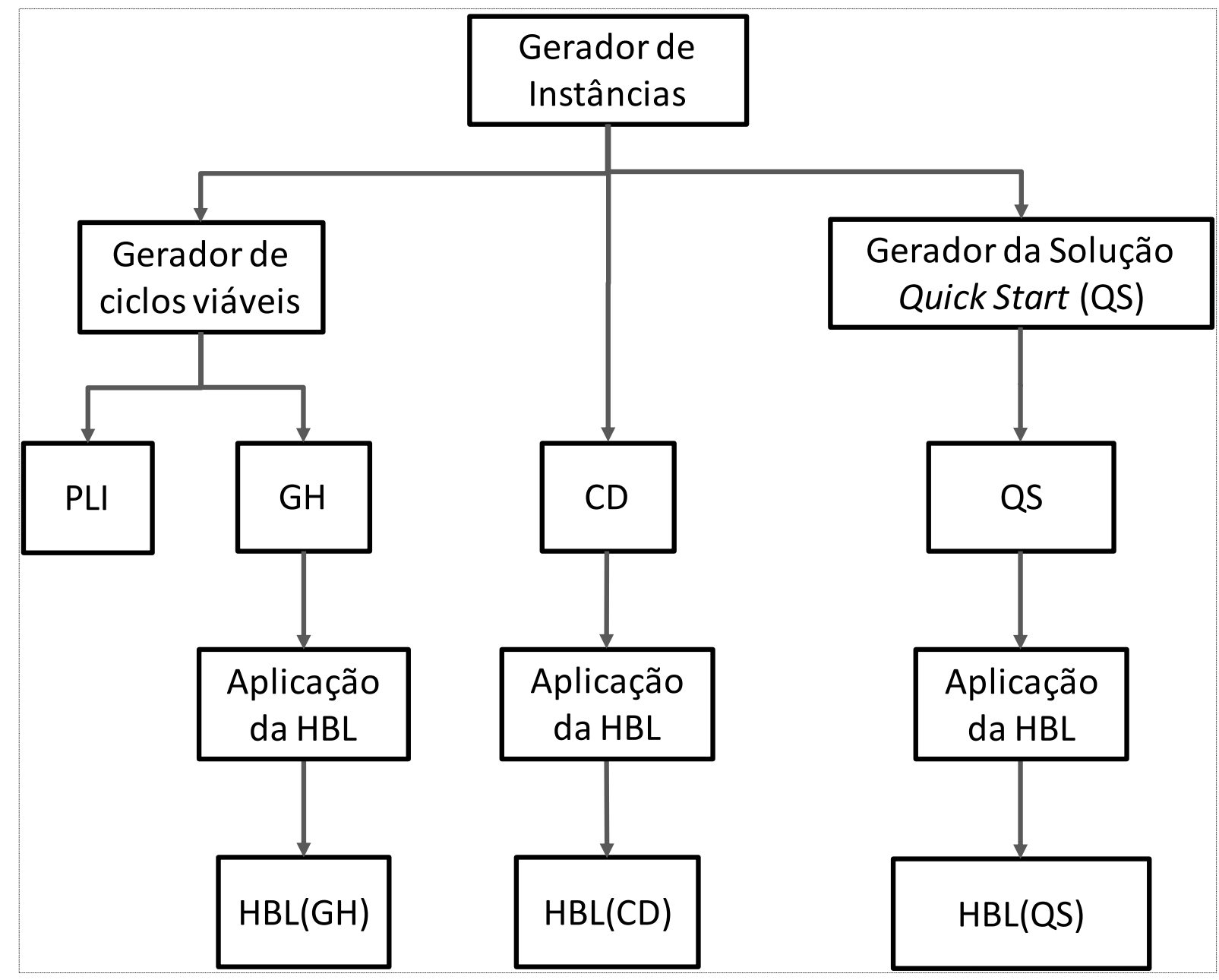

Figura 4-6: Compilação dos algoritmos utilizados 
Uma vez feita a geração de instâncias, é feita a geração de ciclos viáveis a ser utilizado para obtenção das soluções por PLI ou para obtenção dos resultados pela heurística $\mathrm{GH}$.

A heurística $C D$ não depende da geração de todos os ciclos viáveis, e por isso fornece resultados logo após geradas as instancias.

A heurística com Busca Local proposta por este trabalho pode ser aplicada sobre os resultados obtidos por GH, CD ou sobre a solução inicial QS (Quick Start) também proposta por este trabalho.

Para diferenciar os resultados obtidos pela Heurística com Busca Local, chamaremos de $\mathrm{HBL}_{(\mathrm{GH})}$ os resultados obtidos utilizando como solução inicial $\mathrm{GH}$, $\mathrm{HBL}_{(\mathrm{CD})}$ utilizando como solução inicial $\mathrm{CD}$ e $\mathrm{HBL}_{(\mathrm{QS})}$ utilizando a solução inicial $\mathrm{QS}$ proposta por este trabalho.

Para execução dos geradores e heurísticas aqui apresentadas foi utilizado um computador com processador Intel Core i $5^{\circledR}$ de $2,80 \mathrm{GHz}$ com 8 GB de memória RAM rodando no sistema operacional Microsoft Windows 764 bits ${ }^{\circledR}$. 


\subsection{Comparação e Análise dos resultados}

A seguir apresentam-se os resultados obtidos pelo Algoritmo Guloso (GH) proposto por Ergun et al. (2007b), pela Heurística Construtivo-Destrutiva (CD) proposta por Ferri (2009) e pela solução inicial QS proposta por este trabalho.

Para cada um destes resultados é então aplicada a Heurística de melhoria com Busca Local (HBL).

Além disso, também são apresentados os resultados obtidos por Programação Linear Inteira (PLI).

Desta forma, são apresentados os seguintes resultados:

- PLI: resultado obtido por Programação Linear Inteira (PLI).

- GH: resultado obtido pelo Algoritmo Guloso (GH) proposto por Ergun et al. (2007b).

- CD: resultado obtido pela Heurística Construtivo-Destrutiva (CD) proposta por Ferri (2009).

- QS: resultado obtido pela solução inicial Quick Start proposta por este trabalho.

- $\mathrm{HBL}_{(\mathrm{GH})}$ : resultado obtido pela Heurística com Busca Local utilizando como solução inicial o resultado do Algoritmo Guloso $(\mathrm{GH})$.

- $\mathrm{HBL}_{(\mathrm{CD})}$ : resultado obtido pela Heurística com Busca Local utilizando como solução inicial a Heurística Construtivo-Destrutiva (CD).

- $\mathrm{HBL}_{(\mathrm{QS})}$ : resultado obtido pela Heurística com Busca Local utilizando como solução inicial a solução inicial QS proposta por este trabalho. 


\subsubsection{Melhoria realizada pela Heurística com Busca Local (HBL)}

Nesta seção é apresentada a melhoria obtida pela Heurística com Busca Local quando aplicada a diferentes soluções iniciais.

\section{- Problemas balanceados e com um reposicionamento}

Aqui são apresentados os resultados para os problemas balanceados e com um reposicionamento $(\mathrm{DH}=1)$.

Não foi possível obter uma solução factível por PLI para problemas com mais do que 3000 rotas devido limite superior de tempo de execução (8 horas). Para este conjunto de problemas, encontramos diferença entre as soluções inteiras encontradas e as obtidas por relaxação linear. Estas diferenças estão apresentadas na Tabela 4-2.

Pode-se observar na Tabela 4-3 que para este conjunto de instâncias tanto a heurística GH quanto a CD ainda estavam distantes do resultado ótimo, e por isso a Heurística com Busca Local conseguiu reduzir consideravelmente este gap reduzindo em $4,69 \%, 3,81 \%$ e $15,82 \%$ os resultados obtidos por $\mathrm{GH}$, CD e solução inicial QS respectivamente.

Tabela 4-2: Diferença entre as soluções inteiras encontradas e as obtidas por relaxação linear para problemas balanceados e com um reposicionamento

\begin{tabular}{ccccc} 
& & \multicolumn{3}{c}{ Solução Inteira/Relaxação Linear (\%) } \\
\cline { 3 - 5 } DESBAL. & ROTAS & Dígrafo 1 & Dígrafo 2 & Dígrafo 3 \\
\hline $0 \%$ & 100 & $0.0 \%$ & $0.0 \%$ & $0.0 \%$ \\
$0 \%$ & 200 & $0.0 \%$ & $0.0 \%$ & $0.0 \%$ \\
$0 \%$ & 500 & $0.0 \%$ & $0.0 \%$ & $0.0 \%$ \\
$0 \%$ & 1000 & $0.8 \%$ & $0.6 \%$ & $0.9 \%$ \\
$0 \%$ & 1500 & $2.4 \%$ & $2.3 \%$ & $2.1 \%$ \\
$0 \%$ & 3000 & $3.2 \%$ & $3.6 \%$ & $3.3 \%$ \\
\hline
\end{tabular}


Tabela 4-3: Melhoria realizada pela Heurística com Busca Local (HBL) quando aplicada a diferentes soluções iniciais para problemas balanceados e um reposicionamento

\begin{tabular}{|c|c|c|c|c|c|c|c|c|c|c|c|c|}
\hline \multirow{2}{*}{\multicolumn{2}{|c|}{ DESBAL. DÍGRAFO }} & \multirow[b]{2}{*}{ ROTAS } & \multicolumn{4}{|c|}{ RESULTADOS (\#) } & \multicolumn{3}{|c|}{ RESULTADOS HBL (\#) } & \multicolumn{3}{|c|}{ Melhoria HBL (\%) } \\
\hline & & & PLI & GH & CD & QS & $\mathrm{HBL}_{(\mathrm{GH})}$ & $\mathrm{HBL}_{(\mathrm{CD})}$ & $\mathrm{HBL}_{(\mathrm{QS})}$ & $H_{B L}(G H) \times G H$ & $H B L_{(C D)} \times C D$ & $\mathrm{HBL}_{(\mathrm{QS})} \times \mathrm{QS}$ \\
\hline $0 \%$ & 1 & 100 & 77.305 & 77.637 & 77.579 & 79.195 & 77.305 & 77.305 & 77.305 & $-0,43 \%$ & $-0,35 \%$ & $-2,39 \%$ \\
\hline $0 \%$ & 1 & 200 & 172.736 & 174.005 & 173.886 & 178.467 & 172.851 & 172.851 & 172.958 & $-0,66 \%$ & $-0,60 \%$ & $-3,09 \%$ \\
\hline $0 \%$ & 1 & 500 & 327.525 & 345.317 & 346.425 & 385.129 & 336.571 & 334.204 & 332.179 & $-2,53 \%$ & $-3,53 \%$ & $-13,75 \%$ \\
\hline $0 \%$ & 1 & 1000 & 580.237 & 640.844 & 642.580 & 726.744 & 617.819 & 616.355 & 608.125 & $-3,59 \%$ & $-4,08 \%$ & $-16,32 \%$ \\
\hline $0 \%$ & 1 & 1500 & 831.544 & 924.190 & 922.100 & 1.059 .734 & 887.859 & 878.023 & 867.686 & $-3,93 \%$ & $-4,78 \%$ & $-18,12 \%$ \\
\hline $0 \%$ & 1 & 3000 & 1.581 .662 & 1.784 .136 & 1.737 .880 & 2.028 .163 & 1.680 .615 & 1.673 .797 & 1.650 .126 & $-5,80 \%$ & $-3,69 \%$ & $-18,64 \%$ \\
\hline $0 \%$ & 1 & 5000 & & 2.932 .096 & 2.825 .262 & 3.277 .254 & 2.741 .544 & 2.733 .100 & 2.683.155 & $-6,50 \%$ & $-3,26 \%$ & $-18,13 \%$ \\
\hline \multicolumn{3}{|c|}{ SUBTOTAL DÍGRAFO 1} & 3.571 .008 & 3.946 .129 & 3.900 .450 & 4.457 .432 & 3.773 .020 & 3.752 .535 & 3.708.379 & $-4,39 \%$ & $-3,79 \%$ & $-16,80 \%$ \\
\hline $0 \%$ & 2 & 100 & 85.669 & 85.906 & 86.040 & 86.903 & 85.669 & 85.669 & 85.669 & $-0,28 \%$ & $-0,43 \%$ & $-1,42 \%$ \\
\hline $0 \%$ & 2 & 200 & 157.432 & 157.786 & 158.103 & 162.395 & 157.433 & 157.432 & 157.432 & $-0,22 \%$ & $-0,42 \%$ & $-3,06 \%$ \\
\hline $0 \%$ & 2 & 500 & 308.894 & 328.016 & 328.331 & 360.826 & 315.591 & 314.538 & 312.683 & $-3,79 \%$ & $-4,20 \%$ & $-13,34 \%$ \\
\hline $0 \%$ & 2 & 1000 & 542.408 & 608.394 & 605.067 & 688.588 & 585.169 & 577.278 & 571.859 & $-3,82 \%$ & $-4,59 \%$ & $-16,95 \%$ \\
\hline $0 \%$ & 2 & 1500 & 782.459 & 876.350 & 867.934 & 995.798 & 837.989 & 827.516 & 820.207 & $-4,38 \%$ & $-4,66 \%$ & $-17,63 \%$ \\
\hline $0 \%$ & 2 & 3000 & 1.513 .408 & 1.693 .664 & 1.645 .884 & 1.894 .797 & 1.591 .653 & 1.571 .434 & 1.552 .418 & $-6,02 \%$ & $-4,52 \%$ & $-18,07 \%$ \\
\hline $0 \%$ & 2 & 5000 & & 2.796 .445 & 2.683 .028 & 3.038 .320 & 2.596 .324 & 2.592 .057 & 2.543 .302 & $-7,16 \%$ & $-3,39 \%$ & $-16,29 \%$ \\
\hline \multicolumn{3}{|c|}{ SUBTOTAL DÍGRAFO 2} & 3.390 .270 & 3.750 .116 & 3.691 .359 & 4.189.309 & 3.573 .504 & 3.533 .867 & 3.500 .268 & $-4,71 \%$ & $-4,27 \%$ & $-16,45 \%$ \\
\hline $0 \%$ & 3 & 100 & 65.762 & 65.778 & 65.781 & 66.655 & 65.762 & 65.762 & 65.762 & $-0,02 \%$ & $-0,03 \%$ & $-1,34 \%$ \\
\hline $0 \%$ & 3 & 200 & 143.608 & 144.425 & 144.492 & 149.058 & 143.608 & 143.608 & 143.612 & $-0,57 \%$ & $-0,61 \%$ & $-3,65 \%$ \\
\hline $0 \%$ & 3 & 500 & 275.114 & 294.010 & 291.594 & 321.304 & 283.246 & 282.121 & 281.671 & $-3,66 \%$ & $-3,25 \%$ & $-12,34 \%$ \\
\hline $0 \%$ & 3 & 1000 & 474.987 & 543.121 & 532.919 & 601.291 & 521.210 & 512.551 & 508.505 & $-4,03 \%$ & $-3,82 \%$ & $-15,43 \%$ \\
\hline $0 \%$ & 3 & 1500 & 693.970 & 788.870 & 771.326 & 865.058 & 750.434 & 736.816 & 730.439 & $-4,87 \%$ & $-4,47 \%$ & $-15,56 \%$ \\
\hline $0 \%$ & 3 & 3000 & 1.148 .001 & 1.285 .635 & 1.226 .552 & 1.352 .377 & 1.200 .217 & 1.192 .923 & 1.165 .015 & $-6,64 \%$ & $-2,74 \%$ & $-13,85 \%$ \\
\hline $0 \%$ & 3 & 5000 & & 2.512.771 & 2.383 .696 & 2.541 .401 & 2.347 .826 & 2.325 .641 & 2.281.831 & $-6,56 \%$ & $-2,44 \%$ & $-10,21 \%$ \\
\hline \multicolumn{3}{|c|}{ SUBTOTAL DÍGRAFO 3} & 2.801 .440 & 3.121 .839 & 3.032 .663 & 3.355 .743 & 2.964 .476 & 2.933 .780 & 2.895 .003 & $-5,04 \%$ & $-3,26 \%$ & $-13,73 \%$ \\
\hline \multicolumn{3}{|c|}{ TOTAL } & 9.762 .719 & 10.818 .084 & 10.624 .473 & 12.002 .484 & 10.311 .000 & 10.220 .182 & 10.103 .650 & $-4,69 \%$ & $-3,81 \%$ & $-15,82 \%$ \\
\hline
\end{tabular}




\section{- Problemas desbalanceados e com um reposicionamento}

Nesta seção são apresentados os resultados para os problemas desbalanceados e com um reposicionamento $(\mathrm{DH}=1)$.

Para este conjunto de problemas também não foi possível obter resultados por PLI para problemas com mais do que 3000 rotas por ter sido atingido limite superior de tempo de execução. Para este conjunto de problemas também encontramos diferença entre as soluções inteiras encontradas e as obtidas por relaxação linear. Estas diferenças estão apresentadas na Tabela 4-4.

Da mesma forma que para os problemas balanceados e com um reposicionamento, tanto a heurística $\mathrm{GH}$ quanto a CD ainda estavam distantes do resultado ótimo, como se pode observar na Tabela 4-5, Tabela 4-6 e Tabela 4-7. Entretanto, pode-se notar que à medida que são tratados problemas mais desbalanceados, menor é a redução percentual fornecida pela Heurística com Busca Local.

Tabela 4-4: Diferença entre as soluções inteiras encontradas e as obtidas por relaxação linear para problemas desbalanceados e com um reposicionamento

\begin{tabular}{ccccc} 
& & \multicolumn{3}{c}{ Solução Inteira/Relaxação Linear (\%) } \\
\cline { 3 - 5 } DESBAL. & ROTAS & Dígrafo 1 & Dígrafo 2 & Dígrafo 3 \\
\hline $25 \%$ & 100 & $0.0 \%$ & $0.0 \%$ & $0.0 \%$ \\
$25 \%$ & 200 & $0.0 \%$ & $0.0 \%$ & $0.0 \%$ \\
$25 \%$ & 500 & $0.0 \%$ & $0.0 \%$ & $0.0 \%$ \\
$25 \%$ & 1000 & $0.4 \%$ & $0.0 \%$ & $0.5 \%$ \\
$25 \%$ & 1500 & $1.9 \%$ & $1.4 \%$ & $1.3 \%$ \\
$25 \%$ & 3000 & $3.4 \%$ & $3.1 \%$ & $2.0 \%$ \\
\hline $50 \%$ & 100 & $0.0 \%$ & $0.0 \%$ & $0.0 \%$ \\
$50 \%$ & 200 & $0.0 \%$ & $0.0 \%$ & $0.0 \%$ \\
$50 \%$ & 500 & $0.0 \%$ & $0.0 \%$ & $0.0 \%$ \\
$50 \%$ & 1000 & $0.0 \%$ & $0.2 \%$ & $0.0 \%$ \\
$50 \%$ & 1500 & $0.4 \%$ & $0.3 \%$ & $0.0 \%$ \\
$50 \%$ & 3000 & $1.0 \%$ & $0.6 \%$ & $0.7 \%$ \\
\hline $75 \%$ & 100 & $0.0 \%$ & $0.0 \%$ & $0.0 \%$ \\
$75 \%$ & 200 & $0.0 \%$ & $0.0 \%$ & $0.0 \%$ \\
$75 \%$ & 500 & $0.0 \%$ & $0.0 \%$ & $0.0 \%$ \\
$75 \%$ & 1000 & $0.0 \%$ & $0.0 \%$ & $0.0 \%$ \\
$75 \%$ & 1500 & $0.0 \%$ & $0.0 \%$ & $0.0 \%$ \\
$75 \%$ & 3000 & $0.1 \%$ & $0.0 \%$ & $0.0 \%$ \\
\hline
\end{tabular}


Tabela 4-5: Melhoria realizada pela Heurística com Busca Local (HBL) quando aplicada a diferentes soluções iniciais para problemas desbalanceados $(25 \%)$ e um reposicionamento

\begin{tabular}{|c|c|c|c|c|c|c|c|c|c|c|c|c|}
\hline \multirow[b]{2}{*}{ DESBAL. } & \multirow[b]{2}{*}{ GRAFO } & \multirow[b]{2}{*}{ ROTAS } & \multicolumn{4}{|c|}{ RESULTADOS (\#) } & \multicolumn{3}{|c|}{ RESULTADOS HBL (\#) } & \multicolumn{3}{|c|}{ Melhoria HBL (\%) } \\
\hline & & & PLI & GH & CD & QS & $\mathrm{HBL}_{(\mathrm{GH})}$ & $\mathrm{HBL}_{(\mathrm{CD})}$ & $\mathrm{HBL}_{(\mathrm{QS})}$ & $H_{B L}(G H) \times G H$ & $H B L_{(C D)} \times C D$ & $H_{B L}(Q S) \times Q S$ \\
\hline $25 \%$ & 1 & 100 & 75.723 & 75.815 & 75.972 & 76.430 & 75.723 & 75.723 & 75.723 & $-0,12 \%$ & $-0,33 \%$ & $-0,93 \%$ \\
\hline $25 \%$ & 1 & 200 & 174.587 & 176.155 & 176.438 & 180.622 & 174.717 & 174.733 & 174.620 & $-0,82 \%$ & $-0,97 \%$ & $-3,32 \%$ \\
\hline $25 \%$ & 1 & 500 & 346.923 & 364.815 & 365.337 & 393.076 & 356.287 & 353.811 & 351.099 & $-2,34 \%$ & $-3,15 \%$ & $-10,68 \%$ \\
\hline $25 \%$ & 1 & 1000 & 622.111 & 677.777 & 677.314 & 749.037 & 655.087 & 654.249 & 643.777 & $-3,35 \%$ & $-3,41 \%$ & $-14,05 \%$ \\
\hline $25 \%$ & 1 & 1500 & 892.689 & 990.436 & 986.462 & 1.095 .571 & 957.863 & 941.251 & 930.985 & $-3,29 \%$ & $-4,58 \%$ & $-15,02 \%$ \\
\hline $25 \%$ & 1 & 3000 & 1.710 .515 & 1.914 .986 & 1.866 .704 & 2.098 .269 & 1.805 .369 & 1.791 .865 & 1.763 .208 & $-5,72 \%$ & $-4,01 \%$ & $-15,97 \%$ \\
\hline $25 \%$ & 1 & 5000 & & 3.149 .396 & 3.052 .436 & 3.416 .861 & 2.948 .893 & 2.940 .174 & 2.876.359 & $-6,37 \%$ & $-3,68 \%$ & $-15,82 \%$ \\
\hline \multicolumn{3}{|c|}{ SUBTOTAL DÍGRAFO 1} & 3.822 .548 & 4.199 .984 & 4.148 .227 & 4.593 .006 & 4.025 .046 & 3.991 .632 & 3.939 .412 & $-4,17 \%$ & $-3,77 \%$ & $-14,23 \%$ \\
\hline $25 \%$ & 2 & 100 & 67.667 & 67.777 & 67.805 & 68.349 & 67.667 & 67.667 & 67.667 & $-0,16 \%$ & $-0,20 \%$ & $-1,00 \%$ \\
\hline $25 \%$ & 2 & 200 & 154.621 & 155.793 & 156.024 & 161.512 & 154.622 & 154.622 & 154.622 & $-0,75 \%$ & $-0,90 \%$ & $-4,27 \%$ \\
\hline $25 \%$ & 2 & 500 & 323.726 & 337.609 & 336.628 & 365.007 & 331.127 & 328.506 & 326.944 & $-1,92 \%$ & $-2,41 \%$ & $-10,43 \%$ \\
\hline $25 \%$ & 2 & 1000 & 584.265 & 638.452 & 640.504 & 704.262 & 619.531 & 615.939 & 609.950 & $-2,96 \%$ & $-3,84 \%$ & $-13,39 \%$ \\
\hline $25 \%$ & 2 & 1500 & 841.444 & 937.578 & 928.673 & 1.029 .521 & 910.039 & 890.570 & 879.422 & $-2,94 \%$ & $-4,10 \%$ & $-14,58 \%$ \\
\hline $25 \%$ & 2 & 3000 & 1.659 .276 & 1.832 .789 & 1.781 .880 & 1.979 .075 & 1.744 .069 & 1.715 .974 & 1.686 .081 & $-4,84 \%$ & $-3,70 \%$ & $-14,80 \%$ \\
\hline $25 \%$ & 2 & 5000 & & 3.018 .984 & 2.900 .434 & 3.194 .578 & 2.829 .973 & 2.810 .932 & 2.756 .354 & $-6,26 \%$ & $-3,09 \%$ & $-13,72 \%$ \\
\hline \multicolumn{3}{|c|}{ SUBTOTAL DÍGRAFO 2} & 3.630 .998 & 3.969 .998 & 3.911 .514 & 4.307 .726 & 3.827 .054 & 3.773 .277 & 3.724 .685 & $-3,60 \%$ & $-3,53 \%$ & $-13,53 \%$ \\
\hline $25 \%$ & 3 & 100 & 75.827 & 75.940 & 75.941 & 76.730 & 75.827 & 75.827 & 75.827 & $-0,15 \%$ & $-0,15 \%$ & $-1,18 \%$ \\
\hline $25 \%$ & 3 & 200 & 113.277 & 113.600 & 113.976 & 117.320 & 113.392 & 113.409 & 113.425 & $-0,18 \%$ & $-0,50 \%$ & $-3,32 \%$ \\
\hline $25 \%$ & 3 & 500 & 289.424 & 305.288 & 301.201 & 328.038 & 297.487 & 295.483 & 293.563 & $-2,56 \%$ & $-1,90 \%$ & $-10,51 \%$ \\
\hline $25 \%$ & 3 & 1000 & 521.054 & 575.861 & 570.033 & 621.153 & 554.514 & 551.433 & 545.673 & $-3,71 \%$ & $-3,26 \%$ & $-12,15 \%$ \\
\hline $25 \%$ & 3 & 1500 & 752.391 & 842.608 & 829.154 & 899.528 & 816.836 & 800.064 & 790.668 & $-3,06 \%$ & $-3,51 \%$ & $-12,10 \%$ \\
\hline $25 \%$ & 3 & 3000 & 1.088 .220 & 1.191 .881 & 1.151 .798 & 1.238 .630 & 1.140 .888 & 1.113 .260 & 1.100 .662 & $-4,28 \%$ & $-3,35 \%$ & $-11,14 \%$ \\
\hline $25 \%$ & 3 & 5000 & & 2.723 .393 & 2.602 .968 & 2.757 .816 & 2.588 .231 & 2.562 .463 & 2.510 .665 & $-4,96 \%$ & $-1,56 \%$ & $-8,96 \%$ \\
\hline \multicolumn{3}{|c|}{ SUBTOTAL DÍGRAFO 3} & 2.840 .193 & 3.105 .178 & 3.042 .103 & 3.281 .399 & 2.998 .945 & 2.949 .478 & 2.919 .818 & $-3,42 \%$ & $-3,04 \%$ & $-11,02 \%$ \\
\hline \multicolumn{3}{|c|}{ TOTAL } & 10.293 .739 & 11.275 .159 & 11.101 .844 & 12.182 .132 & 10.851 .045 & 10.714 .387 & 10.583 .915 & $-3,76 \%$ & $-3,49 \%$ & $-13,12 \%$ \\
\hline
\end{tabular}


Tabela 4-6: Melhoria realizada pela Heurística com Busca Local (HBL) quando aplicada a diferentes soluções iniciais para problemas desbalanceados $(50 \%)$ e um reposicionamento

\begin{tabular}{|c|c|c|c|c|c|c|c|c|c|c|c|c|}
\hline \multirow[b]{2}{*}{ DESBAL. } & \multirow[b]{2}{*}{ GRAFO } & \multirow[b]{2}{*}{ ROTAS } & \multicolumn{4}{|c|}{ RESULTADOS (\#) } & \multicolumn{3}{|c|}{ RESULTADOS HBL (\#) } & \multicolumn{3}{|c|}{ Melhoria HBL (\%) } \\
\hline & & & PLI & GH & CD & QS & $\mathrm{HBL}_{(\mathrm{GH})}$ & $\mathrm{HBL}_{(\mathrm{CD})}$ & $\mathrm{HBL}_{(\mathrm{QS})}$ & $\mathrm{HBL}_{(\mathrm{GH})} \times \mathrm{GH}$ & $\mathrm{HBL}_{(\mathrm{CD})} \times \mathrm{CD}$ & $\mathrm{HBL}_{(\mathrm{QS})} \times \mathrm{QS}$ \\
\hline $50 \%$ & 1 & 100 & 74.148 & 74.247 & 74.387 & 74.677 & 74.148 & 74.148 & 74.148 & $-0,13 \%$ & $-0,32 \%$ & $-0,71 \%$ \\
\hline $50 \%$ & 1 & 200 & 174.275 & 175.588 & 175.847 & 179.448 & 174.723 & 174.644 & 174.275 & $-0,49 \%$ & $-0,68 \%$ & $-2,88 \%$ \\
\hline $50 \%$ & 1 & 500 & 377.438 & 390.088 & 390.105 & 409.599 & 383.795 & 381.673 & 380.932 & $-1,61 \%$ & $-2,16 \%$ & $-7,00 \%$ \\
\hline $50 \%$ & 1 & 1000 & 697.800 & 738.409 & 739.185 & 789.064 & 728.198 & 722.034 & 713.585 & $-1,38 \%$ & $-2,32 \%$ & $-9,57 \%$ \\
\hline $50 \%$ & 1 & 1500 & 1.002 .675 & 1.082 .122 & 1.077 .530 & 1.148 .446 & 1.056 .744 & 1.053 .542 & 1.035 .240 & $-2,35 \%$ & $-2,23 \%$ & $-9,86 \%$ \\
\hline $50 \%$ & 1 & 3000 & 1.937.044 & 2.126.739 & 2.102 .168 & 2.245 .263 & 2.055 .420 & 2.049 .627 & 1.996 .067 & $-3,35 \%$ & $-2,50 \%$ & $-11,10 \%$ \\
\hline $50 \%$ & 1 & 5000 & & 3.505 .627 & 3.436 .206 & 3.681 .461 & 3.359 .966 & 3.353 .969 & 3.275 .803 & $-4,16 \%$ & $-2,39 \%$ & $-11,02 \%$ \\
\hline \multicolumn{3}{|c|}{ SUBTOTAL DÍGRAFO 1} & 4.263 .380 & 4.587 .194 & 4.559 .222 & 4.846 .498 & 4.473 .029 & 4.455 .669 & 4.374 .249 & $-2,49 \%$ & $-2,27 \%$ & $-9,74 \%$ \\
\hline $50 \%$ & 2 & 100 & 90.355 & 90.482 & 90.495 & 91.014 & 90.355 & 90.355 & 90.355 & $-0,14 \%$ & $-0,15 \%$ & $-0,72 \%$ \\
\hline $50 \%$ & 2 & 200 & 168.629 & 169.701 & 169.711 & 173.191 & 168.629 & 168.629 & 168.629 & $-0,63 \%$ & $-0,64 \%$ & $-2,63 \%$ \\
\hline $50 \%$ & 2 & 500 & 353.500 & 363.217 & 365.201 & 387.246 & 358.987 & 357.423 & 356.559 & $-1,16 \%$ & $-2,13 \%$ & $-7,92 \%$ \\
\hline $50 \%$ & 2 & 1000 & 662.347 & 705.234 & 704.204 & 745.322 & 689.295 & 689.524 & 678.523 & $-2,26 \%$ & $-2,08 \%$ & $-8,96 \%$ \\
\hline $50 \%$ & 2 & 1500 & 959.467 & 1.037 .308 & 1.029 .239 & 1.093 .987 & 1.012 .934 & 1.002 .128 & 991.069 & $-2,35 \%$ & $-2,63 \%$ & $-9,41 \%$ \\
\hline $50 \%$ & 2 & 3000 & 1.869 .976 & 2.051 .016 & 2.012 .254 & 2.143 .348 & 1.981 .325 & 1.964 .038 & 1.927.327 & $-3,40 \%$ & $-2,40 \%$ & $-10,08 \%$ \\
\hline $50 \%$ & 2 & 5000 & & 3.370 .886 & 3.292 .006 & 3.486 .477 & 3.239.227 & 3.220 .302 & 3.158 .800 & $-3,91 \%$ & $-2,18 \%$ & $-9,40 \%$ \\
\hline \multicolumn{3}{|c|}{ SUBTOTAL DÍGRAFO 2} & 4.104 .274 & 4.416 .957 & 4.371 .103 & 4.634 .108 & 4.301 .525 & 4.272 .097 & 4.212 .463 & $-2,61 \%$ & $-2,27 \%$ & $-9,10 \%$ \\
\hline $50 \%$ & 3 & 100 & 63.378 & 63.386 & 63.386 & 63.774 & 63.378 & 63.378 & 63.378 & $-0,01 \%$ & $-0,01 \%$ & $-0,62 \%$ \\
\hline $50 \%$ & 3 & 200 & 146.786 & 147.298 & 147.686 & 150.208 & 146.793 & 146.786 & 146.786 & $-0,34 \%$ & $-0,61 \%$ & $-2,28 \%$ \\
\hline $50 \%$ & 3 & 500 & 320.659 & 331.703 & 330.541 & 347.912 & 326.069 & 325.776 & 325.219 & $-1,70 \%$ & $-1,44 \%$ & $-6,52 \%$ \\
\hline $50 \%$ & 3 & 1000 & 612.866 & 652.370 & 648.098 & 681.552 & 637.472 & 633.680 & 629.951 & $-2,28 \%$ & $-2,22 \%$ & $-7,57 \%$ \\
\hline $50 \%$ & 3 & 1500 & 902.320 & 967.176 & 954.308 & 1.005 .099 & 951.604 & 940.510 & 927.276 & $-1,61 \%$ & $-1,45 \%$ & $-7,74 \%$ \\
\hline $50 \%$ & 3 & 3000 & 1.796 .078 & 1.914 .462 & 1.871 .316 & 1.953 .023 & 1.877 .057 & 1.848 .917 & 1.814 .655 & $-1,95 \%$ & $-1,20 \%$ & $-7,08 \%$ \\
\hline $50 \%$ & 3 & 5000 & & 3.138 .422 & 3.054 .280 & 3.155 .338 & 3.064 .170 & 3.026 .708 & 2.974 .474 & $-2,37 \%$ & $-0,90 \%$ & $-5,73 \%$ \\
\hline \multicolumn{3}{|c|}{ SUBTOTAL DÍGRAFO 3} & 3.842 .087 & 4.076 .395 & 4.015 .336 & 4.201 .568 & 4.002 .373 & 3.959 .047 & 3.907 .265 & $-1,82 \%$ & $-1,40 \%$ & $-7,00 \%$ \\
\hline \multicolumn{3}{|c|}{ TOTAL } & 12.209 .741 & 13.080 .547 & 12.945 .662 & 13.682 .174 & 12.776 .927 & 12.686 .812 & 12.493 .977 & $-2,32 \%$ & $-2,00 \%$ & $-8,68 \%$ \\
\hline
\end{tabular}


Tabela 4-7: Melhoria realizada pela Heurística com Busca Local (HBL) quando aplicada a diferentes soluções iniciais para problemas desbalanceados $(75 \%)$ e um reposicionamento

\begin{tabular}{|c|c|c|c|c|c|c|c|c|c|c|c|c|}
\hline \multirow[b]{2}{*}{ DESBAL. } & \multirow[b]{2}{*}{ ÍGRAFO } & \multirow[b]{2}{*}{ ROTAS } & \multicolumn{4}{|c|}{ RESULTADOS (\#) } & \multicolumn{3}{|c|}{ RESULTADOS HBL (\#) } & \multicolumn{3}{|c|}{ Melhoria HBL (\%) } \\
\hline & & & PLI & GH & CD & QS & $\mathrm{HBL}_{(\mathrm{GH})}$ & $\mathrm{HBL}_{(\mathrm{CD})}$ & $\mathrm{HBL}_{(\mathrm{QS})}$ & $H_{B L}(G H) \times G H$ & $\mathrm{HBL}_{(\mathrm{CD})} \times \mathrm{CD}$ & $\mathrm{HBL}_{(\mathrm{QS})} \times \mathrm{QS}$ \\
\hline $75 \%$ & 1 & 100 & 77.798 & 77.833 & 77.833 & 78.403 & 77.798 & 77.798 & 77.798 & $-0,04 \%$ & $-0,04 \%$ & $-0,77 \%$ \\
\hline $75 \%$ & 1 & 200 & 145.882 & 146.506 & 146.986 & 148.833 & 145.882 & 145.882 & 145.882 & $-0,43 \%$ & $-0,75 \%$ & $-1,98 \%$ \\
\hline $75 \%$ & 1 & 500 & 345.746 & 352.102 & 352.257 & 357.500 & 348.472 & 348.128 & 347.055 & $-1,03 \%$ & $-1,17 \%$ & $-2,92 \%$ \\
\hline $75 \%$ & 1 & 1000 & 818.008 & 839.687 & 840.243 & 859.773 & 833.987 & 833.215 & 825.533 & $-0,68 \%$ & $-0,84 \%$ & $-3,98 \%$ \\
\hline $75 \%$ & 1 & 1500 & 1.216 .692 & 1.255 .215 & 1.251 .418 & 1.285 .186 & 1.245 .701 & 1.240 .791 & 1.230 .171 & $-0,76 \%$ & $-0,85 \%$ & $-4,28 \%$ \\
\hline $75 \%$ & 1 & 3000 & 2.359 .643 & 2.456 .721 & 2.441 .308 & 2.518 .332 & 2.437 .767 & 2.425 .021 & 2.397 .968 & $-0,77 \%$ & $-0,67 \%$ & $-4,78 \%$ \\
\hline $75 \%$ & 1 & 5000 & & 4.078 .829 & 4.048 .168 & 4.187.121 & 4.038 .386 & 4.026 .684 & 3.978 .033 & $-0,99 \%$ & $-0,53 \%$ & $-4,99 \%$ \\
\hline \multicolumn{3}{|c|}{ SUBTOTAL DÍGRAFO 1} & 4.963 .769 & 5.128 .065 & 5.110 .046 & 5.248 .027 & 5.089 .607 & 5.070 .835 & 5.024 .408 & $-0,75 \%$ & $-0,77 \%$ & $-4,26 \%$ \\
\hline $75 \%$ & 2 & 100 & 87.693 & 92.096 & 91.935 & 92.192 & 91.889 & 91.889 & 91.889 & $-0,23 \%$ & $-0,05 \%$ & $-0,33 \%$ \\
\hline $75 \%$ & 2 & 200 & 141.074 & 141.739 & 141.679 & 143.542 & 141.085 & 141.074 & 141.074 & $-0,46 \%$ & $-0,43 \%$ & $-1,72 \%$ \\
\hline $75 \%$ & 2 & 500 & 415.665 & 420.544 & 420.469 & 428.569 & 418.085 & 418.246 & 417.351 & $-0,58 \%$ & $-0,53 \%$ & $-2,62 \%$ \\
\hline $75 \%$ & 2 & 1000 & 801.916 & 820.207 & 819.668 & 838.129 & 814.836 & 812.948 & 808.173 & $-0,65 \%$ & $-0,82 \%$ & $-3,57 \%$ \\
\hline $75 \%$ & 2 & 1500 & 1.186 .251 & 1.223 .872 & 1.221 .488 & 1.251 .769 & 1.212 .033 & 1.209 .352 & 1.200 .355 & $-0,97 \%$ & $-0,99 \%$ & $-4,11 \%$ \\
\hline $75 \%$ & 2 & 3000 & 2.317 .696 & 2.413 .048 & 2.399 .014 & 2.462 .726 & 2.389 .092 & 2.379 .667 & 2.350 .445 & $-0,99 \%$ & $-0,81 \%$ & $-4,56 \%$ \\
\hline $75 \%$ & 2 & 5000 & & 4.003 .733 & 3.966 .348 & 4.069.396 & 3.964 .939 & 3.944 .797 & 3.901 .160 & $-0,97 \%$ & $-0,54 \%$ & $-4,13 \%$ \\
\hline \multicolumn{3}{|c|}{ SUBTOTAL DÍGRAFO 2} & 4.950 .294 & 5.111 .507 & 5.094 .252 & 5.216 .926 & 5.067 .019 & 5.053 .177 & 5.009 .286 & $-0,87 \%$ & $-0,81 \%$ & $-3,98 \%$ \\
\hline $75 \%$ & 3 & 100 & 83.560 & 83.605 & 83.604 & 83.566 & 83.560 & 83.560 & 83.560 & $-0,05 \%$ & $-0,05 \%$ & $-0,01 \%$ \\
\hline $75 \%$ & 3 & 200 & 158.263 & 158.378 & 158.568 & 160.287 & 158.346 & 158.266 & 158.436 & $-0,02 \%$ & $-0,19 \%$ & $-1,15 \%$ \\
\hline $75 \%$ & 3 & 500 & 383.717 & 388.904 & 389.064 & 396.115 & 386.764 & 385.895 & 384.867 & $-0,55 \%$ & $-0,81 \%$ & $-2,84 \%$ \\
\hline $75 \%$ & 3 & 1000 & 748.307 & 763.599 & 763.007 & 774.635 & 759.173 & 758.219 & 753.352 & $-0,58 \%$ & $-0,63 \%$ & $-2,75 \%$ \\
\hline $75 \%$ & 3 & 1500 & 1.112 .842 & 1.138 .325 & 1.133 .958 & 1.153 .040 & 1.132 .253 & 1.129 .510 & 1.121 .647 & $-0,53 \%$ & $-0,39 \%$ & $-2,72 \%$ \\
\hline $75 \%$ & 3 & 3000 & 2.194 .993 & 2.261 .580 & 2.241 .582 & 2.271 .061 & 2.247 .542 & 2.231 .414 & 2.212.555 & $-0,62 \%$ & $-0,45 \%$ & $-2,58 \%$ \\
\hline $75 \%$ & 3 & 5000 & & 3.740 .017 & 3.696 .492 & 3.754 .006 & 3.713 .131 & 3.685 .276 & 3.655 .685 & $-0,72 \%$ & $-0,30 \%$ & $-2,62 \%$ \\
\hline \multicolumn{3}{|c|}{ SUBTOTAL DÍGRAFO 3} & 4.681 .682 & 4.794 .392 & 4.769 .783 & 4.838 .704 & 4.767 .638 & 4.746 .864 & 4.714.417 & $-0,56 \%$ & $-0,48 \%$ & $-2,57 \%$ \\
\hline \multicolumn{3}{|c|}{ TOTAL } & 14.595 .746 & 15.033 .964 & 14.974 .081 & 15.303 .658 & 14.924 .264 & 14.870 .876 & 14.748 .111 & $-0,73 \%$ & $-0,69 \%$ & $-3,63 \%$ \\
\hline
\end{tabular}




\section{- Problemas balanceados e com dois reposicionamentos}

Aqui são apresentados os resultados para os problemas balanceados e com dois reposicionamentos permissíveis $(\mathrm{DH}=2)$.

Não foi possível obter resultados por PLI para problemas com mais do que 500 rotas devido limite superior de tempo de execução (8 horas). Para este conjunto de problemas não houve diferença entre a solução inteira encontrada e a relaxação linear.

Também não foi possível obter resultados por GH para problemas com mais do que 1500 rotas por ter sido atingido o limite de memória no processo de geração de ciclos viáveis.

Pode-se observar pela Tabela 4-8 que para este conjunto de instâncias a heurística GH e CD já estavam mais próximas dos resultados obtidos por PLI e por isso Heurística com Busca conseguiu reduzir apenas 0,65\% e 0,50\% os resultados obtidos por $\mathrm{GH}$ e CD respectivamente. 
Tabela 4-8: Melhoria realizada pela Heurística com Busca Local (HBL) quando aplicada a diferentes soluções iniciais para problemas balanceados e dois reposicionamentos

\begin{tabular}{|c|c|c|c|c|c|c|c|c|c|c|c|c|}
\hline \multirow{2}{*}{\multicolumn{2}{|c|}{ DESBAL. DÍGRAFO }} & \multirow[b]{2}{*}{ ROTAS } & \multicolumn{4}{|c|}{ RESULTADOS (\#) } & \multicolumn{3}{|c|}{ RESULTADOS HBL (\#) } & \multicolumn{3}{|c|}{ Melhoria HBL (\%) } \\
\hline & & & PLI & GH & CD & QS & $\mathrm{HBL}_{(\mathrm{GH})}$ & $\mathrm{HBL}_{(\mathrm{CD})}$ & $\mathrm{HBL}_{(\mathrm{QS})}$ & $H_{B L_{(G H)}} \times G H$ & $\mathrm{HBL}_{(\mathrm{CD})} \times \mathrm{CD}$ & $\mathrm{HBL}_{(\mathrm{QS})} \times \mathrm{QS}$ \\
\hline $0 \%$ & 1 & 100 & 51.358 & 52.426 & 52.234 & 77.591 & 51.668 & 51.631 & 51.658 & $-1,45 \%$ & $-1,15 \%$ & $-33,42 \%$ \\
\hline $0 \%$ & 1 & 200 & 116.427 & 119.138 & 118.614 & 178.467 & 117.978 & 117.664 & 118.239 & $-0,97 \%$ & $-0,80 \%$ & $-33,75 \%$ \\
\hline $0 \%$ & 1 & 500 & 263.497 & 268.726 & 268.588 & 385.129 & 267.138 & 267.481 & 268.362 & $-0,59 \%$ & $-0,41 \%$ & $-30,32 \%$ \\
\hline $0 \%$ & 1 & 1000 & & 522.851 & 523.305 & 726.744 & 520.737 & 521.453 & 522.875 & $-0,40 \%$ & $-0,35 \%$ & $-28,05 \%$ \\
\hline $0 \%$ & 1 & 1500 & & 786.021 & 786.686 & 1.059 .734 & 784.359 & 783.696 & 785.174 & $-0,21 \%$ & $-0,38 \%$ & $-25,91 \%$ \\
\hline $0 \%$ & 1 & 3000 & & & 1.557 .542 & 2.028 .163 & & 1.550 .918 & 1.552 .275 & & $-0,43 \%$ & $-23,46 \%$ \\
\hline $0 \%$ & 1 & 5000 & & & 2.606 .612 & 3.277 .254 & & 2.579.999 & 2.580 .302 & & $-1,02 \%$ & $-21,27 \%$ \\
\hline \multicolumn{3}{|c|}{ SUBTOTAL DÍGRAFO 1} & 431.282 & 440.291 & 439.436 & 641.186 & 436.785 & 436.777 & 438.259 & $-0,80 \%$ & $-0,61 \%$ & $-31,65 \%$ \\
\hline $0 \%$ & 2 & 100 & 42.724 & 43.518 & 43.530 & 67.683 & 43.111 & 43.172 & 43.173 & $-0,94 \%$ & $-0,82 \%$ & $-36,21 \%$ \\
\hline $0 \%$ & 2 & 200 & 102.518 & 105.305 & 104.942 & 162.395 & 104.095 & 103.762 & 103.726 & $-1,15 \%$ & $-1,12 \%$ & $-36,13 \%$ \\
\hline $0 \%$ & 2 & 500 & 154.740 & 156.809 & 156.147 & 224.144 & 156.015 & 155.695 & 155.519 & $-0,51 \%$ & $-0,29 \%$ & $-30,62 \%$ \\
\hline $0 \%$ & 2 & 1000 & & 497.464 & 497.892 & 688.588 & 495.954 & 496.259 & 496.168 & $-0,30 \%$ & $-0,33 \%$ & $-27,94 \%$ \\
\hline $0 \%$ & 2 & 1500 & & 741.118 & 743.777 & 995.798 & 739.603 & 740.232 & 740.327 & $-0,20 \%$ & $-0,48 \%$ & $-25,65 \%$ \\
\hline $0 \%$ & 2 & 3000 & & & 1.492 .946 & 1.894 .797 & & 1.483 .198 & 1.483 .101 & & $-0,65 \%$ & $-21,73 \%$ \\
\hline $0 \%$ & 2 & 5000 & & & 2.499 .178 & 3.038 .320 & & 2.472 .539 & 2.472 .666 & & $-1,07 \%$ & $-18,62 \%$ \\
\hline \multicolumn{3}{|c|}{ SUBTOTAL DÍGRAFO 2} & 299.982 & 305.633 & 304.619 & 454.222 & 303.221 & 302.629 & 302.418 & $-0,79 \%$ & $-0,65 \%$ & $-33,42 \%$ \\
\hline $0 \%$ & 3 & 100 & 50.455 & 50.975 & 50.857 & 79.355 & 50.524 & 50.521 & 50.580 & $-0,88 \%$ & $-0,66 \%$ & $-36,26 \%$ \\
\hline $0 \%$ & 3 & 200 & 96.891 & 97.416 & 97.235 & 149.058 & 96.994 & 96.975 & 97.014 & $-0,43 \%$ & $-0,27 \%$ & $-34,92 \%$ \\
\hline $0 \%$ & 3 & 500 & 226.113 & 226.925 & 226.867 & 321.304 & 226.438 & 226.505 & 226.511 & $-0,21 \%$ & $-0,16 \%$ & $-29,50 \%$ \\
\hline $0 \%$ & 3 & 1000 & & 444.514 & 444.967 & 601.291 & 443.810 & 444.149 & 444.138 & $-0,16 \%$ & $-0,18 \%$ & $-26,14 \%$ \\
\hline $0 \%$ & 3 & 1500 & & 490.407 & 491.168 & 627.069 & 489.797 & 490.166 & 490.237 & $-0,12 \%$ & $-0,20 \%$ & $-21,82 \%$ \\
\hline $0 \%$ & 3 & 3000 & & & 1.356 .350 & 1.610 .287 & & 1.350 .496 & 1.348 .708 & & $-0,43 \%$ & $-16,24 \%$ \\
\hline $0 \%$ & 3 & 5000 & & & 2.254 .606 & 2.541 .401 & & 2.239 .641 & 2.235 .166 & & $-0,66 \%$ & $-12,05 \%$ \\
\hline \multicolumn{3}{|c|}{ SUBTOTAL DÍGRAFO 3} & 373.459 & 375.317 & 374.959 & 549.717 & 373.956 & 374.002 & 374.106 & $-0,36 \%$ & $-0,26 \%$ & $-31,95 \%$ \\
\hline \multicolumn{3}{|c|}{ TOTAL } & 1.104 .724 & 1.121 .241 & 1.119 .015 & 1.645 .126 & 1.113 .961 & 1.113 .407 & 1.114 .782 & $-0,65 \%$ & $-0,50 \%$ & $-32,24 \%$ \\
\hline
\end{tabular}


- Problemas desbalanceados e com dois reposicionamentos

Nesta seção são apresentados os resultados para os problemas desbalanceados e com dois reposicionamentos $(\mathrm{DH}=2)$.

Para este conjunto de problemas também não foi possível obter resultados por PLI para problemas com mais do que 500 rotas devido limite superior de tempo de execução (8 horas). Para este conjunto de problemas não houve diferença entre a solução inteira encontrada e a relaxação linear.

Também não foi possível obter resultados por GH para problemas com mais do que 1500 rotas por ter sido atingido o limite de memória no processo de geração de ciclos viáveis.

Para estes conjuntos de instâncias as heurísticas CD e GH também estavam mais próximas do resultado obtido por PLI, e por isso a Heurística com Busca Local forneceu uma baixa redução de custo, como se pode observar pela Tabela 4-9, Tabela 4-10 e Tabela 4-11. 
Tabela 4-9: Melhoria realizada pela Heurística com Busca Local (HBL) quando aplicada a diferentes soluções iniciais para problemas desbalanceados $(25 \%)$ e dois reposicionamentos

RESULTADOS (\#)

\begin{tabular}{|c|c|c|c|c|c|c|c|c|c|c|c|c|}
\hline \multirow[b]{2}{*}{ DESBAL. } & \multirow[b]{2}{*}{ DÍGRAFO } & \multirow[b]{2}{*}{ ROTAS } & \multicolumn{4}{|c|}{ RESULTADOS (\#) } & \multicolumn{3}{|c|}{ RESULTADOS HBL (\#) } & \multicolumn{3}{|c|}{ Melhoria HBL (\%) } \\
\hline & & & PLI & GH & CD & QS & $\mathrm{HBL}_{(\mathrm{GH})}$ & $\mathrm{HBL}_{(\mathrm{CD})}$ & $\mathrm{HBL}_{(\mathrm{QS})}$ & $H_{B L_{(G H)}} \times G H$ & $\mathrm{HBL}_{(\mathrm{CD})} \times \mathrm{CD}$ & $\mathrm{HBL}_{(\mathrm{QS})} \times \mathrm{QS}$ \\
\hline $25 \%$ & 1 & 100 & 63.640 & 64.845 & 65.046 & 97.634 & 63.952 & 63.931 & 64.293 & $-1,38 \%$ & $-1,71 \%$ & $-34,15 \%$ \\
\hline $25 \%$ & 1 & 200 & 116.314 & 119.133 & 118.960 & 180.622 & 117.777 & 117.773 & 117.983 & $-1,14 \%$ & $-1,00 \%$ & $-34,68 \%$ \\
\hline $25 \%$ & 1 & 500 & 276.697 & 281.784 & 281.318 & 393.076 & 279.506 & 279.261 & 279.700 & $-0,81 \%$ & $-0,73 \%$ & $-28,84 \%$ \\
\hline $25 \%$ & 1 & 1000 & & 545.972 & 545.780 & 749.037 & 543.338 & 543.602 & 543.533 & $-0,48 \%$ & $-0,40 \%$ & $-27,44 \%$ \\
\hline $25 \%$ & 1 & 1500 & & 820.459 & 821.923 & 1.095 .571 & 816.798 & 817.791 & 817.614 & $-0,45 \%$ & $-0,50 \%$ & $-25,37 \%$ \\
\hline $25 \%$ & 1 & 3000 & & & 1.641 .050 & 2.098 .269 & & 1.632 .875 & 1.632 .514 & & $-0,50 \%$ & $-22,20 \%$ \\
\hline $25 \%$ & 1 & 5000 & & & 2.760 .182 & 3.416 .861 & & 2.735 .715 & 2.735 .004 & & $-0,89 \%$ & $-19,96 \%$ \\
\hline \multicolumn{3}{|c|}{ SUBTOTAL DÍGRAFO 1} & 456.652 & 465.763 & 465.324 & 671.333 & 461.236 & 460.965 & 461.976 & $-0,97 \%$ & $-0,94 \%$ & $-31,19 \%$ \\
\hline $25 \%$ & 2 & 100 & 55.759 & 56.882 & 56.754 & 85.867 & 56.014 & 56.176 & 56.065 & $-1,53 \%$ & $-1,02 \%$ & $-34,71 \%$ \\
\hline $25 \%$ & 2 & 200 & 106.333 & 107.859 & 107.910 & 161.512 & 106.942 & 107.064 & 107.144 & $-0,85 \%$ & $-0,78 \%$ & $-33,66 \%$ \\
\hline $25 \%$ & 2 & 500 & 260.945 & 262.649 & 262.753 & 365.007 & 261.564 & 261.652 & 261.755 & $-0,41 \%$ & $-0,42 \%$ & $-28,29 \%$ \\
\hline $25 \%$ & 2 & 1000 & & 532.271 & 532.903 & 704.262 & 530.304 & 530.564 & 530.550 & $-0,37 \%$ & $-0,44 \%$ & $-24,67 \%$ \\
\hline $25 \%$ & 2 & 1500 & & 797.129 & 798.605 & 1.029 .521 & 795.208 & 795.557 & 795.521 & $-0,24 \%$ & $-0,38 \%$ & $-22,73 \%$ \\
\hline $25 \%$ & 2 & 3000 & & & 1.605 .154 & 1.979 .075 & & 1.596 .425 & 1.596 .315 & & $-0,54 \%$ & $-19,34 \%$ \\
\hline $25 \%$ & 2 & 5000 & & & 2.674 .514 & 3.194 .578 & & 2.655 .682 & 2.655 .041 & & $-0,70 \%$ & $-16,89 \%$ \\
\hline \multicolumn{3}{|c|}{ SUBTOTAL DÍGRAFO 2} & 423.037 & 427.390 & 427.416 & 612.385 & 424.520 & 424.892 & 424.964 & $-0,67 \%$ & $-0,59 \%$ & $-30,61 \%$ \\
\hline $25 \%$ & 3 & 100 & 40.338 & 40.507 & 40.517 & 62.511 & 40.404 & 40.371 & 40.425 & $-0,25 \%$ & $-0,36 \%$ & $-35,33 \%$ \\
\hline $25 \%$ & 3 & 200 & 95.685 & 96.126 & 95.972 & 148.210 & 95.878 & 95.778 & 95.933 & $-0,26 \%$ & $-0,20 \%$ & $-35,27 \%$ \\
\hline $25 \%$ & 3 & 500 & 238.806 & 239.428 & 239.661 & 328.038 & 239.061 & 239.116 & 239.085 & $-0,15 \%$ & $-0,23 \%$ & $-27,12 \%$ \\
\hline $25 \%$ & 3 & 1000 & & 485.644 & 486.083 & 621.153 & 484.788 & 484.954 & 484.948 & $-0,18 \%$ & $-0,23 \%$ & $-21,93 \%$ \\
\hline $25 \%$ & 3 & 1500 & & 728.902 & 730.172 & 899.528 & 727.870 & 728.150 & 728.084 & $-0,14 \%$ & $-0,28 \%$ & $-19,06 \%$ \\
\hline $25 \%$ & 3 & 3000 & & & 1.485 .614 & 1.716 .713 & & 1.478 .720 & 1.478 .641 & & $-0,46 \%$ & $-13,87 \%$ \\
\hline $25 \%$ & 3 & 5000 & & & 2.484 .610 & 2.757 .816 & & 2.472 .392 & 2.471.179 & & $-0,49 \%$ & $-10,39 \%$ \\
\hline \multicolumn{3}{|c|}{ SUBTOTAL DÍGRAFO 3} & 374.829 & 376.061 & 376.150 & 538.759 & 375.344 & 375.266 & 375.443 & $-0,19 \%$ & $-0,24 \%$ & $-30,31 \%$ \\
\hline \multicolumn{3}{|c|}{ TOTAL } & 1.254 .518 & 1.269 .214 & 1.268 .890 & 1.822 .477 & 1.261.100 & 1.261 .122 & 1.262 .383 & $-0,64 \%$ & $-0,61 \%$ & $-30,73 \%$ \\
\hline
\end{tabular}


Tabela 4-10: Melhoria realizada pela Heurística com Busca Local (HBL) quando aplicada a diferentes soluções iniciais para problemas desbalanceados $(50 \%)$ e dois reposicionamentos

\begin{tabular}{|c|c|c|c|c|c|c|c|c|c|c|c|c|}
\hline \multirow{3}{*}{ DESBAL. } & \multirow{3}{*}{ DÍGRAFO } & \multirow[b]{3}{*}{ ROTAS } & \multirow{2}{*}{\multicolumn{4}{|c|}{ RESULTADOS (\#) }} & \multirow{2}{*}{\multicolumn{3}{|c|}{ RESULTADOS HBL (\#) }} & \multirow{2}{*}{\multicolumn{3}{|c|}{ Melhoria HBL (\%) }} \\
\hline & & & & & & & & & & & & \\
\hline & & & PLI & GH & CD & QS & $\mathrm{HBL}_{(\mathrm{GH})}$ & $\mathrm{HBL}_{(\mathrm{CD})}$ & $\mathrm{HBL}_{(\mathrm{QS})}$ & $\mathrm{HBL}_{(\mathrm{GH})} \times \mathrm{GH}$ & $H B L_{(C D)} \times C D$ & $H_{B L}(Q S) \times Q S$ \\
\hline $50 \%$ & 1 & 100 & 51.440 & 52.353 & 52.158 & 78.781 & 51.713 & 51.669 & 52.048 & $-1,22 \%$ & $-0,94 \%$ & $-33,93 \%$ \\
\hline $50 \%$ & 1 & 200 & 122.417 & 125.313 & 125.421 & 179.448 & 123.576 & 123.538 & 123.532 & $-1,39 \%$ & $-1,50 \%$ & $-31,16 \%$ \\
\hline $50 \%$ & 1 & 500 & 296.335 & 300.453 & 300.246 & 409.599 & 297.578 & 298.005 & 297.635 & $-0,96 \%$ & $-0,75 \%$ & $-27,34 \%$ \\
\hline $50 \%$ & 1 & 1000 & & 597.389 & 597.938 & 789.064 & 592.500 & 592.597 & 592.476 & $-0,82 \%$ & $-0,89 \%$ & $-24,91 \%$ \\
\hline $50 \%$ & 1 & 1500 & & 891.968 & 893.536 & 1.148 .446 & 885.892 & 885.937 & 885.941 & $-0,68 \%$ & $-0,85 \%$ & $-22,86 \%$ \\
\hline $50 \%$ & 1 & 3000 & & & 1.808 .890 & 2.245 .263 & & 1.788 .619 & 1.788 .434 & & $-1,12 \%$ & $-20,35 \%$ \\
\hline $50 \%$ & 1 & 5000 & & & 3.026 .590 & 3.681 .461 & & 2.985 .431 & 2.984 .834 & & $-1,36 \%$ & $-18,92 \%$ \\
\hline \multicolumn{3}{|c|}{ SUBTOTAL DÍGRAFO 1} & 470.192 & 478.119 & 477.825 & 667.828 & 472.867 & 473.212 & 473.214 & $-1,10 \%$ & $-0,97 \%$ & $-29,14 \%$ \\
\hline $50 \%$ & 2 & 100 & 48.837 & 49.666 & 49.556 & 72.012 & 49.153 & 49.008 & 49.255 & $-1,03 \%$ & $-1,11 \%$ & $-31,60 \%$ \\
\hline $50 \%$ & 2 & 200 & 119.264 & 120.407 & 120.325 & 173.191 & 119.763 & 119.668 & 119.854 & $-0,53 \%$ & $-0,55 \%$ & $-30,80 \%$ \\
\hline $50 \%$ & 2 & 500 & 296.213 & 297.980 & 298.268 & 387.246 & 296.576 & 296.617 & 296.577 & $-0,47 \%$ & $-0,55 \%$ & $-23,41 \%$ \\
\hline $50 \%$ & 2 & 1000 & & 587.469 & 588.540 & 745.322 & 585.393 & 585.494 & 585.361 & $-0,35 \%$ & $-0,52 \%$ & $-21,46 \%$ \\
\hline $50 \%$ & 2 & 1500 & & 884.467 & 886.018 & 1.093 .987 & 881.179 & 881.234 & 881.240 & $-0,37 \%$ & $-0,54 \%$ & $-19,45 \%$ \\
\hline $50 \%$ & 2 & 3000 & & & 1.790 .564 & 2.143 .348 & & 1.778 .970 & 1.778 .864 & & $-0,65 \%$ & $-17,01 \%$ \\
\hline $50 \%$ & 2 & 5000 & & & 2.996 .908 & 3.486 .477 & & 2.964 .937 & 2.964 .625 & & $-1,07 \%$ & $-14,97 \%$ \\
\hline \multicolumn{3}{|c|}{ SUBTOTAL DÍGRAFO 2} & 464.314 & 468.053 & 468.149 & 632.449 & 465.493 & 465.293 & 465.686 & $-0,55 \%$ & $-0,61 \%$ & $-26,37 \%$ \\
\hline $50 \%$ & 3 & 100 & 55.296 & 55.445 & 55.472 & 77.367 & 55.317 & 55.321 & 55.316 & $-0,23 \%$ & $-0,27 \%$ & $-28,50 \%$ \\
\hline $50 \%$ & 3 & 200 & 108.692 & 109.036 & 109.094 & 150.208 & 108.750 & 108.763 & 108.756 & $-0,26 \%$ & $-0,30 \%$ & $-27,60 \%$ \\
\hline $50 \%$ & 3 & 500 & 198.233 & 198.971 & 199.067 & 251.285 & 198.328 & 198.356 & 198.342 & $-0,32 \%$ & $-0,36 \%$ & $-21,07 \%$ \\
\hline $50 \%$ & 3 & 1000 & & 409.638 & 409.926 & 491.025 & 408.544 & 408.601 & 408.567 & $-0,27 \%$ & $-0,32 \%$ & $-16,79 \%$ \\
\hline $50 \%$ & 3 & 1500 & & 867.691 & 868.877 & 1.005 .099 & 865.808 & 865.874 & 865.823 & $-0,22 \%$ & $-0,35 \%$ & $-13,86 \%$ \\
\hline $50 \%$ & 3 & 3000 & & & 1.753 .194 & 1.953 .023 & & 1.743 .909 & 1.743 .802 & & $-0,53 \%$ & $-10,71 \%$ \\
\hline $50 \%$ & 3 & 5000 & & & 2.904 .914 & 3.155 .338 & & 2.884 .394 & 2.883 .786 & & $-0,71 \%$ & $-8,61 \%$ \\
\hline \multicolumn{3}{|c|}{ SUBTOTAL DÍGRAFO 3} & 362.221 & 363.452 & 363.633 & 478.861 & 362.394 & 362.440 & 362.415 & $-0,29 \%$ & $-0,33 \%$ & $-24,32 \%$ \\
\hline \multicolumn{3}{|c|}{ TOTAL } & 1.296 .727 & 1.309 .623 & 1.309 .607 & 1.779 .138 & 1.300 .753 & 1.300 .945 & 1.301 .315 & $-0,68 \%$ & $-0,66 \%$ & $-26,86 \%$ \\
\hline
\end{tabular}


Tabela 4-11: Melhoria realizada pela Heurística com Busca Local (HBL) quando aplicada a diferentes soluções iniciais para problemas desbalanceados $(75 \%)$ e dois reposicionamentos

\begin{tabular}{|c|c|c|c|c|c|c|c|c|c|c|c|c|}
\hline \multirow{2}{*}{\multicolumn{2}{|c|}{ DESBAL. DÍGRAFO }} & \multirow[b]{2}{*}{ ROTAS } & \multicolumn{4}{|c|}{ RESULTADOS (\#) } & \multicolumn{3}{|c|}{ RESULTADOS HBL (\#) } & \multicolumn{3}{|c|}{ Melhoria HBL (\%) } \\
\hline & & & PLI & GH & CD & QS & $\mathrm{HBL}_{(\mathrm{GH})}$ & $\mathrm{HBL}_{(\mathrm{CD})}$ & $\mathrm{HBL}_{(\mathrm{QS})}$ & $H_{B L}(G H) \times G H$ & $\mathrm{HBL}_{(\mathrm{CD})} \times \mathrm{CD}$ & $\mathrm{HBL}_{(\mathrm{QS})} \times \mathrm{QS}$ \\
\hline $75 \%$ & 1 & 100 & 67.165 & 68.047 & 68.237 & 95.825 & 67.506 & 67.528 & 67.475 & $-0,80 \%$ & $-1,04 \%$ & $-29,58 \%$ \\
\hline $75 \%$ & 1 & 200 & 132.924 & 135.290 & 135.190 & 181.557 & 133.641 & 133.565 & 133.595 & $-1,22 \%$ & $-1,20 \%$ & $-26,42 \%$ \\
\hline $75 \%$ & 1 & 500 & 197.557 & 200.126 & 200.456 & 267.630 & 198.317 & 198.403 & 198.251 & $-0,90 \%$ & $-1,02 \%$ & $-25,92 \%$ \\
\hline $75 \%$ & 1 & 1000 & & 666.753 & 668.786 & 859.773 & 660.639 & 660.673 & 660.416 & $-0,92 \%$ & $-1,21 \%$ & $-23,19 \%$ \\
\hline $75 \%$ & 1 & 1500 & & 1.014 .785 & 1.019 .530 & 1.285 .186 & 1.004 .077 & 1.004 .007 & 1.004 .001 & $-1,06 \%$ & $-1,52 \%$ & $-21,88 \%$ \\
\hline $75 \%$ & 1 & 3000 & & & 2.039.182 & 2.518 .332 & & 1.998 .069 & 1.997.924 & & $-2,02 \%$ & $-20,66 \%$ \\
\hline $75 \%$ & 1 & 5000 & & & 3.449 .802 & 4.187.121 & & 3.354 .094 & 3.353.615 & & $-2,77 \%$ & $-19,91 \%$ \\
\hline \multicolumn{3}{|c|}{ SUBTOTAL DÍGRAFO 1} & 397.646 & 403.463 & 403.883 & 545.012 & 399.464 & 399.495 & 399.322 & $-0,99 \%$ & $-1,09 \%$ & $-26,73 \%$ \\
\hline $75 \%$ & 2 & 100 & 67.371 & 67.978 & 68.039 & 92.192 & 67.404 & 67.480 & 67.478 & $-0,84 \%$ & $-0,82 \%$ & $-26,81 \%$ \\
\hline $75 \%$ & 2 & 200 & 138.818 & 140.174 & 140.203 & 180.408 & 138.891 & 139.101 & 138.917 & $-0,92 \%$ & $-0,79 \%$ & $-23,00 \%$ \\
\hline $75 \%$ & 2 & 500 & 285.165 & 286.974 & 287.255 & 355.513 & 285.287 & 285.308 & 285.303 & $-0,59 \%$ & $-0,68 \%$ & $-19,75 \%$ \\
\hline $75 \%$ & 2 & 1000 & & 690.305 & 691.501 & 838.129 & 686.151 & 686.109 & 686.024 & $-0,60 \%$ & $-0,78 \%$ & $-18,15 \%$ \\
\hline $75 \%$ & 2 & 1500 & & 1.041 .428 & 1.044 .222 & 1.251 .769 & 1.036 .431 & 1.036 .302 & 1.036.179 & $-0,48 \%$ & $-0,76 \%$ & $-17,22 \%$ \\
\hline $75 \%$ & 2 & 3000 & & & 2.104 .776 & 2.462 .726 & & 2.074 .632 & 2.074 .465 & & $-1,43 \%$ & $-15,77 \%$ \\
\hline $75 \%$ & 2 & 5000 & & & 3.549 .604 & 4.069.396 & & 3.453 .160 & 3.452 .970 & & $-2,72 \%$ & $-15,15 \%$ \\
\hline \multicolumn{3}{|c|}{ SUBTOTAL DÍGRAFO 2} & 491.354 & 495.127 & 495.496 & 628.113 & 491.582 & 491.889 & 491.698 & $-0,72 \%$ & $-0,73 \%$ & $-21,72 \%$ \\
\hline $75 \%$ & 3 & 100 & 66.944 & 67.193 & 67.272 & 83.566 & 66.957 & 66.954 & 66.951 & $-0,35 \%$ & $-0,47 \%$ & $-19,88 \%$ \\
\hline $75 \%$ & 3 & 200 & 134.478 & 134.906 & 135.095 & 160.287 & 134.510 & 134.519 & 134.495 & $-0,29 \%$ & $-0,43 \%$ & $-16,09 \%$ \\
\hline $75 \%$ & 3 & 500 & 295.741 & 296.412 & 296.703 & 334.703 & 295.777 & 295.786 & 295.774 & $-0,21 \%$ & $-0,31 \%$ & $-11,63 \%$ \\
\hline $75 \%$ & 3 & 1000 & & 696.790 & 697.490 & 774.635 & 695.188 & 695.191 & 695.169 & $-0,23 \%$ & $-0,33 \%$ & $-10,26 \%$ \\
\hline $75 \%$ & 3 & 1500 & & 1.047 .082 & 1.049 .882 & 1.153 .040 & 1.044 .674 & 1.044 .639 & 1.044 .601 & $-0,23 \%$ & $-0,50 \%$ & $-9,40 \%$ \\
\hline $75 \%$ & 3 & 3000 & & & 2.113 .180 & 2.271 .061 & & 2.087 .898 & 2.087.717 & & $-1,20 \%$ & $-8,07 \%$ \\
\hline $75 \%$ & 3 & 5000 & & & 3.519 .928 & 3.754 .006 & & 3.455 .323 & 3.454 .885 & & $-1,84 \%$ & $-7,97 \%$ \\
\hline \multicolumn{3}{|c|}{ SUBTOTAL DÍGRAFO 3} & 497.164 & 498.511 & 499.070 & 578.556 & 497.244 & 497.259 & 497.221 & $-0,25 \%$ & $-0,36 \%$ & $-14,06 \%$ \\
\hline \multicolumn{3}{|c|}{ TOTAL } & 1.386 .163 & 1.397 .101 & 1.398 .449 & 1.751 .680 & 1.388 .291 & 1.388 .643 & 1.388 .240 & $-0,63 \%$ & $-0,70 \%$ & $-20,75 \%$ \\
\hline
\end{tabular}




\subsubsection{Comparação dos resultados obtidos pela Heurística com Busca Local}

Nesta seção é feita uma comparação entre os resultados obtidos pela Heurística com Busca Local.

- Problemas balanceados e com um reposicionamento

Para este conjunto de problemas, como apresentado na Tabela 4-12, os resultados obtidos pela Heurística com Busca Local (HBL) quando aplicados à solução inicial QS ficaram melhores que os obtidos aplicando-se a Heurística com Busca Local nas soluções fornecidas por GH e CD $(2,01 \%$ e $1,14 \%$ abaixo respectivamente). 
Tabela 4-12: Comparação dos diferentes resultados obtidos pela Heurística com Busca Local (HBL) para problemas balanceados e com um reposicionamento

\begin{tabular}{|c|c|c|c|c|c|c|c|c|c|c|c|c|}
\hline \multirow{2}{*}{\multicolumn{2}{|c|}{ DESBAL. DÍGRAFO }} & \multirow[b]{2}{*}{ ROTAS } & \multirow[b]{2}{*}{ PLI } & \multicolumn{3}{|c|}{ RESULTADOS HBL (\#) } & \multicolumn{3}{|c|}{ Diferenças PLI (\%) } & \multicolumn{3}{|c|}{ Diferenças HBL (\%) } \\
\hline & & & & $\mathrm{HBL}_{(\mathrm{GH})}$ & $\mathrm{HBL}_{(\mathrm{CD})}$ & $\mathrm{HBL}_{(\mathrm{QS})}$ & $\mathrm{HBL}_{(\mathrm{GH})} \times \mathrm{PLI}$ & $\mathrm{HBL}_{(\mathrm{CD})} \times \mathrm{PLI}$ & $\mathrm{HBL}_{(\mathrm{QS})} \times \mathrm{PLI}$ & $\mathrm{HBL}_{(\mathrm{QS})} \times \mathrm{HBL}_{(\mathrm{GH})}$ & $\mathrm{HBL}_{(\mathrm{QS})} \times \mathrm{HBL}_{(\mathrm{CD})}$ & $\mathrm{HBL}_{(\mathrm{CD})} \times \mathrm{HBL}_{(\mathrm{GH})}$ \\
\hline $0 \%$ & 1 & 100 & 77.305 & 77.305 & 77.305 & 77.305 & $0,00 \%$ & $0,00 \%$ & $0,00 \%$ & $0,00 \%$ & $0,00 \%$ & $0,00 \%$ \\
\hline $0 \%$ & 1 & 200 & 172.736 & 172.851 & 172.851 & 172.958 & $0,07 \%$ & $0,07 \%$ & $0,13 \%$ & $0,06 \%$ & $0,06 \%$ & $0,00 \%$ \\
\hline $0 \%$ & 1 & 500 & 327.525 & 336.571 & 334.204 & 332.179 & $2,76 \%$ & $2,04 \%$ & $1,42 \%$ & $-1,31 \%$ & $-0,61 \%$ & $-0,70 \%$ \\
\hline $0 \%$ & 1 & 1000 & 580.237 & 617.819 & 616.355 & 608.125 & $6,48 \%$ & $6,22 \%$ & $4,81 \%$ & $-1,57 \%$ & $-1,34 \%$ & $-0,24 \%$ \\
\hline $0 \%$ & 1 & 1500 & 831.544 & 887.859 & 878.023 & 867.686 & $6,77 \%$ & $5,59 \%$ & $4,35 \%$ & $-2,27 \%$ & $-1,18 \%$ & $-1,11 \%$ \\
\hline $0 \%$ & 1 & 3000 & 1.581 .662 & 1.680 .615 & 1.673 .797 & 1.650 .126 & $6,26 \%$ & $5,83 \%$ & $4,33 \%$ & $-1,81 \%$ & $-1,41 \%$ & $-0,41 \%$ \\
\hline $0 \%$ & 1 & 5000 & & 2.741 .544 & 2.733 .100 & 2.683.155 & & & & $-2,13 \%$ & $-1,83 \%$ & $-0,31 \%$ \\
\hline \multicolumn{3}{|c|}{ SUBTOTAL DÍGRAFO 1} & 3.571 .008 & 3.773 .020 & 3.752 .535 & 3.708.379 & $5,66 \%$ & $5,08 \%$ & $3,85 \%$ & $-1,71 \%$ & $-1,18 \%$ & $-0,54 \%$ \\
\hline $0 \%$ & 2 & 100 & 85.669 & 85.669 & 85.669 & 85.669 & $0,00 \%$ & $0,00 \%$ & $0,00 \%$ & $0,00 \%$ & $0,00 \%$ & $0,00 \%$ \\
\hline $0 \%$ & 2 & 200 & 157.432 & 157.433 & 157.432 & 157.432 & $0,00 \%$ & $0,00 \%$ & $0,00 \%$ & $0,00 \%$ & $0,00 \%$ & $0,00 \%$ \\
\hline $0 \%$ & 2 & 500 & 308.894 & 315.591 & 314.538 & 312.683 & $2,17 \%$ & $1,83 \%$ & $1,23 \%$ & $-0,92 \%$ & $-0,59 \%$ & $-0,33 \%$ \\
\hline $0 \%$ & 2 & 1000 & 542.408 & 585.169 & 577.278 & 571.859 & $7,88 \%$ & $6,43 \%$ & $5,43 \%$ & $-2,27 \%$ & $-0,94 \%$ & $-1,35 \%$ \\
\hline $0 \%$ & 2 & 1500 & 782.459 & 837.989 & 827.516 & 820.207 & $7,10 \%$ & $5,76 \%$ & $4,82 \%$ & $-2,12 \%$ & $-0,88 \%$ & $-1,25 \%$ \\
\hline $0 \%$ & 2 & 3000 & 1.513 .408 & 1.591 .653 & 1.571 .434 & 1.552 .418 & $5,17 \%$ & $3,83 \%$ & $2,58 \%$ & $-2,47 \%$ & $-1,21 \%$ & $-1,27 \%$ \\
\hline $0 \%$ & 2 & 5000 & & 2.596 .324 & 2.592 .057 & 2.543.302 & & & & $-2,04 \%$ & $-1,88 \%$ & $-0,16 \%$ \\
\hline \multicolumn{3}{|c|}{ SUBTOTAL DÍGRAFO 2} & 3.390 .270 & 3.573 .504 & 3.533 .867 & 3.500 .268 & $5,40 \%$ & $4,24 \%$ & $3,24 \%$ & $-2,05 \%$ & $-0,95 \%$ & $-1,11 \%$ \\
\hline $0 \%$ & 3 & 100 & 65.762 & 65.762 & 65.762 & 65.762 & $0,00 \%$ & $0,00 \%$ & $0,00 \%$ & $0,00 \%$ & $0,00 \%$ & $0,00 \%$ \\
\hline $0 \%$ & 3 & 200 & 143.608 & 143.608 & 143.608 & 143.612 & $0,00 \%$ & $0,00 \%$ & $0,00 \%$ & $0,00 \%$ & $0,00 \%$ & $0,00 \%$ \\
\hline $0 \%$ & 3 & 500 & 275.114 & 283.246 & 282.121 & 281.671 & $2,96 \%$ & $2,55 \%$ & $2,38 \%$ & $-0,56 \%$ & $-0,16 \%$ & $-0,40 \%$ \\
\hline $0 \%$ & 3 & 1000 & 474.987 & 521.210 & 512.551 & 508.505 & $9,73 \%$ & $7,91 \%$ & $7,06 \%$ & $-2,44 \%$ & $-0,79 \%$ & $-1,66 \%$ \\
\hline $0 \%$ & 3 & 1500 & 693.970 & 750.434 & 736.816 & 730.439 & $8,14 \%$ & $6,17 \%$ & $5,26 \%$ & $-2,66 \%$ & $-0,87 \%$ & $-1,81 \%$ \\
\hline $0 \%$ & 3 & 3000 & 1.148 .001 & 1.200 .217 & 1.192 .923 & 1.165 .015 & $4,55 \%$ & $3,91 \%$ & $1,48 \%$ & $-2,93 \%$ & $-2,34 \%$ & $-0,61 \%$ \\
\hline $0 \%$ & 3 & 5000 & & 2.347 .826 & 2.325 .641 & 2.281.831 & & & & $-2,81 \%$ & $-1,88 \%$ & $-0,94 \%$ \\
\hline \multicolumn{3}{|c|}{ SUBTOTAL DÍGRAFO 3} & 2.801 .440 & 2.964 .476 & 2.933 .780 & 2.895 .003 & $5,82 \%$ & $4,72 \%$ & $3,34 \%$ & $-2,34 \%$ & $-1,32 \%$ & $-1,04 \%$ \\
\hline \multicolumn{3}{|c|}{ TOTAL } & 9.762 .719 & 10.311 .000 & 10.220 .182 & 10.103 .650 & $5,62 \%$ & $4,69 \%$ & $3,49 \%$ & $-2,01 \%$ & $-1,14 \%$ & $-0,88 \%$ \\
\hline
\end{tabular}


- Problemas desbalanceados e com um reposicionamento

Da mesma forma que para os problemas balanceados e com um reposicionamento, nos problemas desbalanceados e com um reposicionamento a HBL quando aplicada sobre a solução inicial QS apresentou (no resultado total) os melhores resultados, como apresentado na Tabela 4-13, Tabela 4-14 e Tabela 4-15. 
Tabela 4-13: Comparação dos diferentes resultados obtidos pela Heurística com Busca Local (HBL) para problemas desbalanceados (25\%) e com um reposicionamento

\begin{tabular}{|c|c|c|c|c|c|c|c|c|c|c|c|c|}
\hline \multirow[b]{2}{*}{ DESBAL. } & \multirow[b]{2}{*}{ DÍGRAFO } & \multirow[b]{2}{*}{ ROTAS } & \multirow[b]{2}{*}{ PLI } & \multicolumn{3}{|c|}{ RESULTADOS HBL (\#) } & \multicolumn{3}{|c|}{ Diferenças PLI (\%) } & \multicolumn{3}{|c|}{ Diferenças HBL (\%) } \\
\hline & & & & $\mathrm{HBL}_{(\mathrm{GH})}$ & $\mathrm{HBL}_{(\mathrm{CD})}$ & $\mathrm{HBL}_{(\mathrm{QS})}$ & $\mathrm{HBL}_{(\mathrm{GH})} \times \mathrm{PLI}$ & $\mathrm{HBL}_{(\mathrm{CD})} \times \mathrm{PLI}$ & $\mathrm{HBL}_{(\mathrm{QS})} \times \mathrm{PLI}$ & $\mathrm{HBL}_{(\mathrm{QS})} \times \mathrm{HBL}_{(\mathrm{GH})}$ & $\mathrm{HBL}_{(\mathrm{QS})} \times \mathrm{HBL}_{(\mathrm{CD})}$ & $\mathrm{HBL}_{(\mathrm{CD})} \times \mathrm{HBL}_{(\mathrm{GH})}$ \\
\hline $25 \%$ & 1 & 100 & 75.723 & 75.723 & 75.723 & 75.723 & $0,00 \%$ & $0,00 \%$ & $0,00 \%$ & $0,00 \%$ & $0,00 \%$ & $0,00 \%$ \\
\hline $25 \%$ & 1 & 200 & 174.587 & 174.717 & 174.733 & 174.620 & $0,07 \%$ & $0,08 \%$ & $0,02 \%$ & $-0,06 \%$ & $-0,06 \%$ & $0,01 \%$ \\
\hline $25 \%$ & 1 & 500 & 346.923 & 356.287 & 353.811 & 351.099 & $2,70 \%$ & $1,99 \%$ & $1,20 \%$ & $-1,46 \%$ & $-0,77 \%$ & $-0,70 \%$ \\
\hline $25 \%$ & 1 & 1000 & 622.111 & 655.087 & 654.249 & 643.777 & $5,30 \%$ & $5,17 \%$ & $3,48 \%$ & $-1,73 \%$ & $-1,60 \%$ & $-0,13 \%$ \\
\hline $25 \%$ & 1 & 1500 & 892.689 & 957.863 & 941.251 & 930.985 & $7,30 \%$ & $5,44 \%$ & $4,29 \%$ & $-2,81 \%$ & $-1,09 \%$ & $-1,73 \%$ \\
\hline $25 \%$ & 1 & 3000 & 1.710 .515 & 1.805 .369 & 1.791 .865 & 1.763 .208 & $5,55 \%$ & $4,76 \%$ & $3,08 \%$ & $-2,34 \%$ & $-1,60 \%$ & $-0,75 \%$ \\
\hline $25 \%$ & 1 & 5000 & & 2.948 .893 & 2.940 .174 & 2.876.359 & & & & $-2,46 \%$ & $-2,17 \%$ & $-0,30 \%$ \\
\hline \multicolumn{3}{|c|}{ SUBTOTAL DÍGRAFO 1} & 3.822 .548 & 4.025 .046 & 3.991 .632 & 3.939 .412 & $5,30 \%$ & $4,42 \%$ & $3,06 \%$ & $-2,13 \%$ & $-1,31 \%$ & $-0,83 \%$ \\
\hline $25 \%$ & 2 & 100 & 67.667 & 67.667 & 67.667 & 67.667 & $0,00 \%$ & $0,00 \%$ & $0,00 \%$ & $0,00 \%$ & $0,00 \%$ & $0,00 \%$ \\
\hline $25 \%$ & 2 & 200 & 154.621 & 154.622 & 154.622 & 154.622 & $0,00 \%$ & $0,00 \%$ & $0,00 \%$ & $0,00 \%$ & $0,00 \%$ & $0,00 \%$ \\
\hline $25 \%$ & 2 & 500 & 323.726 & 331.127 & 328.506 & 326.944 & $2,29 \%$ & $1,48 \%$ & $0,99 \%$ & $-1,26 \%$ & $-0,48 \%$ & $-0,79 \%$ \\
\hline $25 \%$ & 2 & 1000 & 584.265 & 619.531 & 615.939 & 609.950 & $6,04 \%$ & $5,42 \%$ & $4,40 \%$ & $-1,55 \%$ & $-0,97 \%$ & $-0,58 \%$ \\
\hline $25 \%$ & 2 & 1500 & 841.444 & 910.039 & 890.570 & 879.422 & $8,15 \%$ & $5,84 \%$ & $4,51 \%$ & $-3,36 \%$ & $-1,25 \%$ & $-2,14 \%$ \\
\hline $25 \%$ & 2 & 3000 & 1.659 .276 & 1.744 .069 & 1.715 .974 & 1.686 .081 & $5,11 \%$ & $3,42 \%$ & $1,62 \%$ & $-3,32 \%$ & $-1,74 \%$ & $-1,61 \%$ \\
\hline $25 \%$ & 2 & 5000 & & 2.829 .973 & 2.810 .932 & 2.756.354 & & & & $-2,60 \%$ & $-1,94 \%$ & $-0,67 \%$ \\
\hline \multicolumn{3}{|c|}{ SUBTOTAL DÍGRAFO 2} & 3.630 .998 & 3.827 .054 & 3.773 .277 & 3.724 .685 & $5,40 \%$ & $3,92 \%$ & $2,58 \%$ & $-2,67 \%$ & $-1,29 \%$ & $-1,41 \%$ \\
\hline $25 \%$ & 3 & 100 & 75.827 & 75.827 & 75.827 & 75.827 & $0,00 \%$ & $0,00 \%$ & $0,00 \%$ & $0,00 \%$ & $0,00 \%$ & $0,00 \%$ \\
\hline $25 \%$ & 3 & 200 & 113.277 & 113.392 & 113.409 & 113.425 & $0,10 \%$ & $0,12 \%$ & $0,13 \%$ & $0,03 \%$ & $0,01 \%$ & $0,02 \%$ \\
\hline $25 \%$ & 3 & 500 & 289.424 & 297.487 & 295.483 & 293.563 & $2,79 \%$ & $2,09 \%$ & $1,43 \%$ & $-1,32 \%$ & $-0,65 \%$ & $-0,67 \%$ \\
\hline $25 \%$ & 3 & 1000 & 521.054 & 554.514 & 551.433 & 545.673 & $6,42 \%$ & $5,83 \%$ & $4,73 \%$ & $-1,59 \%$ & $-1,04 \%$ & $-0,56 \%$ \\
\hline $25 \%$ & 3 & 1500 & 752.391 & 816.836 & 800.064 & 790.668 & $8,57 \%$ & $6,34 \%$ & $5,09 \%$ & $-3,20 \%$ & $-1,17 \%$ & $-2,05 \%$ \\
\hline $25 \%$ & 3 & 3000 & 1.088 .220 & 1.140 .888 & 1.113 .260 & 1.100 .662 & $4,84 \%$ & $2,30 \%$ & $1,14 \%$ & $-3,53 \%$ & $-1,13 \%$ & $-2,42 \%$ \\
\hline $25 \%$ & 3 & 5000 & & 2.588 .231 & 2.562 .463 & 2.510 .665 & & & & $-3,00 \%$ & $-2,02 \%$ & $-1,00 \%$ \\
\hline \multicolumn{3}{|c|}{ SUBTOTAL DÍGRAFO 3} & 2.840 .193 & 2.998 .945 & 2.949 .478 & 2.919 .818 & $5,59 \%$ & $3,85 \%$ & $2,80 \%$ & $-2,64 \%$ & $-1,01 \%$ & $-1,65 \%$ \\
\hline \multicolumn{3}{|c|}{ TOTAL } & 10.293 .739 & 10.851 .045 & 10.714 .387 & 10.583 .915 & $5,41 \%$ & $4,09 \%$ & $2,82 \%$ & $-2,46 \%$ & $-1,22 \%$ & $-1,26 \%$ \\
\hline
\end{tabular}


Tabela 4-14: Comparação dos diferentes resultados obtidos pela Heurística com Busca Local (HBL) para problemas desbalanceados (50\%) e com um reposicionamento

\begin{tabular}{|c|c|c|c|c|c|c|c|c|c|c|c|c|}
\hline \multirow[b]{2}{*}{ DESBAL. } & \multirow[b]{2}{*}{ GRAFO } & \multirow[b]{2}{*}{ ROTAS } & \multirow[b]{2}{*}{ PLI } & \multicolumn{3}{|c|}{ RESULTADOS HBL (\#) } & \multicolumn{3}{|c|}{ Diferenças PLI (\%) } & \multicolumn{3}{|c|}{ Diferenças HBL (\%) } \\
\hline & & & & $\mathrm{HBL}_{(\mathrm{GH})}$ & $\mathrm{HBL}_{(\mathrm{CD})}$ & $\mathrm{HBL}_{(\mathrm{QS})}$ & $\mathrm{HBL}_{(\mathrm{GH})} \times \mathrm{PLI}$ & $\mathrm{HBL}_{(\mathrm{CD})} \times \mathrm{PLI}$ & $\mathrm{HBL}_{(\mathrm{QS})} \times \mathrm{PLI}$ & $\mathrm{HBL}_{(\mathrm{QS})} \mathrm{xHBL_{(GH) }}$ & $\mathrm{HBL}_{(\mathrm{QS})} \times \mathrm{HBL}_{(\mathrm{CD})}$ & $\mathrm{HBL}_{(\mathrm{CD})} \times \mathrm{HBL}_{(\mathrm{GH})}$ \\
\hline $50 \%$ & 1 & 100 & 74.148 & 74.148 & 74.148 & 74.148 & $0,00 \%$ & $0,00 \%$ & $0,00 \%$ & $0,00 \%$ & $0,00 \%$ & $0,00 \%$ \\
\hline $50 \%$ & 1 & 200 & 174.275 & 174.723 & 174.644 & 174.275 & $0,26 \%$ & $0,21 \%$ & $0,00 \%$ & $-0,26 \%$ & $-0,21 \%$ & $-0,05 \%$ \\
\hline $50 \%$ & 1 & 500 & 377.438 & 383.795 & 381.673 & 380.932 & $1,68 \%$ & $1,12 \%$ & $0,93 \%$ & $-0,75 \%$ & $-0,19 \%$ & $-0,55 \%$ \\
\hline $50 \%$ & 1 & 1000 & 697.800 & 728.198 & 722.034 & 713.585 & $4,36 \%$ & $3,47 \%$ & $2,26 \%$ & $-2,01 \%$ & $-1,17 \%$ & $-0,85 \%$ \\
\hline $50 \%$ & 1 & 1500 & 1.002 .675 & 1.056 .744 & 1.053 .542 & 1.035 .240 & $5,39 \%$ & $5,07 \%$ & $3,25 \%$ & $-2,03 \%$ & $-1,74 \%$ & $-0,30 \%$ \\
\hline $50 \%$ & 1 & 3000 & 1.937 .044 & 2.055 .420 & 2.049 .627 & 1.996 .067 & $6,11 \%$ & $5,81 \%$ & $3,05 \%$ & $-2,89 \%$ & $-2,61 \%$ & $-0,28 \%$ \\
\hline $50 \%$ & 1 & 5000 & & 3.359 .966 & 3.353 .969 & 3.275.803 & & & & $-2,50 \%$ & $-2,33 \%$ & $-0,18 \%$ \\
\hline \multicolumn{3}{|c|}{ SUBTOTAL DÍGRAFO 1} & 4.263 .380 & 4.473 .029 & 4.455 .669 & 4.374 .249 & $4,92 \%$ & $4,51 \%$ & $2,60 \%$ & $-2,21 \%$ & $-1,83 \%$ & $-0,39 \%$ \\
\hline $50 \%$ & 2 & 100 & 90.355 & 90.355 & 90.355 & 90.355 & $0,00 \%$ & $0,00 \%$ & $0,00 \%$ & $0,00 \%$ & $0,00 \%$ & $0,00 \%$ \\
\hline $50 \%$ & 2 & 200 & 168.629 & 168.629 & 168.629 & 168.629 & $0,00 \%$ & $0,00 \%$ & $0,00 \%$ & $0,00 \%$ & $0,00 \%$ & $0,00 \%$ \\
\hline $50 \%$ & 2 & 500 & 353.500 & 358.987 & 357.423 & 356.559 & $1,55 \%$ & $1,11 \%$ & $0,87 \%$ & $-0,68 \%$ & $-0,24 \%$ & $-0,44 \%$ \\
\hline $50 \%$ & 2 & 1000 & 662.347 & 689.295 & 689.524 & 678.523 & $4,07 \%$ & $4,10 \%$ & $2,44 \%$ & $-1,56 \%$ & $-1,60 \%$ & $0,03 \%$ \\
\hline $50 \%$ & 2 & 1500 & 959.467 & 1.012 .934 & 1.002 .128 & 991.069 & $5,57 \%$ & $4,45 \%$ & $3,29 \%$ & $-2,16 \%$ & $-1,10 \%$ & $-1,07 \%$ \\
\hline $50 \%$ & 2 & 3000 & 1.869 .976 & 1.981 .325 & 1.964 .038 & 1.927 .327 & $5,95 \%$ & $5,03 \%$ & $3,07 \%$ & $-2,73 \%$ & $-1,87 \%$ & $-0,87 \%$ \\
\hline $50 \%$ & 2 & 5000 & & 3.239 .227 & 3.220 .302 & 3.158 .800 & & & & $-2,48 \%$ & $-1,91 \%$ & $-0,58 \%$ \\
\hline \multicolumn{3}{|c|}{ SUBTOTAL DÍGRAFO 2} & 4.104 .274 & 4.301 .525 & 4.272 .097 & 4.212 .463 & $4,81 \%$ & $4,09 \%$ & $2,64 \%$ & $-2,07 \%$ & $-1,40 \%$ & $-0,68 \%$ \\
\hline $50 \%$ & 3 & 100 & 63.378 & 63.378 & 63.378 & 63.378 & $0,00 \%$ & $0,00 \%$ & $0,00 \%$ & $0,00 \%$ & $0,00 \%$ & $0,00 \%$ \\
\hline $50 \%$ & 3 & 200 & 146.786 & 146.793 & 146.786 & 146.786 & $0,00 \%$ & $0,00 \%$ & $0,00 \%$ & $0,00 \%$ & $0,00 \%$ & $0,00 \%$ \\
\hline $50 \%$ & 3 & 500 & 320.659 & 326.069 & 325.776 & 325.219 & $1,69 \%$ & $1,60 \%$ & $1,42 \%$ & $-0,26 \%$ & $-0,17 \%$ & $-0,09 \%$ \\
\hline $50 \%$ & 3 & 1000 & 612.866 & 637.472 & 633.680 & 629.951 & $4,01 \%$ & $3,40 \%$ & $2,79 \%$ & $-1,18 \%$ & $-0,59 \%$ & $-0,59 \%$ \\
\hline $50 \%$ & 3 & 1500 & 902.320 & 951.604 & 940.510 & 927.276 & $5,46 \%$ & $4,23 \%$ & $2,77 \%$ & $-2,56 \%$ & $-1,41 \%$ & $-1,17 \%$ \\
\hline $50 \%$ & 3 & 3000 & 1.796 .078 & 1.877.057 & 1.848 .917 & 1.814 .655 & $4,51 \%$ & $2,94 \%$ & $1,03 \%$ & $-3,32 \%$ & $-1,85 \%$ & $-1,50 \%$ \\
\hline $50 \%$ & 3 & 5000 & & 3.064 .170 & 3.026 .708 & 2.974.474 & & & & $-2,93 \%$ & $-1,73 \%$ & $-1,22 \%$ \\
\hline \multicolumn{3}{|c|}{ SUBTOTAL DÍGRAFO 3} & 3.842 .087 & 4.002 .373 & 3.959 .047 & 3.907 .265 & $4,17 \%$ & $3,04 \%$ & $1,70 \%$ & $-2,38 \%$ & $-1,31 \%$ & $-1,08 \%$ \\
\hline \multicolumn{3}{|c|}{ TOTAL } & 12.209 .741 & 12.776 .927 & 12.686 .812 & 12.493 .977 & $4,65 \%$ & $3,91 \%$ & $2,33 \%$ & $-2,21 \%$ & $-1,52 \%$ & $-0,71 \%$ \\
\hline
\end{tabular}


Tabela 4-15: Comparação dos diferentes resultados obtidos pela Heurística com Busca Local (HBL) para problemas desbalanceados (75\%) e com um reposicionamento

\begin{tabular}{|c|c|c|c|c|c|c|c|c|c|c|c|c|}
\hline \multirow[b]{2}{*}{ DESBAL. } & \multirow[b]{2}{*}{ DÍGRAFO } & \multirow[b]{2}{*}{ ROTAS } & \multirow[b]{2}{*}{ PLI } & \multicolumn{3}{|c|}{ RESULTADOS HBL (\#) } & \multicolumn{3}{|c|}{ Diferenças PLI (\%) } & \multicolumn{3}{|c|}{ Diferenças HBL (\%) } \\
\hline & & & & $\mathrm{HBL}_{(\mathrm{GH})}$ & $\mathrm{HBL}_{(\mathrm{CD})}$ & $\mathrm{HBL}_{(\mathrm{QS})}$ & $\mathrm{HBL}_{(\mathrm{GH})} \times \mathrm{PLI}$ & $\mathrm{HBL}_{(\mathrm{CD})} \times \mathrm{PLI}$ & $\mathrm{HBL}_{(\mathrm{QS})} \times \mathrm{PLI}$ & $\mathrm{HBL}_{(\mathrm{QS})} \times \mathrm{HBL}_{(\mathrm{GH})}$ & $\mathrm{HBL}_{(\mathrm{QS})} \times \mathrm{HBL}_{(\mathrm{CD})}$ & $\mathrm{HBL}_{(\mathrm{CD})} \times \mathrm{HBL}_{(\mathrm{GH})}$ \\
\hline $75 \%$ & 1 & 100 & 77.798 & 77.798 & 77.798 & 77.798 & $0,00 \%$ & $0,00 \%$ & $0,00 \%$ & $0,00 \%$ & $0,00 \%$ & $0,00 \%$ \\
\hline $75 \%$ & 1 & 200 & 145.882 & 145.882 & 145.882 & 145.882 & $0,00 \%$ & $0,00 \%$ & $0,00 \%$ & $0,00 \%$ & $0,00 \%$ & $0,00 \%$ \\
\hline $75 \%$ & 1 & 500 & 345.746 & 348.472 & 348.128 & 347.055 & $0,79 \%$ & $0,69 \%$ & $0,38 \%$ & $-0,41 \%$ & $-0,31 \%$ & $-0,10 \%$ \\
\hline $75 \%$ & 1 & 1000 & 818.008 & 833.987 & 833.215 & 825.533 & $1,95 \%$ & $1,86 \%$ & $0,92 \%$ & $-1,01 \%$ & $-0,92 \%$ & $-0,09 \%$ \\
\hline $75 \%$ & 1 & 1500 & 1.216 .692 & 1.245 .701 & 1.240 .791 & 1.230 .171 & $2,38 \%$ & $1,98 \%$ & $1,11 \%$ & $-1,25 \%$ & $-0,86 \%$ & $-0,39 \%$ \\
\hline $75 \%$ & 1 & 3000 & 2.359 .643 & 2.437 .767 & 2.425 .021 & 2.397 .968 & $3,31 \%$ & $2,77 \%$ & $1,62 \%$ & $-1,63 \%$ & $-1,12 \%$ & $-0,52 \%$ \\
\hline $75 \%$ & 1 & 5000 & & 4.038 .386 & 4.026 .684 & 3.978.033 & & & & $-1,49 \%$ & $-1,21 \%$ & $-0,29 \%$ \\
\hline \multicolumn{3}{|c|}{ SUBTOTAL DÍGRAFO 1} & 4.963 .769 & 5.089 .607 & 5.070 .835 & 5.024 .408 & $2,54 \%$ & $2,16 \%$ & $1,22 \%$ & $-1,28 \%$ & $-0,92 \%$ & $-0,37 \%$ \\
\hline $75 \%$ & 2 & 100 & 87.693 & 91.889 & 91.889 & 91.889 & $4,78 \%$ & $4,78 \%$ & $4,78 \%$ & $0,00 \%$ & $0,00 \%$ & $0,00 \%$ \\
\hline $75 \%$ & 2 & 200 & 141.074 & 141.085 & 141.074 & 141.074 & $0,01 \%$ & $0,00 \%$ & $0,00 \%$ & $-0,01 \%$ & $0,00 \%$ & $-0,01 \%$ \\
\hline $75 \%$ & 2 & 500 & 415.665 & 418.085 & 418.246 & 417.351 & $0,58 \%$ & $0,62 \%$ & $0,41 \%$ & $-0,18 \%$ & $-0,21 \%$ & $0,04 \%$ \\
\hline $75 \%$ & 2 & 1000 & 801.916 & 814.836 & 812.948 & 808.173 & $1,61 \%$ & $1,38 \%$ & $0,78 \%$ & $-0,82 \%$ & $-0,59 \%$ & $-0,23 \%$ \\
\hline $75 \%$ & 2 & 1500 & 1.186 .251 & 1.212 .033 & 1.209 .352 & 1.200 .355 & $2,17 \%$ & $1,95 \%$ & $1,19 \%$ & $-0,96 \%$ & $-0,74 \%$ & $-0,22 \%$ \\
\hline $75 \%$ & 2 & 3000 & 2.317 .696 & 2.389 .092 & 2.379 .667 & 2.350 .445 & $3,08 \%$ & $2,67 \%$ & $1,41 \%$ & $-1,62 \%$ & $-1,23 \%$ & $-0,39 \%$ \\
\hline $75 \%$ & 2 & 5000 & & 3.964 .939 & 3.944 .797 & 3.901 .160 & & & & $-1,61 \%$ & $-1,11 \%$ & $-0,51 \%$ \\
\hline \multicolumn{3}{|c|}{ SUBTOTAL DÍGRAFO 2} & 4.950 .294 & 5.067 .019 & 5.053 .177 & 5.009 .286 & $2,36 \%$ & $2,08 \%$ & $1,19 \%$ & $-1,14 \%$ & $-0,87 \%$ & $-0,27 \%$ \\
\hline $75 \%$ & 3 & 100 & 83.560 & 83.560 & 83.560 & 83.560 & $0,00 \%$ & $0,00 \%$ & $0,00 \%$ & $0,00 \%$ & $0,00 \%$ & $0,00 \%$ \\
\hline $75 \%$ & 3 & 200 & 158.263 & 158.346 & 158.266 & 158.436 & $0,05 \%$ & $0,00 \%$ & $0,11 \%$ & $0,06 \%$ & $0,11 \%$ & $-0,05 \%$ \\
\hline $75 \%$ & 3 & 500 & 383.717 & 386.764 & 385.895 & 384.867 & $0,79 \%$ & $0,57 \%$ & $0,30 \%$ & $-0,49 \%$ & $-0,27 \%$ & $-0,22 \%$ \\
\hline $75 \%$ & 3 & 1000 & 748.307 & 759.173 & 758.219 & 753.352 & $1,45 \%$ & $1,32 \%$ & $0,67 \%$ & $-0,77 \%$ & $-0,64 \%$ & $-0,13 \%$ \\
\hline $75 \%$ & 3 & 1500 & 1.112 .842 & 1.132 .253 & 1.129 .510 & 1.121 .647 & $1,74 \%$ & $1,50 \%$ & $0,79 \%$ & $-0,94 \%$ & $-0,70 \%$ & $-0,24 \%$ \\
\hline $75 \%$ & 3 & 3000 & 2.194 .993 & 2.247 .542 & 2.231 .414 & 2.212 .555 & $2,39 \%$ & $1,66 \%$ & $0,80 \%$ & $-1,56 \%$ & $-0,85 \%$ & $-0,72 \%$ \\
\hline $75 \%$ & 3 & 5000 & & 3.713.131 & 3.685 .276 & 3.655.685 & & & & $-1,55 \%$ & $-0,80 \%$ & $-0,75 \%$ \\
\hline \multicolumn{3}{|c|}{ SUBTOTAL DÍGRAFO 3} & 4.681 .682 & 4.767 .638 & 4.746 .864 & 4.714 .417 & $1,84 \%$ & $1,39 \%$ & $0,70 \%$ & $-1,12 \%$ & $-0,68 \%$ & $-0,44 \%$ \\
\hline \multicolumn{3}{|c|}{ TOTAL } & 14.595 .746 & 14.924 .264 & 14.870 .876 & 14.748 .111 & $2,25 \%$ & $1,89 \%$ & $1,04 \%$ & $-1,18 \%$ & $-0,83 \%$ & $-0,36 \%$ \\
\hline
\end{tabular}


- Problemas balanceados e com dois reposicionamentos

Como apresentado na Tabela 4-16, ao contrário dos problemas balanceados e com um reposicionamento permissível, os resultados obtidos pela Heurística com busca local quando aplicados à solução inicial QS não ficaram melhores que os obtidos aplicando-se a heurística com busca local nas soluções fornecidas por GH e $\mathrm{CD}$, entretanto os resultados ficaram muito próximos.

Para este conjunto de problemas a HBL apresentou os melhores resultados quando aplicada sobre $\mathrm{GH}$, mas com a desvantagem de não ter solução para problemas com mais de 1500 rotas. 
Tabela 4-16: Comparação dos diferentes resultados obtidos pela Heurística com Busca Local (HBL) para problemas balanceados e com dois reposicionamentos

\begin{tabular}{|c|c|c|c|c|c|c|c|c|c|c|c|c|}
\hline \multirow[b]{2}{*}{ DESBAL. } & \multirow[b]{2}{*}{ GRAFO } & \multirow[b]{2}{*}{ ROTAS } & \multirow[b]{2}{*}{ PLI } & \multicolumn{3}{|c|}{ RESULTADOS HBL (\#) } & \multicolumn{3}{|c|}{ Diferenças PLI (\%) } & \multicolumn{3}{|c|}{ Diferenças HBL (\%) } \\
\hline & & & & $\mathrm{HBL}_{(\mathrm{GH})}$ & $\mathrm{HBL}_{(\mathrm{CD})}$ & $\mathrm{HBL}_{(\mathrm{QS})}$ & $\mathrm{HBL}_{(\mathrm{GH})} \times \mathrm{PLI}$ & $\mathrm{HBL}_{(\mathrm{CD})} \times \mathrm{PLI}$ & $\mathrm{HBL}_{(\mathrm{QS})} \times \mathrm{PLI}$ & $\mathrm{HBL}_{(\mathrm{QS})} \times \mathrm{HBL}_{(\mathrm{GH})}$ & $\mathrm{HBL}_{(\mathrm{QS})} \times \mathrm{HBL}_{(\mathrm{CD})}$ & $\mathrm{HBL}_{(\mathrm{CD})} \times \mathrm{HBL}_{(\mathrm{GH})}$ \\
\hline $0 \%$ & 1 & 100 & 51.358 & 51.668 & 51.631 & 51.658 & $0,60 \%$ & $0,53 \%$ & $0,58 \%$ & $-0,02 \%$ & $0,05 \%$ & $-0,07 \%$ \\
\hline $0 \%$ & 1 & 200 & 116.427 & 117.978 & 117.664 & 118.239 & $1,33 \%$ & $1,06 \%$ & $1,56 \%$ & $0,22 \%$ & $0,49 \%$ & $-0,27 \%$ \\
\hline $0 \%$ & 1 & 500 & 263.497 & 267.138 & 267.481 & 268.362 & $1,38 \%$ & $1,51 \%$ & $1,85 \%$ & $0,46 \%$ & $0,33 \%$ & $0,13 \%$ \\
\hline $0 \%$ & 1 & 1000 & & 520.737 & 521.453 & 522.875 & & & & $0,41 \%$ & $0,27 \%$ & $0,14 \%$ \\
\hline $0 \%$ & 1 & 1500 & & 784.359 & 783.696 & 785.174 & & & & $0,10 \%$ & $0,19 \%$ & $-0,08 \%$ \\
\hline $0 \%$ & 1 & 3000 & & & 1.550 .918 & 1.552 .275 & & & & & $0,09 \%$ & \\
\hline $0 \%$ & 1 & 5000 & & & 2.579.999 & 2.580 .302 & & & & & $0,01 \%$ & \\
\hline \multicolumn{3}{|c|}{ SUBTOTAL DÍGRAFO 1} & 431.282 & 436.785 & 436.777 & 438.259 & $1,28 \%$ & $1,27 \%$ & $1,62 \%$ & $0,34 \%$ & $0,34 \%$ & $0,00 \%$ \\
\hline $0 \%$ & 2 & 100 & 42.724 & 43.111 & 43.172 & 43.173 & $0,90 \%$ & $1,05 \%$ & $1,05 \%$ & $0,14 \%$ & $0,00 \%$ & $0,14 \%$ \\
\hline $0 \%$ & 2 & 200 & 102.518 & 104.095 & 103.762 & 103.726 & $1,54 \%$ & $1,21 \%$ & $1,18 \%$ & $-0,35 \%$ & $-0,03 \%$ & $-0,32 \%$ \\
\hline $0 \%$ & 2 & 500 & 154.740 & 156.015 & 155.695 & 155.519 & $0,82 \%$ & $0,62 \%$ & $0,50 \%$ & $-0,32 \%$ & $-0,11 \%$ & $-0,21 \%$ \\
\hline $0 \%$ & 2 & 1000 & & 495.954 & 496.259 & 496.168 & & & & $0,04 \%$ & $-0,02 \%$ & $0,06 \%$ \\
\hline $0 \%$ & 2 & 1500 & & 739.603 & 740.232 & 740.327 & & & & $0,10 \%$ & $0,01 \%$ & $0,09 \%$ \\
\hline $0 \%$ & 2 & 3000 & & & 1.483 .198 & 1.483.101 & & & & & $-0,01 \%$ & \\
\hline $0 \%$ & 2 & 5000 & & & 2.472.539 & 2.472 .666 & & & & & $0,01 \%$ & \\
\hline \multicolumn{3}{|c|}{ SUBTOTAL DÍGRAFO 2} & 299.982 & 303.221 & 302.629 & 302.418 & $1,08 \%$ & $0,88 \%$ & $0,81 \%$ & $-0,26 \%$ & $-0,07 \%$ & $-0,20 \%$ \\
\hline $0 \%$ & 3 & 100 & 50.455 & 50.524 & 50.521 & 50.580 & $0,14 \%$ & $0,13 \%$ & $0,25 \%$ & $0,11 \%$ & $0,12 \%$ & $-0,01 \%$ \\
\hline $0 \%$ & 3 & 200 & 96.891 & 96.994 & 96.975 & 97.014 & $0,11 \%$ & $0,09 \%$ & $0,13 \%$ & $0,02 \%$ & $0,04 \%$ & $-0,02 \%$ \\
\hline $0 \%$ & 3 & 500 & 226.113 & 226.438 & 226.505 & 226.511 & $0,14 \%$ & $0,17 \%$ & $0,18 \%$ & $0,03 \%$ & $0,00 \%$ & $0,03 \%$ \\
\hline $0 \%$ & 3 & 1000 & & 443.810 & 444.149 & 444.138 & & & & $0,07 \%$ & $0,00 \%$ & $0,08 \%$ \\
\hline $0 \%$ & 3 & 1500 & & 489.797 & 490.166 & 490.237 & & & & $0,09 \%$ & $0,01 \%$ & $0,08 \%$ \\
\hline $0 \%$ & 3 & 3000 & & & 1.350 .496 & 1.348 .708 & & & & & $-0,13 \%$ & \\
\hline $0 \%$ & 3 & 5000 & & & 2.239 .641 & 2.235.166 & & & & & $-0,20 \%$ & \\
\hline \multicolumn{3}{|c|}{ SUBTOTAL DÍGRAFO 3} & 373.459 & 373.956 & 374.002 & 374.106 & $0,13 \%$ & $0,15 \%$ & $0,17 \%$ & $0,04 \%$ & $0,03 \%$ & $0,01 \%$ \\
\hline \multicolumn{3}{|c|}{ TOTAL } & 1.104 .724 & 1.113 .961 & 1.113 .407 & 1.114 .782 & $0,84 \%$ & $0,79 \%$ & $0,91 \%$ & $0,07 \%$ & $0,12 \%$ & $-0,05 \%$ \\
\hline
\end{tabular}


- Problemas desbalanceados e com dois reposicionamentos

Para problemas desbalanceados e com dois reposicionamentos é possível observar que os resultados da HBL ficaram muito próximos, sendo que da mesma forma que para problemas balanceados e com um reposicionamento, $\mathrm{HBL}_{(\mathrm{GH})}$ possui a desvantagem de não apresentar resultados para problemas com mais de 1500 rotas, como apresentado na Tabela 4-17, Tabela 4-18 e Tabela 4-19. 
Tabela 4-17: Comparação dos diferentes resultados obtidos pela Heurística com Busca Local (HBL) para problemas desbalanceados (25\%) e com dois reposicionamentos

\begin{tabular}{|c|c|c|c|c|c|c|c|c|c|c|c|c|}
\hline \multirow[b]{2}{*}{ DESBAL. } & \multirow[b]{2}{*}{ GRAFO } & \multirow[b]{2}{*}{ ROTAS } & \multirow[b]{2}{*}{ PLI } & \multicolumn{3}{|c|}{ RESULTADOS HBL (\#) } & \multicolumn{3}{|c|}{ Diferenças PLI (\%) } & \multicolumn{3}{|c|}{ Diferenças HBL (\%) } \\
\hline & & & & $\mathrm{HBL}_{(\mathrm{GH})}$ & $\mathrm{HBL}_{(\mathrm{CD})}$ & $\mathrm{HBL}_{(\mathrm{QS})}$ & $\mathrm{HBL}_{(\mathrm{GH})} \times \mathrm{PLI}$ & $\mathrm{HBL}_{(\mathrm{CD})} \times \mathrm{PLI}$ & $\mathrm{HBL}_{(\mathrm{QS})} \times \mathrm{PLI}$ & $\mathrm{HBL}_{(\mathrm{QS})} \times \mathrm{HBL}_{(\mathrm{GH})}$ & $\mathrm{HBL}_{(\mathrm{QS})} \times \mathrm{HBL}_{(\mathrm{CD})}$ & $\mathrm{HBL}_{(\mathrm{CD})} \mathrm{xHBL_{(GH) }}$ \\
\hline $25 \%$ & 1 & 100 & 63.640 & 63.952 & 63.931 & 64.293 & $0,49 \%$ & $0,46 \%$ & $1,03 \%$ & $0,53 \%$ & $0,57 \%$ & $-0,03 \%$ \\
\hline $25 \%$ & 1 & 200 & 116.314 & 117.777 & 117.773 & 117.983 & $1,26 \%$ & $1,25 \%$ & $1,43 \%$ & $0,17 \%$ & $0,18 \%$ & $0,00 \%$ \\
\hline $25 \%$ & 1 & 500 & 276.697 & 279.506 & 279.261 & 279.700 & $1,02 \%$ & $0,93 \%$ & $1,09 \%$ & $0,07 \%$ & $0,16 \%$ & $-0,09 \%$ \\
\hline $25 \%$ & 1 & 1000 & & 543.338 & 543.602 & 543.533 & & & & $0,04 \%$ & $-0,01 \%$ & $0,05 \%$ \\
\hline $25 \%$ & 1 & 1500 & & 816.798 & 817.791 & 817.614 & & & & $0,10 \%$ & $-0,02 \%$ & $0,12 \%$ \\
\hline $25 \%$ & 1 & 3000 & & & 1.632 .875 & 1.632 .514 & & & & & $-0,02 \%$ & \\
\hline $25 \%$ & 1 & 5000 & & & 2.735 .715 & 2.735 .004 & & & & & $-0,03 \%$ & \\
\hline \multicolumn{3}{|c|}{ SUBTOTAL DÍGRAFO 1} & 456.652 & 461.236 & 460.965 & 461.976 & $1,00 \%$ & $0,94 \%$ & $1,17 \%$ & $0,16 \%$ & $0,22 \%$ & $-0,06 \%$ \\
\hline $25 \%$ & 2 & 100 & 55.759 & 56.014 & 56.176 & 56.065 & $0,46 \%$ & $0,75 \%$ & $0,55 \%$ & $0,09 \%$ & $-0,20 \%$ & $0,29 \%$ \\
\hline $25 \%$ & 2 & 200 & 106.333 & 106.942 & 107.064 & 107.144 & $0,57 \%$ & $0,69 \%$ & $0,76 \%$ & $0,19 \%$ & $0,08 \%$ & $0,11 \%$ \\
\hline $25 \%$ & 2 & 500 & 260.945 & 261.564 & 261.652 & 261.755 & $0,24 \%$ & $0,27 \%$ & $0,31 \%$ & $0,07 \%$ & $0,04 \%$ & $0,03 \%$ \\
\hline $25 \%$ & 2 & 1000 & & 530.304 & 530.564 & 530.550 & & & & $0,05 \%$ & $0,00 \%$ & $0,05 \%$ \\
\hline $25 \%$ & 2 & 1500 & & 795.208 & 795.557 & 795.521 & & & & $0,04 \%$ & $0,00 \%$ & $0,04 \%$ \\
\hline $25 \%$ & 2 & 3000 & & & 1.596 .425 & 1.596 .315 & & & & & $-0,01 \%$ & \\
\hline $25 \%$ & 2 & 5000 & & & 2.655 .682 & 2.655.041 & & & & & $-0,02 \%$ & \\
\hline \multicolumn{3}{|c|}{ SUBTOTAL DÍGRAFO 2} & 423.037 & 424.520 & 424.892 & 424.964 & $0,35 \%$ & $0,44 \%$ & $0,46 \%$ & $0,10 \%$ & $0,02 \%$ & $0,09 \%$ \\
\hline $25 \%$ & 3 & 100 & 40.338 & 40.404 & 40.371 & 40.425 & $0,17 \%$ & $0,08 \%$ & $0,22 \%$ & $0,05 \%$ & $0,13 \%$ & $-0,08 \%$ \\
\hline $25 \%$ & 3 & 200 & 95.685 & 95.878 & 95.778 & 95.933 & $0,20 \%$ & $0,10 \%$ & $0,26 \%$ & $0,06 \%$ & $0,16 \%$ & $-0,10 \%$ \\
\hline $25 \%$ & 3 & 500 & 238.806 & 239.061 & 239.116 & 239.085 & $0,11 \%$ & $0,13 \%$ & $0,12 \%$ & $0,01 \%$ & $-0,01 \%$ & $0,02 \%$ \\
\hline $25 \%$ & 3 & 1000 & & 484.788 & 484.954 & 484.948 & & & & $0,03 \%$ & $0,00 \%$ & $0,03 \%$ \\
\hline $25 \%$ & 3 & 1500 & & 727.870 & 728.150 & 728.084 & & & & $0,03 \%$ & $-0,01 \%$ & $0,04 \%$ \\
\hline $25 \%$ & 3 & 3000 & & & 1.478 .720 & 1.478 .641 & & & & & $-0,01 \%$ & \\
\hline $25 \%$ & 3 & 5000 & & & 2.472 .392 & 2.471.179 & & & & & $-0,05 \%$ & \\
\hline \multicolumn{3}{|c|}{ SUBTOTAL DÍGRAFO 3} & 374.829 & 375.344 & 375.266 & 375.443 & $0,14 \%$ & $0,12 \%$ & $0,16 \%$ & $0,03 \%$ & $0,05 \%$ & $-0,02 \%$ \\
\hline \multicolumn{3}{|c|}{ TOTAL } & 1.254 .518 & 1.261 .100 & 1.261 .122 & 1.262 .383 & $0,52 \%$ & $0,53 \%$ & $0,63 \%$ & $0,10 \%$ & $0,10 \%$ & $0,00 \%$ \\
\hline
\end{tabular}


Tabela 4-18: Comparação dos diferentes resultados obtidos pela Heurística com Busca Local (HBL) para problemas desbalanceados (50\%) e com dois reposicionamentos

\begin{tabular}{|c|c|c|c|c|c|c|c|c|c|c|c|c|}
\hline \multirow[b]{2}{*}{ DESBAL. } & \multirow[b]{2}{*}{ GRAFO } & \multirow[b]{2}{*}{ ROTAS } & \multirow[b]{2}{*}{ PLI } & \multicolumn{3}{|c|}{ RESULTADOS HBL (\#) } & \multicolumn{3}{|c|}{ Diferenças PLI (\%) } & \multicolumn{3}{|c|}{ Diferenças HBL (\%) } \\
\hline & & & & $\mathrm{HBL}_{(\mathrm{GH})}$ & $\mathrm{HBL}_{(\mathrm{CD})}$ & $\mathrm{HBL}_{(\mathrm{QS})}$ & $\mathrm{HBL}_{(\mathrm{GH})} \times \mathrm{PLI}$ & $\mathrm{HBL}_{(\mathrm{CD})} \times \mathrm{PLI}$ & $\mathrm{HBL}_{(\mathrm{QS})} \times \mathrm{PLI}$ & $\mathrm{HBL}_{(\mathrm{QS})} \times \mathrm{HBL}_{(\mathrm{GH})}$ & $\mathrm{HBL}_{(\mathrm{QS})} \times \mathrm{HBL}_{(\mathrm{CD})}$ & $\mathrm{HBL}_{(\mathrm{CD})} \mathrm{xHBL_{(GH) }}$ \\
\hline $50 \%$ & 1 & 100 & 51.440 & 51.713 & 51.669 & 52.048 & $0,53 \%$ & $0,44 \%$ & $1,18 \%$ & $0,65 \%$ & $0,73 \%$ & $-0,08 \%$ \\
\hline $50 \%$ & 1 & 200 & 122.417 & 123.576 & 123.538 & 123.532 & $0,95 \%$ & $0,92 \%$ & $0,91 \%$ & $-0,04 \%$ & $0,00 \%$ & $-0,03 \%$ \\
\hline $50 \%$ & 1 & 500 & 296.335 & 297.578 & 298.005 & 297.635 & $0,42 \%$ & $0,56 \%$ & $0,44 \%$ & $0,02 \%$ & $-0,12 \%$ & $0,14 \%$ \\
\hline $50 \%$ & 1 & 1000 & & 592.500 & 592.597 & 592.476 & & & & $0,00 \%$ & $-0,02 \%$ & $0,02 \%$ \\
\hline $50 \%$ & 1 & 1500 & & 885.892 & 885.937 & 885.941 & & & & $0,01 \%$ & $0,00 \%$ & $0,01 \%$ \\
\hline $50 \%$ & 1 & 3000 & & & 1.788 .619 & 1.788 .434 & & & & & $-0,01 \%$ & \\
\hline $50 \%$ & 1 & 5000 & & & 2.985 .431 & 2.984.834 & & & & & $-0,02 \%$ & \\
\hline \multicolumn{3}{|c|}{ SUBTOTAL DÍGRAFO 1} & 470.192 & 472.867 & 473.212 & 473.214 & $0,57 \%$ & $0,64 \%$ & $0,64 \%$ & $0,07 \%$ & $0,00 \%$ & $0,07 \%$ \\
\hline $50 \%$ & 2 & 100 & 48.837 & 49.153 & 49.008 & 49.255 & $0,65 \%$ & $0,35 \%$ & $0,85 \%$ & $0,21 \%$ & $0,50 \%$ & $-0,30 \%$ \\
\hline $50 \%$ & 2 & 200 & 119.264 & 119.763 & 119.668 & 119.854 & $0,42 \%$ & $0,34 \%$ & $0,50 \%$ & $0,08 \%$ & $0,16 \%$ & $-0,08 \%$ \\
\hline $50 \%$ & 2 & 500 & 296.213 & 296.576 & 296.617 & 296.577 & $0,12 \%$ & $0,14 \%$ & $0,12 \%$ & $0,00 \%$ & $-0,01 \%$ & $0,01 \%$ \\
\hline $50 \%$ & 2 & 1000 & & 585.393 & 585.494 & 585.361 & & & & $-0,01 \%$ & $-0,02 \%$ & $0,02 \%$ \\
\hline $50 \%$ & 2 & 1500 & & 881.179 & 881.234 & 881.240 & & & & $0,01 \%$ & $0,00 \%$ & $0,01 \%$ \\
\hline $50 \%$ & 2 & 3000 & & & 1.778 .970 & 1.778 .864 & & & & & $-0,01 \%$ & \\
\hline $50 \%$ & 2 & 5000 & & & 2.964 .937 & 2.964 .625 & & & & & $-0,01 \%$ & \\
\hline \multicolumn{3}{|c|}{ SUBTOTAL DÍGRAFO 2} & 464.314 & 465.493 & 465.293 & 465.686 & $0,25 \%$ & $0,21 \%$ & $0,30 \%$ & $0,04 \%$ & $0,08 \%$ & $-0,04 \%$ \\
\hline $50 \%$ & 3 & 100 & 55.296 & 55.317 & 55.321 & 55.316 & $0,04 \%$ & $0,04 \%$ & $0,04 \%$ & $0,00 \%$ & $-0,01 \%$ & $0,01 \%$ \\
\hline $50 \%$ & 3 & 200 & 108.692 & 108.750 & 108.763 & 108.756 & $0,05 \%$ & $0,07 \%$ & $0,06 \%$ & $0,01 \%$ & $-0,01 \%$ & $0,01 \%$ \\
\hline $50 \%$ & 3 & 500 & 198.233 & 198.328 & 198.356 & 198.342 & $0,05 \%$ & $0,06 \%$ & $0,06 \%$ & $0,01 \%$ & $-0,01 \%$ & $0,01 \%$ \\
\hline $50 \%$ & 3 & 1000 & & 408.544 & 408.601 & 408.567 & & & & $0,01 \%$ & $-0,01 \%$ & $0,01 \%$ \\
\hline $50 \%$ & 3 & 1500 & & 865.808 & 865.874 & 865.823 & & & & $0,00 \%$ & $-0,01 \%$ & $0,01 \%$ \\
\hline $50 \%$ & 3 & 3000 & & & 1.743 .909 & 1.743 .802 & & & & & $-0,01 \%$ & \\
\hline $50 \%$ & 3 & 5000 & & & 2.884 .394 & 2.883 .786 & & & & & $-0,02 \%$ & \\
\hline \multicolumn{3}{|c|}{ SUBTOTAL DÍGRAFO 3} & 362.221 & 362.394 & 362.440 & 362.415 & $0,05 \%$ & $0,06 \%$ & $0,05 \%$ & $0,01 \%$ & $-0,01 \%$ & $0,01 \%$ \\
\hline \multicolumn{3}{|c|}{ TOTAL } & 1.296 .727 & 1.300 .753 & 1.300 .945 & 1.301 .315 & $0,31 \%$ & $0,33 \%$ & $0,35 \%$ & $0,04 \%$ & $0,03 \%$ & $0,01 \%$ \\
\hline
\end{tabular}


Tabela 4-19: Comparação dos diferentes resultados obtidos pela Heurística com Busca Local (HBL) para problemas desbalanceados (75\%) e com dois reposicionamentos

\begin{tabular}{|c|c|c|c|c|c|c|c|c|c|c|c|c|}
\hline \multirow[b]{2}{*}{ DESBAL. } & \multirow[b]{2}{*}{ DÍGRAFO } & \multirow[b]{2}{*}{ ROTAS } & \multirow[b]{2}{*}{ PLI } & \multicolumn{3}{|c|}{ RESULTADOS HBL (\#) } & \multicolumn{3}{|c|}{ Diferenças PLI (\%) } & \multicolumn{3}{|c|}{ Diferenças HBL (\%) } \\
\hline & & & & $\mathrm{HBL}_{(\mathrm{GH})}$ & $\mathrm{HBL}_{(\mathrm{CD})}$ & $\mathrm{HBL}_{(\mathrm{QS})}$ & $\mathrm{HBL}_{(\mathrm{GH})} \times \mathrm{PLI}$ & $\mathrm{HBL}_{(\mathrm{CD})} \times \mathrm{PLI}$ & $\mathrm{HBL}_{(\mathrm{QS})} \times \mathrm{PLI}$ & $\mathrm{HBL}_{(\mathrm{QS})} \times \mathrm{HBL}_{(\mathrm{GH})}$ & $\mathrm{HBL}_{(\mathrm{QS})} \times \mathrm{HBL}_{(\mathrm{CD})}$ & $\mathrm{HBL}_{(\mathrm{CD})} \times \mathrm{HBL}_{(\mathrm{GH})}$ \\
\hline $75 \%$ & 1 & 100 & 67.165 & 67.506 & 67.528 & 67.475 & $0,51 \%$ & $0,54 \%$ & $0,46 \%$ & $-0,04 \%$ & $-0,08 \%$ & $0,03 \%$ \\
\hline $75 \%$ & 1 & 200 & 132.924 & 133.641 & 133.565 & 133.595 & $0,54 \%$ & $0,48 \%$ & $0,50 \%$ & $-0,03 \%$ & $0,02 \%$ & $-0,06 \%$ \\
\hline $75 \%$ & 1 & 500 & 197.557 & 198.317 & 198.403 & 198.251 & $0,38 \%$ & $0,43 \%$ & $0,35 \%$ & $-0,03 \%$ & $-0,08 \%$ & $0,04 \%$ \\
\hline $75 \%$ & 1 & 1000 & & 660.639 & 660.673 & 660.416 & & & & $-0,03 \%$ & $-0,04 \%$ & $0,01 \%$ \\
\hline $75 \%$ & 1 & 1500 & & 1.004 .077 & 1.004 .007 & 1.004 .001 & & & & $-0,01 \%$ & $0,00 \%$ & $-0,01 \%$ \\
\hline $75 \%$ & 1 & 3000 & & & 1.998 .069 & 1.997 .924 & & & & & $-0,01 \%$ & \\
\hline $75 \%$ & 1 & 5000 & & & 3.354 .094 & 3.353.615 & & & & & $-0,01 \%$ & \\
\hline \multicolumn{3}{|c|}{ SUBTOTAL DÍGRAFO 1} & 397.646 & 399.464 & 399.495 & 399.322 & $0,46 \%$ & $0,46 \%$ & $0,42 \%$ & $-0,04 \%$ & $-0,04 \%$ & $0,01 \%$ \\
\hline $75 \%$ & 2 & 100 & 67.371 & 67.404 & 67.480 & 67.478 & $0,05 \%$ & $0,16 \%$ & $0,16 \%$ & $0,11 \%$ & $0,00 \%$ & $0,11 \%$ \\
\hline $75 \%$ & 2 & 200 & 138.818 & 138.891 & 139.101 & 138.917 & $0,05 \%$ & $0,20 \%$ & $0,07 \%$ & $0,02 \%$ & $-0,13 \%$ & $0,15 \%$ \\
\hline $75 \%$ & 2 & 500 & 285.165 & 285.287 & 285.308 & 285.303 & $0,04 \%$ & $0,05 \%$ & $0,05 \%$ & $0,01 \%$ & $0,00 \%$ & $0,01 \%$ \\
\hline $75 \%$ & 2 & 1000 & & 686.151 & 686.109 & 686.024 & & & & $-0,02 \%$ & $-0,01 \%$ & $-0,01 \%$ \\
\hline $75 \%$ & 2 & 1500 & & 1.036 .431 & 1.036 .302 & 1.036 .179 & & & & $-0,02 \%$ & $-0,01 \%$ & $-0,01 \%$ \\
\hline $75 \%$ & 2 & 3000 & & & 2.074 .632 & 2.074 .465 & & & & & $-0,01 \%$ & \\
\hline $75 \%$ & 2 & 5000 & & & 3.453 .160 & 3.452.970 & & & & & $-0,01 \%$ & \\
\hline \multicolumn{3}{|c|}{ SUBTOTAL DÍGRAFO 2} & 491.354 & 491.582 & 491.889 & 491.698 & $0,05 \%$ & $0,11 \%$ & $0,07 \%$ & $0,02 \%$ & $-0,04 \%$ & $0,06 \%$ \\
\hline $75 \%$ & 3 & 100 & 66.944 & 66.957 & 66.954 & 66.951 & $0,02 \%$ & $0,02 \%$ & $0,01 \%$ & $-0,01 \%$ & $0,00 \%$ & $0,00 \%$ \\
\hline $75 \%$ & 3 & 200 & 134.478 & 134.510 & 134.519 & 134.495 & $0,02 \%$ & $0,03 \%$ & $0,01 \%$ & $-0,01 \%$ & $-0,02 \%$ & $0,01 \%$ \\
\hline $75 \%$ & 3 & 500 & 295.741 & 295.777 & 295.786 & 295.774 & $0,01 \%$ & $0,01 \%$ & $0,01 \%$ & $0,00 \%$ & $0,00 \%$ & $0,00 \%$ \\
\hline $75 \%$ & 3 & 1000 & & 695.188 & 695.191 & 695.169 & & & & $0,00 \%$ & $0,00 \%$ & $0,00 \%$ \\
\hline $75 \%$ & 3 & 1500 & & 1.044 .674 & 1.044 .639 & 1.044 .601 & & & & $-0,01 \%$ & $0,00 \%$ & $0,00 \%$ \\
\hline $75 \%$ & 3 & 3000 & & & 2.087 .898 & 2.087.717 & & & & & $-0,01 \%$ & \\
\hline $75 \%$ & 3 & 5000 & & & 3.455 .323 & 3.454.885 & & & & & $-0,01 \%$ & \\
\hline \multicolumn{3}{|c|}{ SUBTOTAL DÍGRAFO 3} & 497.164 & 497.244 & 497.259 & 497.221 & $0,02 \%$ & $0,02 \%$ & $0,01 \%$ & $0,00 \%$ & $-0,01 \%$ & $0,00 \%$ \\
\hline \multicolumn{3}{|c|}{ TOTAL } & 1.386 .163 & 1.388 .291 & 1.388 .643 & 1.388 .240 & $0,15 \%$ & $0,18 \%$ & $0,15 \%$ & $0,00 \%$ & $-0,03 \%$ & $0,03 \%$ \\
\hline
\end{tabular}




\subsubsection{Análise dos tempos de execução}

Neste capítulo são apresentados os tempos de execução para obtenção dos dados obtidos pela HBL utilizando as diferentes soluções iniciais.

Os resultados obtidos por PLI e GH exigem que seja executado o gerador de ciclos viáveis, tendo então o incremento deste tempo em seus resultados.

Da mesma forma, os resultados obtidos por HBL exigem que sejam executadas as heurísticas $\mathrm{GH}, \mathrm{CD}$ e QS, sendo então adicionado o tempo de execução destas heurísticas ao tempo de execução da HBL conforme a solução inicial utilizada.

- Problemas balanceados e com um reposicionamento

A Tabela 4-20 mostra o tempo de processamento em segundos para a execução das instâncias balanceadas e com um reposicionamento. Devido a limites computacionais não foi possível executar o modelo PLI para instâncias com mais de 3000 rotas.

Observa-se que para pequenas instâncias obtemos o melhor tempo através da PLI. Entretanto, conforme partimos para instância de maior porte, PLI passa a ter maiores tempos de execução e não resolve problemas com mais de 3000 rotas. Em seguida encontramos os maiores tempos para $\mathrm{HBL}_{(\mathrm{GH})}$. Os tempos de execução para $\mathrm{HBL}_{(\mathrm{CD})}$ e $\mathrm{HBL}_{(\mathrm{QS})}$ apresentam as mesmas ordens de grandeza. 
Tabela 4-20: Comparação dos tempos de execução para problemas balanceados e com um reposicionamento

TEMPOS DE EXECUÇÃO (s)

TEMPOS DE EXECUÇÃO HBL (s)

\begin{tabular}{|c|c|c|c|c|c|c|c|c|c|}
\hline \multirow{2}{*}{\multicolumn{2}{|c|}{ DESBAL. DÍGRAFO }} & \multirow[b]{2}{*}{ ROTAS } & & \\
\hline & & & PLI & GH & CD & QS & $\mathrm{HBL}_{(\mathrm{GH})}$ & $\mathrm{HBL}_{(\mathrm{CD})}$ & $\mathrm{HBL}_{(\mathrm{QS})}$ \\
\hline $0 \%$ & 1 & 100 & 0,01 & 0,01 & 0,02 & 0,01 & 0,06 & 0,08 & 0,05 \\
\hline $0 \%$ & 1 & 200 & 0,01 & 0,01 & 0,09 & 0,01 & 0,19 & 0,27 & 0,15 \\
\hline $0 \%$ & 1 & 500 & 0,04 & 0,03 & 1,60 & 0,01 & 1,20 & 3,14 & 1,75 \\
\hline $0 \%$ & 1 & 1000 & 0,33 & 0,29 & 4,41 & 0,01 & 4,98 & 10,55 & 6,56 \\
\hline $0 \%$ & 1 & 1500 & 7,18 & 1,44 & 7,79 & 0,01 & 11,46 & 20,37 & 13,44 \\
\hline $0 \%$ & 1 & 3000 & $2.940,27$ & 36,72 & 19,34 & 0,01 & 67,93 & 44,67 & 34,26 \\
\hline $0 \%$ & 1 & 5000 & & 453,55 & 39,74 & 0,01 & 521,71 & 86,98 & 68,00 \\
\hline $0 \%$ & 2 & 100 & 0,01 & 0,01 & 0,10 & 0,01 & 0,07 & 0,16 & 0,06 \\
\hline $0 \%$ & 2 & 200 & 0,01 & 0,01 & 0,50 & 0,01 & 0,15 & 0,68 & 0,20 \\
\hline $0 \%$ & 2 & 500 & 0,04 & 0,03 & 1,83 & 0,01 & 1,54 & 3,67 & 2,03 \\
\hline $0 \%$ & 2 & 1000 & 0,35 & 0,29 & 4,99 & 0,01 & 5,33 & 10,62 & 6,38 \\
\hline $0 \%$ & 2 & 1500 & 6,51 & 1,39 & 8,48 & 0,01 & 11,69 & 20,45 & 13,18 \\
\hline $0 \%$ & 2 & 3000 & $2.799,47$ & 36,22 & 21,94 & 0,01 & 68,40 & 53,67 & 37,35 \\
\hline $0 \%$ & 2 & 5000 & & 444,00 & 45,28 & 0,01 & 518,58 & 92,70 & 67,35 \\
\hline $0 \%$ & 3 & 100 & 0,01 & 0,01 & 0,05 & 0,01 & 0,07 & 0,11 & 0,05 \\
\hline $0 \%$ & 3 & 200 & 0,02 & 0,02 & 0,13 & 0,01 & 0,17 & 0,29 & 0,17 \\
\hline $0 \%$ & 3 & 500 & 0,03 & 0,03 & 2,81 & 0,01 & 1,48 & 4,53 & 1,41 \\
\hline $0 \%$ & 3 & 1000 & 0,35 & 0,30 & 7,20 & 0,01 & 5,56 & 13,36 & 7,14 \\
\hline $0 \%$ & 3 & 1500 & 7,53 & 1,39 & 12,71 & 0,01 & 13,32 & 23,16 & 12,40 \\
\hline $0 \%$ & 3 & 3000 & $2.142,15$ & 28,60 & 26,81 & 0,01 & 54,36 & 43,64 & 25,28 \\
\hline $0 \%$ & 3 & 5000 & & 444,51 & 72,17 & 0,01 & 507,25 & 106,63 & 53,55 \\
\hline
\end{tabular}




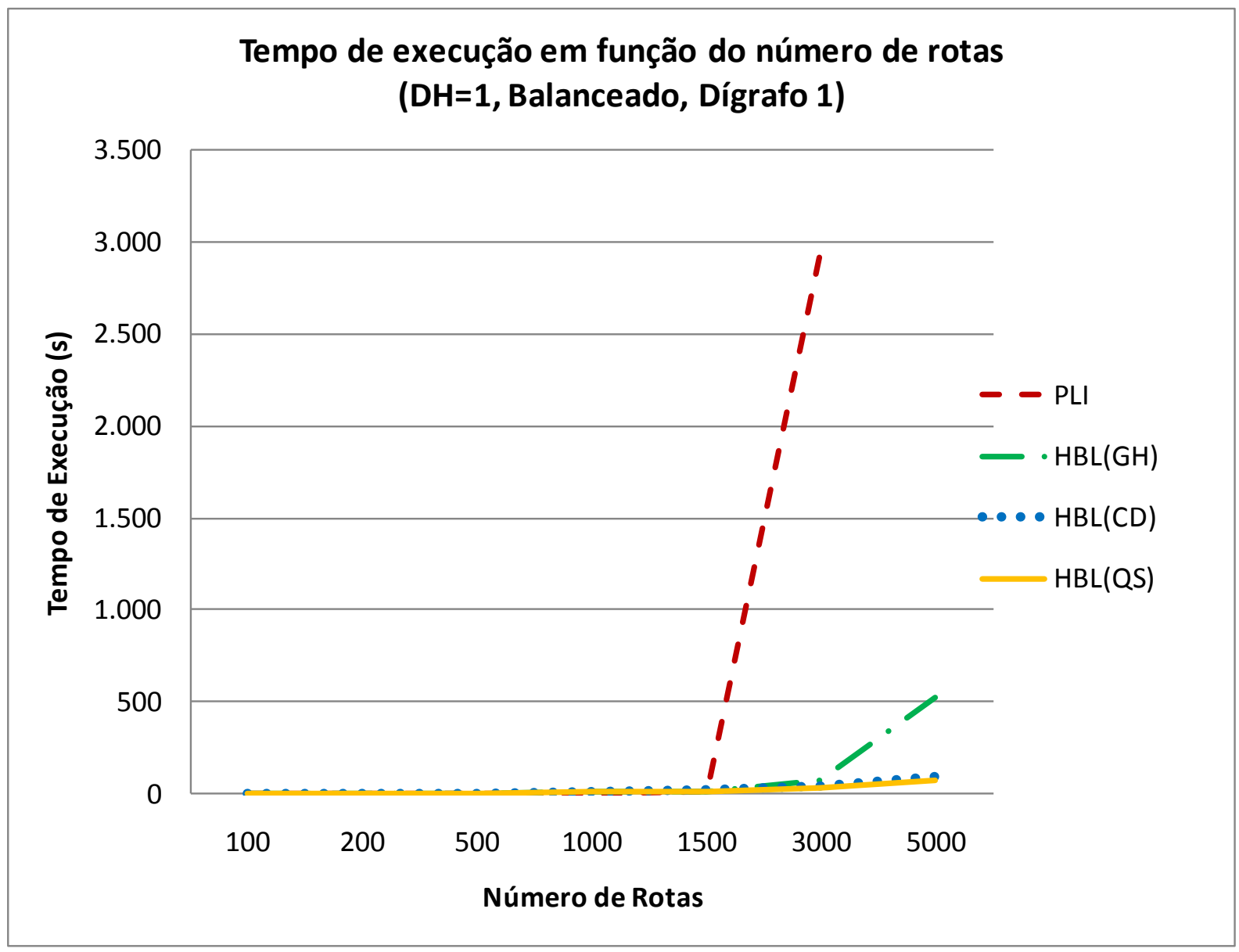

Figura 4-7: Gráfico dos tempos de execução para problemas balanceados e com um reposicionamento (Dígrafo 1)

- Problemas desbalanceados e com um reposicionamento

A Tabela 4-21, Tabela 4-22 e Tabela 4-23 mostram 0 tempo de processamento em segundos para a execução das instâncias desbalanceadas (25\%, 50\% e $75 \%$ respectivamente) e com um reposicionamento permissível.

Da mesma forma que para problemas balanceados, não foi possível encontrar soluções por PLI para problemas com mais de 3000 rotas.

Observa-se que para as maiores instância, à medida que aumentamos o desbalanceamento das instâncias, $\mathrm{HBL}_{(\mathrm{CD})}$ passa a ter maiores tempos de processamento que $\mathrm{HBL}_{(\mathrm{GH})}$, sendo que $\mathrm{HBL}_{(\mathrm{QS})}$ apresenta o melhor tempo de processamento para as instâncias de grande porte (5.000 rotas). 
Tabela 4-21: Comparação dos tempos de execução para problemas desbalanceados (25\%) e com um reposicionamento

TEMPOS DE EXECUÇÃO (s) TEMPOS DE EXECUÇÃO HBL (s)

\begin{tabular}{|c|c|c|c|c|c|c|c|c|c|}
\hline \multirow[b]{2}{*}{ DESBAL. } & \multirow[b]{2}{*}{ DÍGRAFO } & \multirow[b]{2}{*}{ ROTAS } & & \\
\hline & & & PLI & GH & $C D$ & QS & $\mathrm{HBL}_{(\mathrm{GH})}$ & $\mathrm{HBL}_{(\mathrm{CD})}$ & $\mathrm{HBL}_{(\mathrm{QS})}$ \\
\hline $25 \%$ & 1 & 100 & 0,01 & 0,01 & 0,02 & 0,01 & 0,05 & 0,06 & 0,05 \\
\hline $25 \%$ & 1 & 200 & 0,02 & 0,01 & 0,09 & 0,01 & 0,15 & 0,23 & 0,14 \\
\hline $25 \%$ & 1 & 500 & 0,03 & 0,03 & 1,78 & 0,01 & 1,05 & 3,18 & 1,32 \\
\hline $25 \%$ & 1 & 1000 & 0,28 & 0,26 & 5,51 & 0,01 & 4,55 & 9,34 & 4,78 \\
\hline $25 \%$ & 1 & 1500 & 3,39 & 1,18 & 10,65 & 0,01 & 7,24 & 19,91 & 10,00 \\
\hline $25 \%$ & 1 & 3000 & 824,83 & 28,91 & 30,55 & 0,01 & 55,72 & 52,46 & 28,03 \\
\hline $25 \%$ & 1 & 5000 & & 348,53 & 72,39 & 0,01 & 412,32 & 124,24 & 56,97 \\
\hline $25 \%$ & 2 & 100 & 0,01 & 0,01 & 0,09 & 0,01 & 0,05 & 0,13 & 0,05 \\
\hline $25 \%$ & 2 & 200 & 0,02 & 0,01 & 0,50 & 0,01 & 0,17 & 0,70 & 0,16 \\
\hline $25 \%$ & 2 & 500 & 0,03 & 0,03 & 2,16 & 0,01 & 0,87 & 3,28 & 1,21 \\
\hline $25 \%$ & 2 & 1000 & 0,23 & 0,24 & 6,67 & 0,01 & 3,79 & 11,36 & 4,04 \\
\hline $25 \%$ & 2 & 1500 & 2,99 & 1,15 & 12,32 & 0,01 & 7,88 & 20,80 & 9,61 \\
\hline $25 \%$ & 2 & 3000 & 732,15 & 28,14 & 36,38 & 0,01 & 51,05 & 58,18 & 29,38 \\
\hline $25 \%$ & 2 & 5000 & & 344,82 & 84,56 & 0,01 & 405,45 & 130,22 & 44,83 \\
\hline $25 \%$ & 3 & 100 & 0,01 & 0,01 & 0,06 & 0,01 & 0,08 & 0,12 & 0,06 \\
\hline $25 \%$ & 3 & 200 & 0,01 & 0,01 & 0,10 & 0,01 & 0,14 & 0,23 & 0,15 \\
\hline $25 \%$ & 3 & 500 & 0,03 & 0,03 & 3,25 & 0,01 & 1,41 & 4,47 & 1,36 \\
\hline $25 \%$ & 3 & 1000 & 0,25 & 0,26 & 9,96 & 0,01 & 5,43 & 14,52 & 4,75 \\
\hline $25 \%$ & 3 & 1500 & 3,49 & 1,20 & 18,60 & 0,01 & 7,87 & 27,04 & 8,61 \\
\hline $25 \%$ & 3 & 3000 & 942,57 & 24,40 & 44,08 & 0,01 & 42,08 & 63,10 & 21,23 \\
\hline $25 \%$ & 3 & 5000 & & 353,08 & 135,76 & 0,01 & 406,16 & 167,21 & 46,93 \\
\hline
\end{tabular}




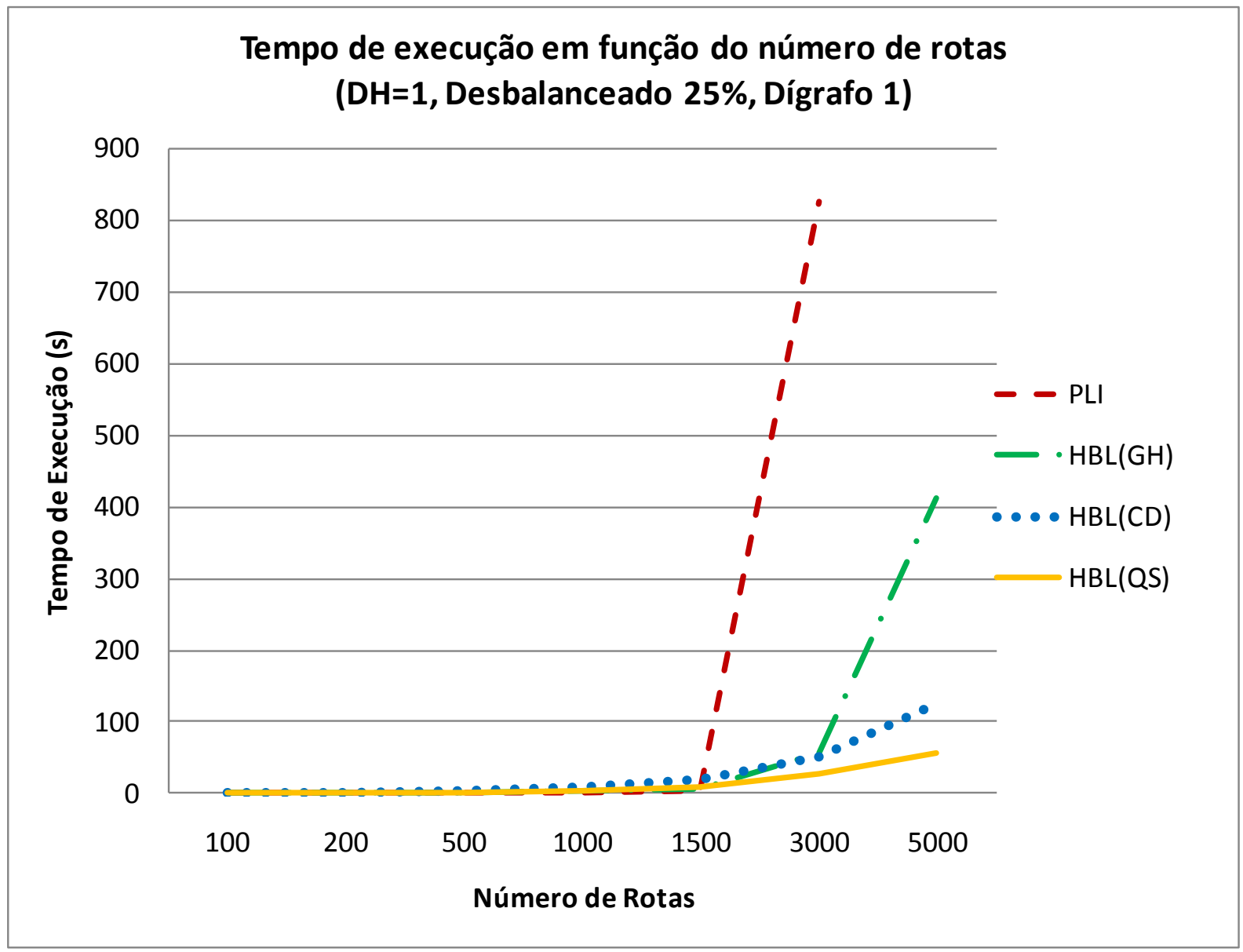

Figura 4-8: Gráfico dos tempos de execução para problemas desbalanceados (25\%) e com um reposicionamento (Dígrafo 1) 
Tabela 4-22: Comparação dos tempos de execução para problemas desbalanceados (50\%) e com um reposicionamento

TEMPOS DE EXECUÇÃO (s) TEMPOS DE EXECUÇÃO HBL (s)

\begin{tabular}{|c|c|c|c|c|c|c|c|c|c|}
\hline \multirow[b]{2}{*}{ DESBAL. } & \multirow[b]{2}{*}{ DÍGRAFO } & \multirow[b]{2}{*}{ ROTAS } & & \\
\hline & & & PLI & GH & $C D$ & QS & $\mathrm{HBL}_{(\mathrm{GH})}$ & $\mathrm{HBL}_{(\mathrm{CD})}$ & $\mathrm{HBL}_{(\mathrm{QS})}$ \\
\hline $50 \%$ & 1 & 100 & 0,02 & 0,01 & 0,02 & 0,01 & 0,05 & 0,07 & 0,05 \\
\hline $50 \%$ & 1 & 200 & 0,01 & 0,01 & 0,09 & 0,01 & 0,16 & 0,25 & 0,15 \\
\hline $50 \%$ & 1 & 500 & 0,03 & 0,03 & 2,16 & 0,01 & 0,58 & 2,98 & 0,90 \\
\hline $50 \%$ & 1 & 1000 & 0,17 & 0,18 & 7,58 & 0,01 & 1,90 & 9,95 & 3,22 \\
\hline $50 \%$ & 1 & 1500 & 1,09 & 0,76 & 15,61 & 0,01 & 5,14 & 19,81 & 6,09 \\
\hline $50 \%$ & 1 & 3000 & 123,55 & 15,91 & 55,15 & 0,01 & 31,79 & 68,21 & 19,42 \\
\hline $50 \%$ & 1 & 5000 & & 191,03 & 141,58 & 0,01 & 236,10 & 177,41 & 46,38 \\
\hline $50 \%$ & 2 & 100 & 0,01 & 0,02 & 0,12 & 0,01 & 0,07 & 0,18 & 0,05 \\
\hline $50 \%$ & 2 & 200 & 0,02 & 0,02 & 0,53 & 0,01 & 0,16 & 0,68 & 0,16 \\
\hline $50 \%$ & 2 & 500 & 0,03 & 0,03 & 2,53 & 0,01 & 0,68 & 3,36 & 0,89 \\
\hline $50 \%$ & 2 & 1000 & 0,18 & 0,19 & 8,90 & 0,01 & 2,53 & 11,21 & 2,93 \\
\hline $50 \%$ & 2 & 1500 & 0,92 & 0,76 & 18,49 & 0,01 & 5,29 & 23,52 & 5,25 \\
\hline $50 \%$ & 2 & 3000 & 108,58 & 15,40 & 66,36 & 0,01 & 32,40 & 81,32 & 18,91 \\
\hline $50 \%$ & 2 & 5000 & & 185,84 & 170,52 & 0,01 & 231,70 & 211,62 & 45,77 \\
\hline $50 \%$ & 3 & 100 & 0,01 & 0,01 & 0,04 & 0,01 & 0,05 & 0,09 & 0,05 \\
\hline $50 \%$ & 3 & 200 & 0,01 & 0,01 & 0,14 & 0,01 & 0,16 & 0,28 & 0,14 \\
\hline $50 \%$ & 3 & 500 & 0,03 & 0,03 & 4,01 & 0,01 & 0,83 & 4,89 & 0,84 \\
\hline $50 \%$ & 3 & 1000 & 0,18 & 0,19 & 14,60 & 0,01 & 2,49 & 17,33 & 2,45 \\
\hline $50 \%$ & 3 & 1500 & 0,78 & 0,74 & 30,99 & 0,01 & 3,82 & 34,34 & 4,81 \\
\hline $50 \%$ & 3 & 3000 & 98,70 & 15,30 & 112,26 & 0,01 & 27,03 & 122,42 & 12,36 \\
\hline $50 \%$ & 3 & 5000 & & 177,63 & 292,98 & 0,01 & 210,63 & 318,57 & 34,71 \\
\hline
\end{tabular}




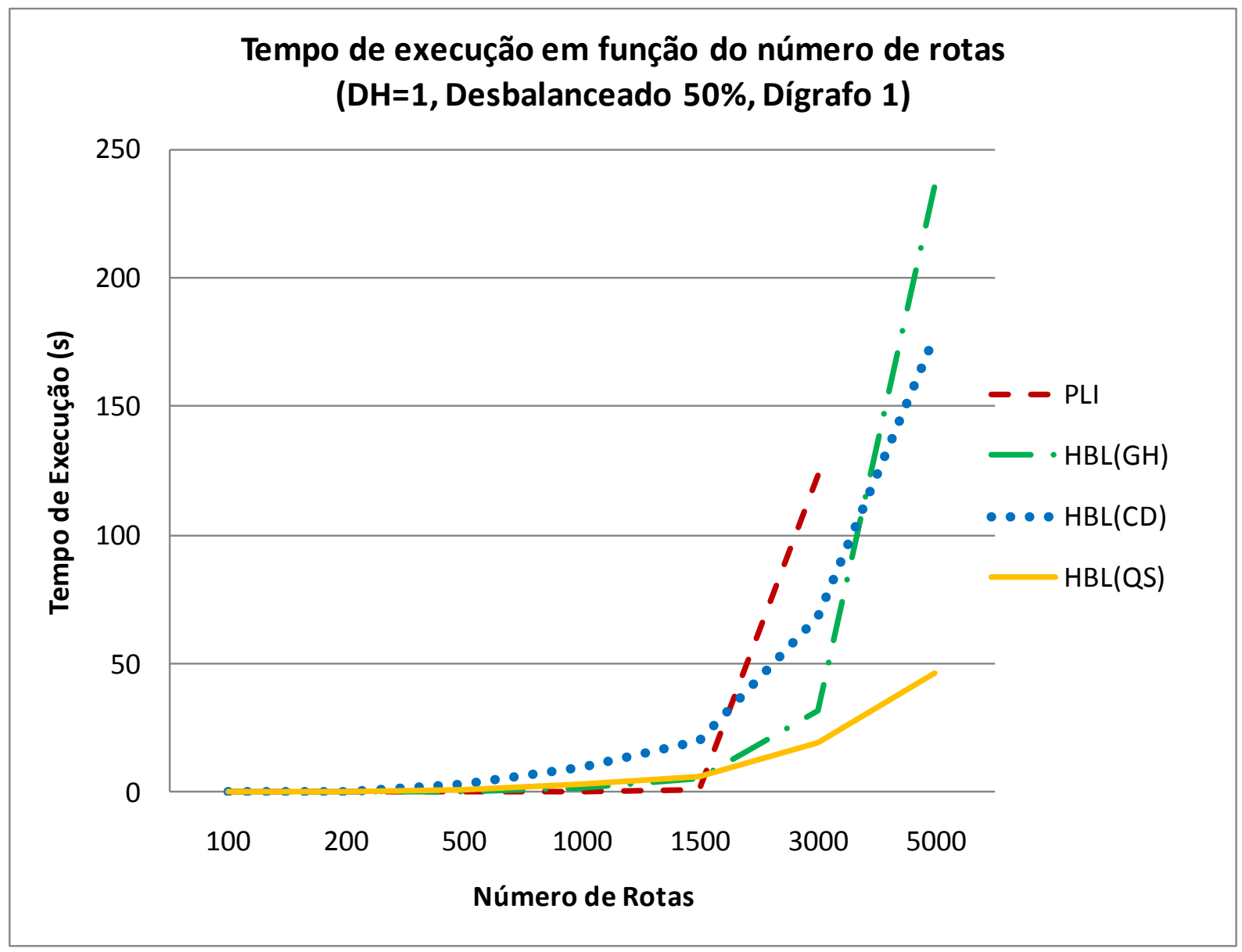

Figura 4-9: Gráfico dos tempos de execução para problemas desbalanceados (50\%) e com um reposicionamento (Dígrafo 1) 
Tabela 4-23: Comparação dos tempos de execução para problemas desbalanceados (75\%) e com um reposicionamento

TEMPOS DE EXECUÇÃO (s) TEMPOS DE EXECUÇÃO HBL (s)

\begin{tabular}{|c|c|c|c|c|c|c|c|c|c|}
\hline \multirow{2}{*}{\multicolumn{2}{|c|}{ DESBAL. DÍGRAFO }} & \multirow{2}{*}{ ROTAS } & & \\
\hline & & & PLI & GH & CD & QS & $\mathrm{HBL}_{(\mathrm{GH})}$ & $\mathrm{HBL}_{(\mathrm{CD})}$ & $\mathrm{HBL}_{(\mathrm{QS})}$ \\
\hline $75 \%$ & 1 & 100 & 0,01 & 0,01 & 0,02 & 0,01 & 0,04 & 0,06 & 0,04 \\
\hline $75 \%$ & 1 & 200 & 0,01 & 0,01 & 0,08 & 0,01 & 0,07 & 0,17 & 0,11 \\
\hline $75 \%$ & 1 & 500 & 0,02 & 0,02 & 2,17 & 0,01 & 0,30 & 2,50 & 0,26 \\
\hline $75 \%$ & 1 & 1000 & 0,10 & 0,11 & 10,30 & 0,01 & 0,91 & 11,29 & 1,27 \\
\hline $75 \%$ & 1 & 1500 & 0,30 & 0,32 & 22,47 & 0,01 & 2,23 & 24,53 & 3,11 \\
\hline $75 \%$ & 1 & 3000 & 4,25 & 3,51 & 85,60 & 0,01 & 10,18 & 92,59 & 11,80 \\
\hline $75 \%$ & 1 & 5000 & & 38,23 & 230,02 & 0,01 & 69,79 & 249,57 & 38,99 \\
\hline $75 \%$ & 2 & 100 & 0,02 & 0,01 & 0,11 & 0,01 & 0,06 & 0,16 & 0,04 \\
\hline $75 \%$ & 2 & 200 & 0,01 & 0,01 & 0,45 & 0,01 & 0,08 & 0,54 & 0,07 \\
\hline $75 \%$ & 2 & 500 & 0,03 & 0,03 & 3,22 & 0,01 & 0,40 & 3,53 & 0,38 \\
\hline $75 \%$ & 2 & 1000 & 0,09 & 0,11 & 12,27 & 0,01 & 1,00 & 13,26 & 1,26 \\
\hline $75 \%$ & 2 & 1500 & 0,30 & 0,32 & 26,76 & 0,01 & 2,57 & 28,89 & 3,16 \\
\hline $75 \%$ & 2 & 3000 & 4,18 & 3,90 & 103,32 & 0,01 & 12,49 & 111,06 & 12,28 \\
\hline $75 \%$ & 2 & 5000 & & 41,34 & 279,11 & 0,01 & 68,32 & 299,01 & 33,09 \\
\hline $75 \%$ & 3 & 100 & 0,02 & 0,01 & 0,06 & 0,01 & 0,05 & 0,11 & 0,05 \\
\hline $75 \%$ & 3 & 200 & 0,02 & 0,01 & 0,14 & 0,01 & 0,10 & 0,27 & 0,12 \\
\hline $75 \%$ & 3 & 500 & 0,02 & 0,03 & 5,15 & 0,01 & 0,34 & 5,48 & 0,38 \\
\hline $75 \%$ & 3 & 1000 & 0,11 & 0,12 & 19,69 & 0,01 & 1,01 & 20,66 & 1,26 \\
\hline $75 \%$ & 3 & 1500 & 0,36 & 0,36 & 43,58 & 0,01 & 2,05 & 45,09 & 2,12 \\
\hline $75 \%$ & 3 & 3000 & 5,33 & 4,62 & 168,35 & 0,01 & 12,48 & 174,93 & 8,90 \\
\hline $75 \%$ & 3 & 5000 & & 47,96 & 456,02 & 0,01 & 75,28 & 475,02 & 24,65 \\
\hline
\end{tabular}




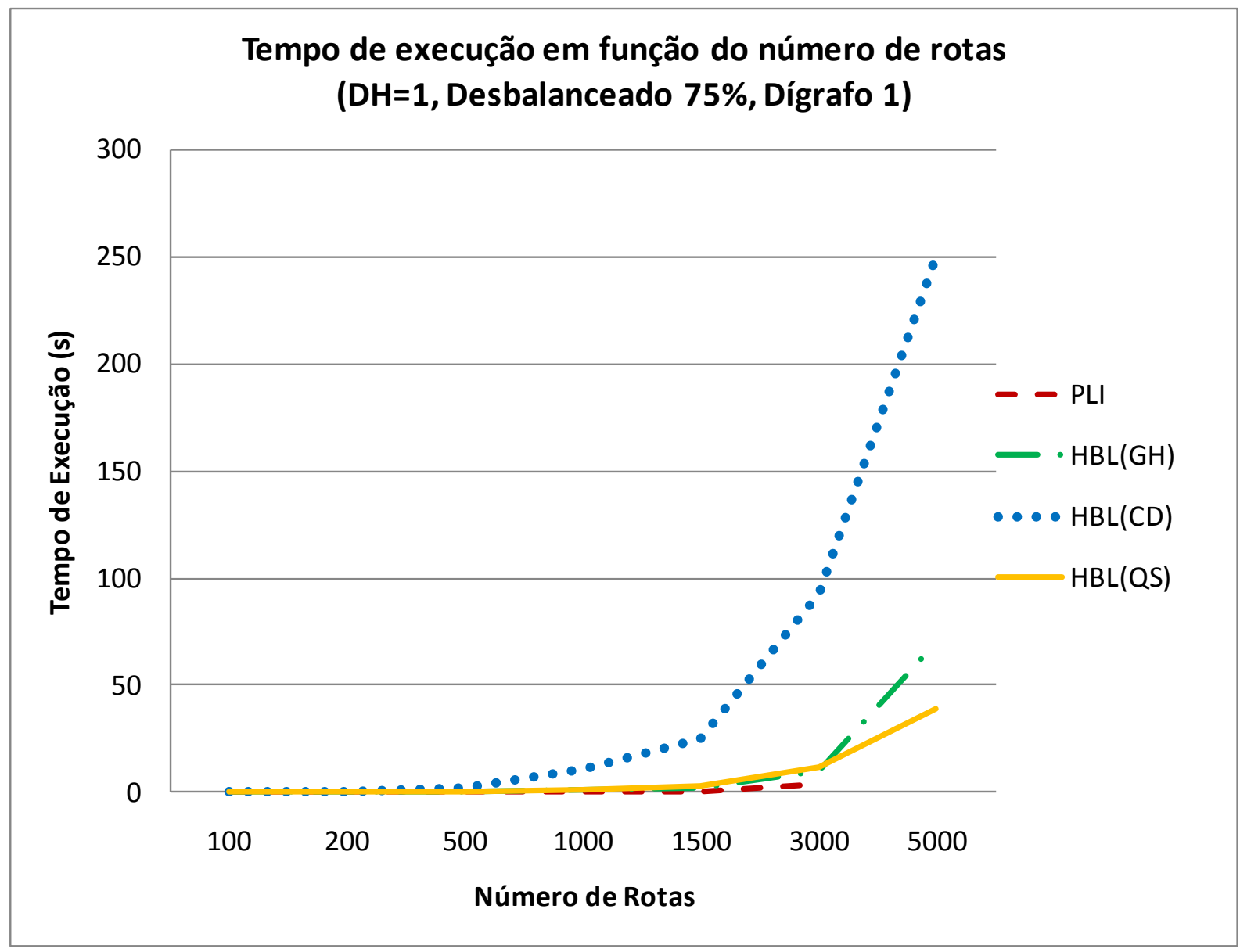

Figura 4-10: Gráfico dos tempos de execução para problemas desbalanceados (75\%) e com um reposicionamento (Dígrafo 1)

\section{- Problemas balanceados e com dois reposicionamentos}

A Tabela 4-24 mostra o tempo de processamento em segundos para a execução das instâncias. Devido a limites computacionais não foi possível executar o modelo PLI para instâncias com mais de 500 rotas e o modelo GH para instâncias com mais de 1500 rotas.

Observa-se no gráfico da Figura 4-11 que PLI não resolve problemas maiores que 500 rotas e $\mathrm{HBL}_{(\mathrm{GH})}$ problemas maiores que 1500 rotas (isso porque não obtevese a solução inicial GH para este grupo de instâncias). Os tempos de execução para $\mathrm{HBL}_{(\mathrm{CD})}$ e $\mathrm{HBL}_{(\mathrm{QS})}$ apresentam as mesmas ordens de grandeza no Dígrafo 1, sendo que conforme partimos para o Dígrafo 2 e $3 \mathrm{HBL}_{(\mathrm{QS})}$ passa a apresentar melhores tempos de processamento. 
Tabela 4-24: Comparação dos tempos de execução para problemas balanceados e com dois reposicionamentos TEMPOS DE EXECUÇÃO (s) TEMPOS DE EXECUÇÃO HBL (s)

\begin{tabular}{|c|c|c|c|c|c|c|c|c|c|}
\hline \multirow[b]{2}{*}{ DESBAL. } & \multirow[b]{2}{*}{ DÍGRAFO } & \multirow[b]{2}{*}{ ROTAS } & & \\
\hline & & & PLI & GH & $C D$ & QS & $\mathrm{HBL}_{(\mathrm{GH})}$ & $\mathrm{HBL}_{(\mathrm{CD})}$ & $\mathrm{HBL}_{(\mathrm{QS})}$ \\
\hline $0 \%$ & 1 & 100 & 0,04 & 0,01 & 0,10 & 0,01 & 0,28 & 0,33 & 0,29 \\
\hline $0 \%$ & 1 & 200 & 0,26 & 0,11 & 0,52 & 0,01 & 0,60 & 1,10 & 0,95 \\
\hline $0 \%$ & 1 & 500 & 10,60 & 2,27 & 1,38 & 0,01 & 5,53 & 3,68 & 4,94 \\
\hline $0 \%$ & 1 & 1000 & & 31,61 & 4,27 & 0,01 & 41,58 & 11,59 & 14,91 \\
\hline $0 \%$ & 1 & 1500 & & 145,35 & 7,98 & 0,01 & 171,54 & 23,88 & 26,13 \\
\hline $0 \%$ & 1 & 3000 & & & 19,39 & 0,01 & & 62,38 & 63,32 \\
\hline $0 \%$ & 1 & 5000 & & & 43,26 & 0,01 & & 150,71 & 151,69 \\
\hline $0 \%$ & 2 & 100 & 0,04 & 0,01 & 0,08 & 0,01 & 0,34 & 0,36 & 0,25 \\
\hline $0 \%$ & 2 & 200 & 0,19 & 0,10 & 0,37 & 0,01 & 0,66 & 1,15 & 1,17 \\
\hline $0 \%$ & 2 & 500 & 5,84 & 1,34 & 0,81 & 0,01 & 3,22 & 2,09 & 3,49 \\
\hline $0 \%$ & 2 & 1000 & & 31,05 & 5,93 & 0,01 & 40,89 & 14,95 & 13,73 \\
\hline $0 \%$ & 2 & 1500 & & 142,86 & 11,12 & 0,01 & 168,27 & 28,80 & 24,18 \\
\hline $0 \%$ & 2 & 3000 & & & 30,53 & 0,01 & & 86,56 & 73,70 \\
\hline $0 \%$ & 2 & 5000 & & & 68,80 & 0,01 & & 225,11 & 156,65 \\
\hline $0 \%$ & 3 & 100 & 0,04 & 0,01 & 0,08 & 0,01 & 0,35 & 0,52 & 0,41 \\
\hline $0 \%$ & 3 & 200 & 0,19 & 0,10 & 0,26 & 0,01 & 0,67 & 1,02 & 0,98 \\
\hline $0 \%$ & 3 & 500 & 9,91 & 2,24 & 2,20 & 0,01 & 5,33 & 4,93 & 6,47 \\
\hline $0 \%$ & 3 & 1000 & & 30,50 & 8,37 & 0,01 & 40,34 & 16,58 & 14,62 \\
\hline $0 \%$ & 3 & 1500 & & 111,60 & 14,83 & 0,01 & 131,24 & 29,39 & 20,19 \\
\hline $0 \%$ & 3 & 3000 & & & 59,19 & 0,01 & & 113,30 & 56,78 \\
\hline $0 \%$ & 3 & 5000 & & & 119,58 & 0,01 & & 216,79 & 114,46 \\
\hline
\end{tabular}




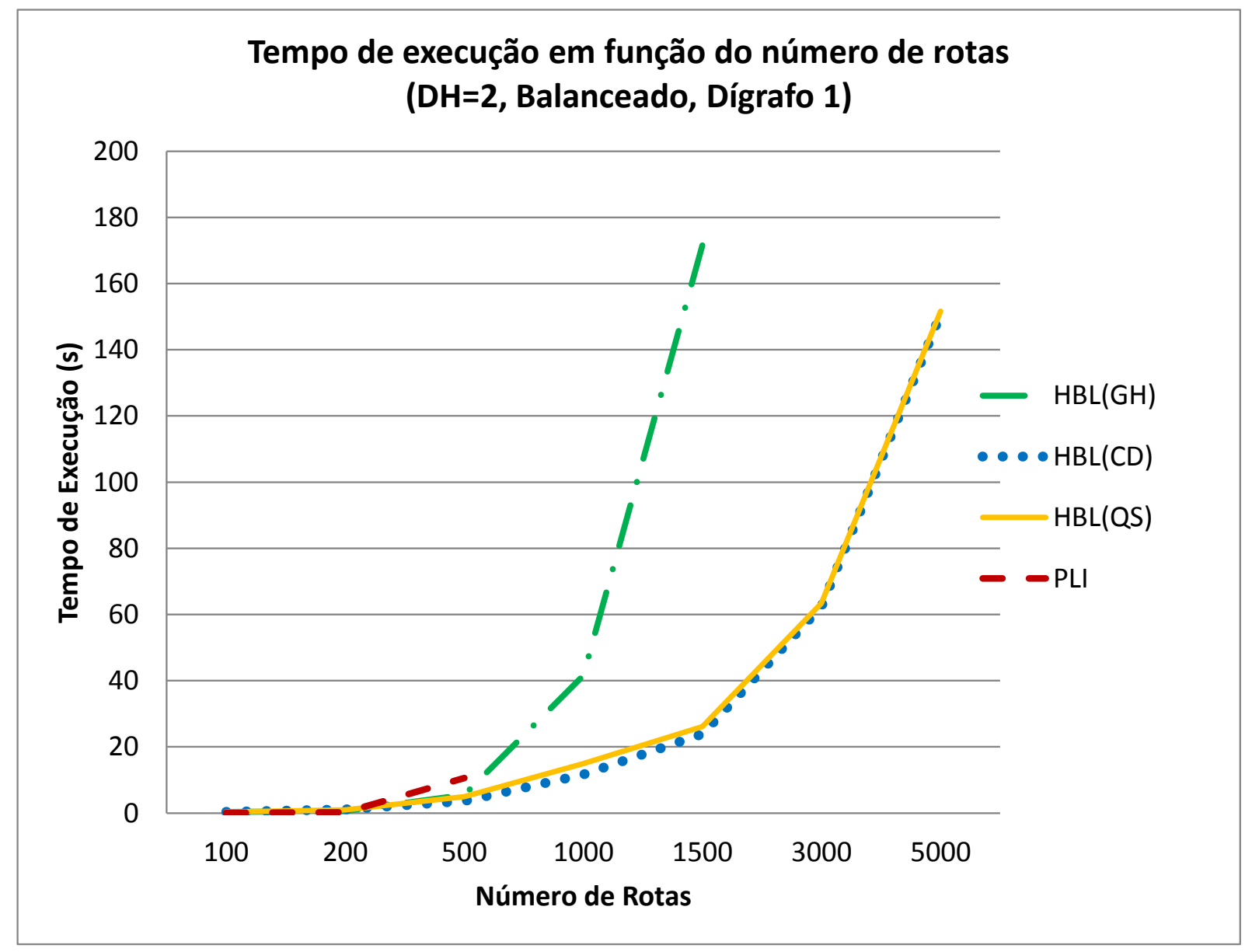

Figura 4-11: Gráfico dos tempos de execução para problemas balanceados e com dois reposicionamentos (Dígrafo 1)

- Problemas desbalanceados e com dois reposicionamentos

Da mesma forma que para problemas balanceados e com dois reposicionamentos, não foram obtidos resultados para PLI para instâncias maiores que 500 rotas e $\mathrm{HBL}_{(\mathrm{GH})}$ para problemas maiores que 1500 rotas.

É possível observar que à medida que aumentamos o desbalanceamento das instâncias (Tabela 4-25, Tabela 4-26 e Tabela 4-27), HBL(QS) passa a apresentar os melhores tempos de execução, enquanto que $\mathrm{HBL}_{(\mathrm{CD})}$ passa a apresentar um crescimento mais acentuado dos seus tempos de processamento. 
Tabela 4-25: Comparação dos tempos de execução para problemas desbalanceados (25\%) e com dois reposicionamentos TEMPOS DE EXECUÇÃO (s)

TEMPOS DE EXECUÇÃO HBL ( $s$ )

\begin{tabular}{|c|c|c|c|c|c|c|c|c|c|}
\hline \multirow[b]{2}{*}{ DESBAL. } & \multirow[b]{2}{*}{ DÍGRAFO } & \multirow[b]{2}{*}{ ROTAS } & & \\
\hline & & & PLI & GH & $C D$ & QS & $\mathrm{HBL}_{(\mathrm{GH})}$ & $\mathrm{HBL}_{(\mathrm{CD})}$ & $\mathrm{HBL}_{(\mathrm{QS})}$ \\
\hline $25 \%$ & 1 & 100 & 0,05 & 0,01 & 0,12 & 0,01 & 0,42 & 0,59 & 0,39 \\
\hline $25 \%$ & 1 & 200 & 0,19 & 0,10 & 0,57 & 0,01 & 0,71 & 1,18 & 1,00 \\
\hline $25 \%$ & 1 & 500 & 9,58 & 2,18 & 1,79 & 0,01 & 4,18 & 4,05 & 5,47 \\
\hline $25 \%$ & 1 & 1000 & & 30,25 & 7,01 & 0,01 & 39,55 & 15,80 & 12,94 \\
\hline $25 \%$ & 1 & 1500 & & 138,17 & 14,42 & 0,01 & 155,21 & 30,61 & 21,03 \\
\hline $25 \%$ & 1 & 3000 & & & 50,41 & 0,01 & & 97,43 & 69,48 \\
\hline $25 \%$ & 1 & 5000 & & & 138,38 & 0,01 & & 261,46 & 163,74 \\
\hline $25 \%$ & 2 & 100 & 0,04 & 0,02 & 0,12 & 0,01 & 0,32 & 0,44 & 0,41 \\
\hline $25 \%$ & 2 & 200 & 0,19 & 0,11 & 0,40 & 0,01 & 0,69 & 0,96 & 0,90 \\
\hline $25 \%$ & 2 & 500 & 8,91 & 2,06 & 2,31 & 0,01 & 4,23 & 5,43 & 4,05 \\
\hline $25 \%$ & 2 & 1000 & & 28,79 & 11,07 & 0,01 & 38,23 & 18,72 & 14,54 \\
\hline $25 \%$ & 2 & 1500 & & 131,47 & 22,23 & 0,01 & 155,65 & 41,69 & 24,19 \\
\hline $25 \%$ & 2 & 3000 & & & 77,58 & 0,01 & & 138,10 & 70,47 \\
\hline $25 \%$ & 2 & 5000 & & & 198,46 & 0,01 & & 341,59 & 153,47 \\
\hline $25 \%$ & 3 & 100 & 0,04 & 0,01 & 0,06 & 0,01 & 0,27 & 0,43 & 0,32 \\
\hline $25 \%$ & 3 & 200 & 0,18 & 0,10 & 0,28 & 0,01 & 0,76 & 1,04 & 0,91 \\
\hline $25 \%$ & 3 & 500 & 8,58 & 2,12 & 3,32 & 0,01 & 5,17 & 6,72 & 4,45 \\
\hline $25 \%$ & 3 & 1000 & & 28,56 & 16,05 & 0,01 & 39,78 & 26,01 & 13,43 \\
\hline $25 \%$ & 3 & 1500 & & 131,50 & 32,07 & 0,01 & 154,70 & 53,28 & 25,15 \\
\hline $25 \%$ & 3 & 3000 & & & 114,32 & 0,01 & & 178,73 & 65,87 \\
\hline $25 \%$ & 3 & 5000 & & & 311,38 & 0,01 & & 435,45 & 151,43 \\
\hline
\end{tabular}




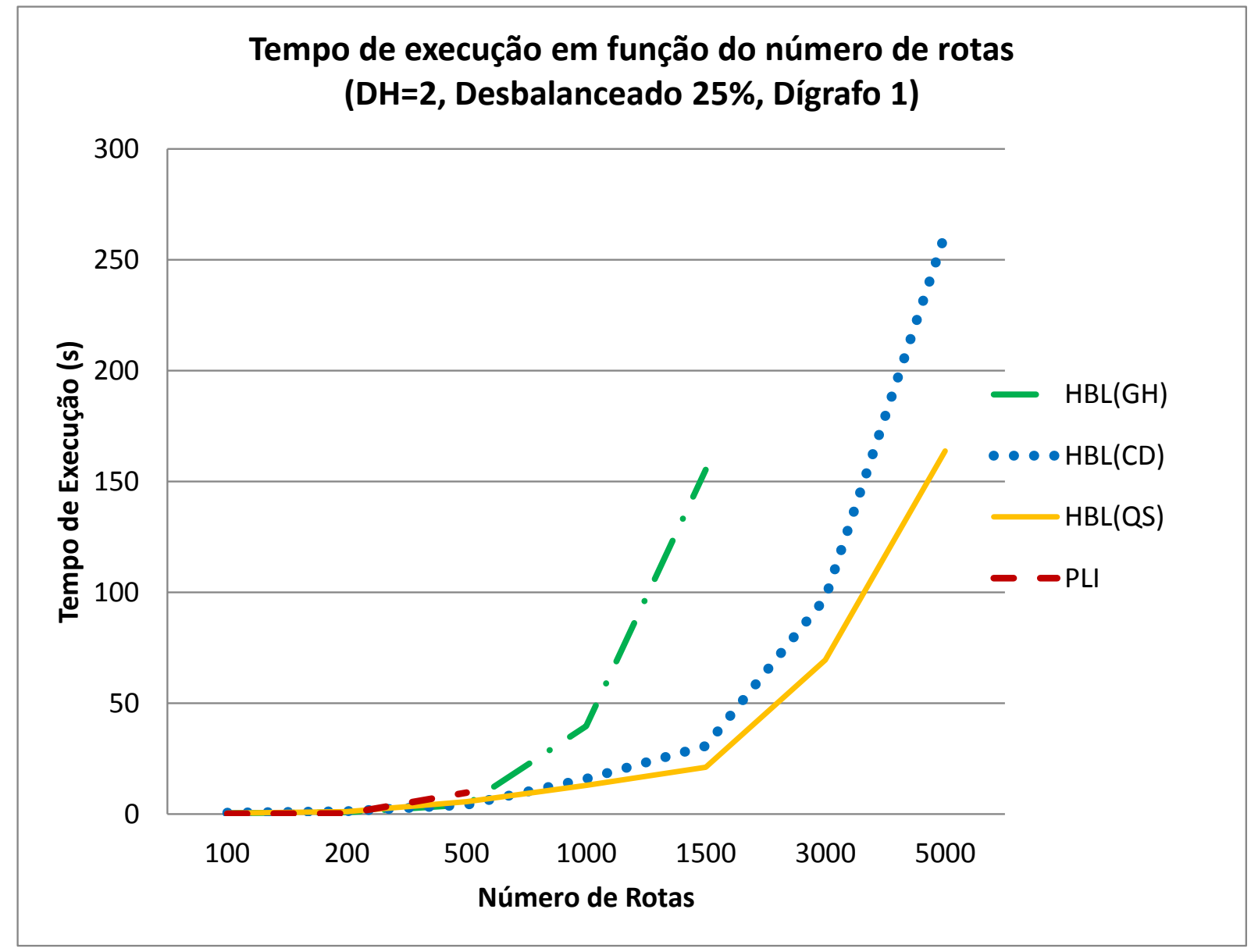

Figura 4-12: Gráfico dos tempos de execução para problemas desbalanceados (25\%) e com dois reposicionamentos (Dígrafo 1) 


\begin{tabular}{|c|c|c|c|c|c|c|c|c|c|}
\hline \multirow[b]{2}{*}{ DESBAL. } & \multirow[b]{2}{*}{ DÍGRAFO } & \multirow[b]{2}{*}{ ROTAS } & \multicolumn{4}{|c|}{ TEMPOS DE EXECUÇÃO (s) } & \multicolumn{3}{|c|}{ TEMPOS DE EXECUÇÃO HBL (s) } \\
\hline & & & PLI & GH & CD & QS & $\mathrm{HBL}_{(\mathrm{GH})}$ & $\mathrm{HBL}_{(\mathrm{CD})}$ & $\mathrm{HBL}_{(\mathrm{QS})}$ \\
\hline $50 \%$ & 1 & 100 & 0,04 & 0,02 & 0,10 & 0,01 & 0,27 & 0,37 & 0,36 \\
\hline $50 \%$ & 1 & 200 & 0,18 & 0,10 & 0,68 & 0,01 & 0,62 & 1,39 & 1,04 \\
\hline $50 \%$ & 1 & 500 & 6,66 & 1,88 & 3,52 & 0,01 & 4,69 & 6,35 & 4,06 \\
\hline $50 \%$ & 1 & 1000 & & 25,92 & 15,99 & 0,01 & 34,80 & 24,15 & 12,28 \\
\hline $50 \%$ & 1 & 1500 & & 118,57 & 35,00 & 0,01 & 137,15 & 50,07 & 22,06 \\
\hline $50 \%$ & 1 & 3000 & & & 135,57 & 0,01 & & 182,47 & 61,98 \\
\hline $50 \%$ & 1 & 5000 & & & 377,09 & 0,01 & & 485,96 & 136,07 \\
\hline $50 \%$ & 2 & 100 & 0,03 & 0,01 & 0,11 & 0,01 & 0,38 & 0,39 & 0,32 \\
\hline $50 \%$ & 2 & 200 & 0,20 & 0,10 & 0,53 & 0,01 & 0,92 & 1,39 & 0,87 \\
\hline $50 \%$ & 2 & 500 & 7,35 & 1,87 & 4,32 & 0,01 & 4,63 & 6,74 & 4,23 \\
\hline $50 \%$ & 2 & 1000 & & 25,25 & 22,10 & 0,01 & 34,36 & 30,80 & 12,20 \\
\hline $50 \%$ & 2 & 1500 & & 115,45 & 48,39 & 0,01 & 133,68 & 66,81 & 20,70 \\
\hline $50 \%$ & 2 & 3000 & & & 186,81 & 0,01 & & 239,36 & 65,93 \\
\hline $50 \%$ & 2 & 5000 & & & 514,80 & 0,01 & & 645,19 & 151,15 \\
\hline $50 \%$ & 3 & 100 & 0,04 & 0,01 & 0,10 & 0,01 & 0,52 & 0,50 & 0,41 \\
\hline $50 \%$ & 3 & 200 & 0,19 & 0,10 & 0,44 & 0,01 & 0,77 & 1,30 & 0,94 \\
\hline $50 \%$ & 3 & 500 & 5,30 & 1,49 & 5,30 & 0,01 & 4,64 & 8,45 & 3,84 \\
\hline $50 \%$ & 3 & 1000 & & 19,60 & 26,64 & 0,01 & 27,75 & 35,38 & 10,15 \\
\hline $50 \%$ & 3 & 1500 & & 107,92 & 73,78 & 0,01 & 129,72 & 94,04 & 22,04 \\
\hline $50 \%$ & 3 & 3000 & & & 286,96 & 0,01 & & 348,31 & 58,14 \\
\hline $50 \%$ & 3 & 5000 & & & 772,86 & 0,01 & & 879,62 & 121,53 \\
\hline
\end{tabular}




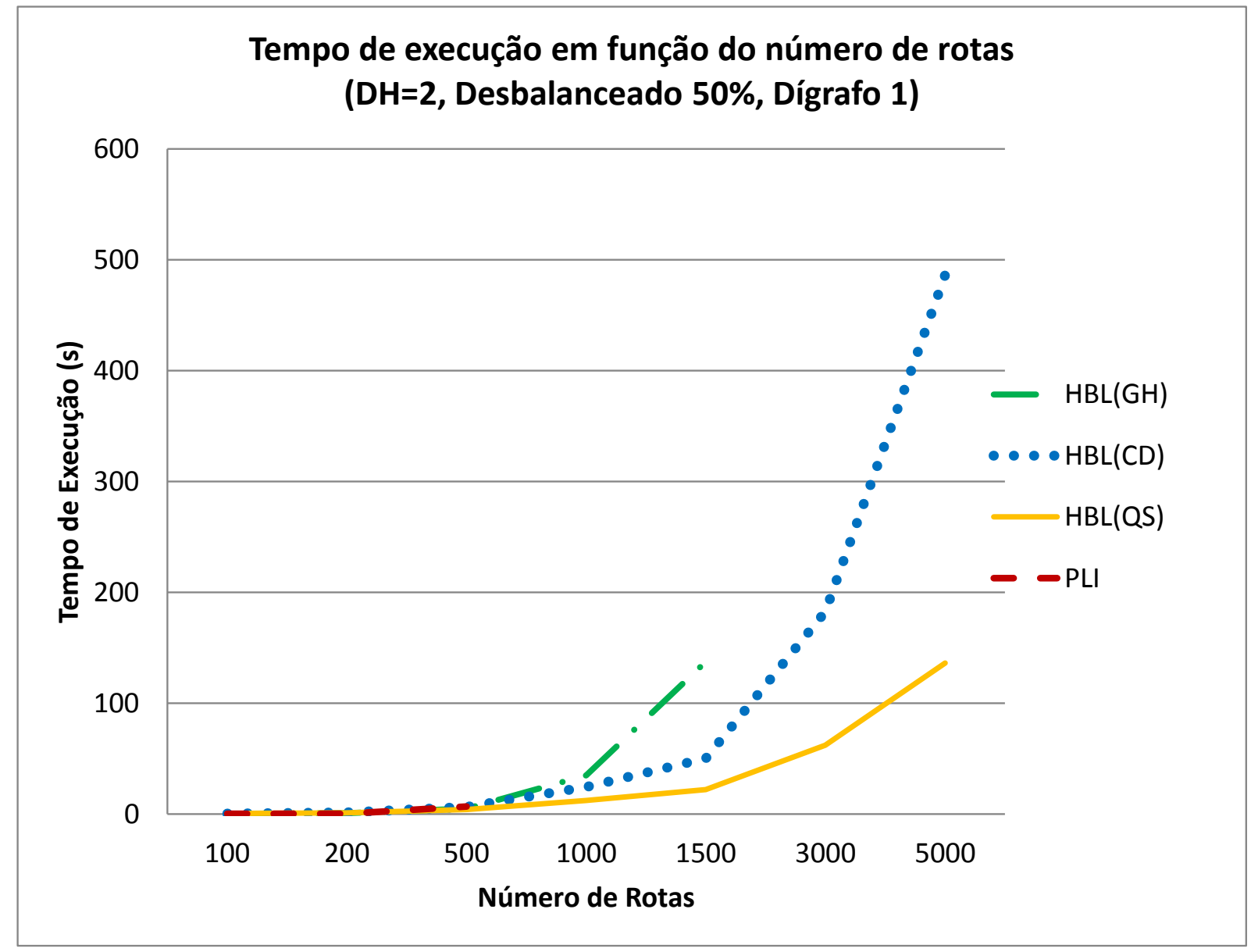

Figura 4-13: Gráfico dos tempos de execução para problemas desbalanceados (50\%) e com dois reposicionamentos (Dígrafo 1) 
Tabela 4-27: Comparação dos tempos de execução para problemas desbalanceados (75\%) e com dois reposicionamentos

TEMPOS DE EXECUÇÃO (s)

TEMPOS DE EXECUÇÃO HBL (s)

\begin{tabular}{|c|c|c|c|c|c|c|c|c|c|}
\hline \multirow{2}{*}{\multicolumn{2}{|c|}{ DESBAL. DÍGRAFO }} & \multirow{2}{*}{ ROTAS } & & \\
\hline & & & PLI & GH & CD & QS & $\mathrm{HBL}_{(\mathrm{GH})}$ & $\mathrm{HBL}_{(\mathrm{CD})}$ & $\mathrm{HBL}_{(\mathrm{QS})}$ \\
\hline $75 \%$ & 1 & 100 & 0,04 & 0,02 & 0,16 & 0,01 & 0,41 & 0,54 & 0,42 \\
\hline $75 \%$ & 1 & 200 & 0,16 & 0,08 & 0,94 & 0,01 & 0,72 & 1,58 & 0,93 \\
\hline $75 \%$ & 1 & 500 & 1,96 & 0,84 & 3,47 & 0,01 & 2,66 & 5,10 & 2,39 \\
\hline $75 \%$ & 1 & 1000 & & 18,46 & 27,42 & 0,01 & 26,53 & 36,07 & 10,06 \\
\hline $75 \%$ & 1 & 1500 & & 82,79 & 61,69 & 0,01 & 97,65 & 78,01 & 18,59 \\
\hline $75 \%$ & 1 & 3000 & & & 245,17 & 0,01 & & 286,50 & 50,64 \\
\hline $75 \%$ & 1 & 5000 & & & 673,71 & 0,01 & & 782,28 & 121,03 \\
\hline $75 \%$ & 2 & 100 & 0,04 & 0,01 & 0,16 & 0,01 & 0,46 & 0,51 & 0,44 \\
\hline $75 \%$ & 2 & 200 & 0,17 & 0,09 & 0,80 & 0,01 & 0,78 & 1,57 & 0,94 \\
\hline $75 \%$ & 2 & 500 & 2,09 & 1,07 & 5,62 & 0,01 & 3,10 & 7,82 & 3,11 \\
\hline $75 \%$ & 2 & 1000 & & 17,59 & 37,50 & 0,01 & 24,84 & 46,31 & 10,75 \\
\hline $75 \%$ & 2 & 1500 & & 79,29 & 83,54 & 0,01 & 91,08 & 99,45 & 19,75 \\
\hline $75 \%$ & 2 & 3000 & & & 340,03 & 0,01 & & 382,49 & 49,62 \\
\hline $75 \%$ & 2 & 5000 & & & 933,53 & 0,01 & & $1.041,98$ & 123,43 \\
\hline $75 \%$ & 3 & 100 & 0,05 & 0,01 & 0,15 & 0,01 & 0,41 & 0,55 & 0,45 \\
\hline $75 \%$ & 3 & 200 & 0,16 & 0,08 & 0,66 & 0,01 & 1,03 & 1,50 & 1,02 \\
\hline $75 \%$ & 3 & 500 & 2,19 & 1,14 & 8,46 & 0,01 & 3,83 & 11,05 & 2,79 \\
\hline $75 \%$ & 3 & 1000 & & 17,53 & 50,67 & 0,01 & 26,55 & 59,77 & 8,82 \\
\hline $75 \%$ & 3 & 1500 & & 76,59 & 114,69 & 0,01 & 90,83 & 130,55 & 16,98 \\
\hline $75 \%$ & 3 & 3000 & & & 462,74 & 0,01 & & 501,13 & 37,55 \\
\hline $75 \%$ & 3 & 5000 & & & $1.265,18$ & 0,01 & & $1.358,40$ & 84,50 \\
\hline
\end{tabular}




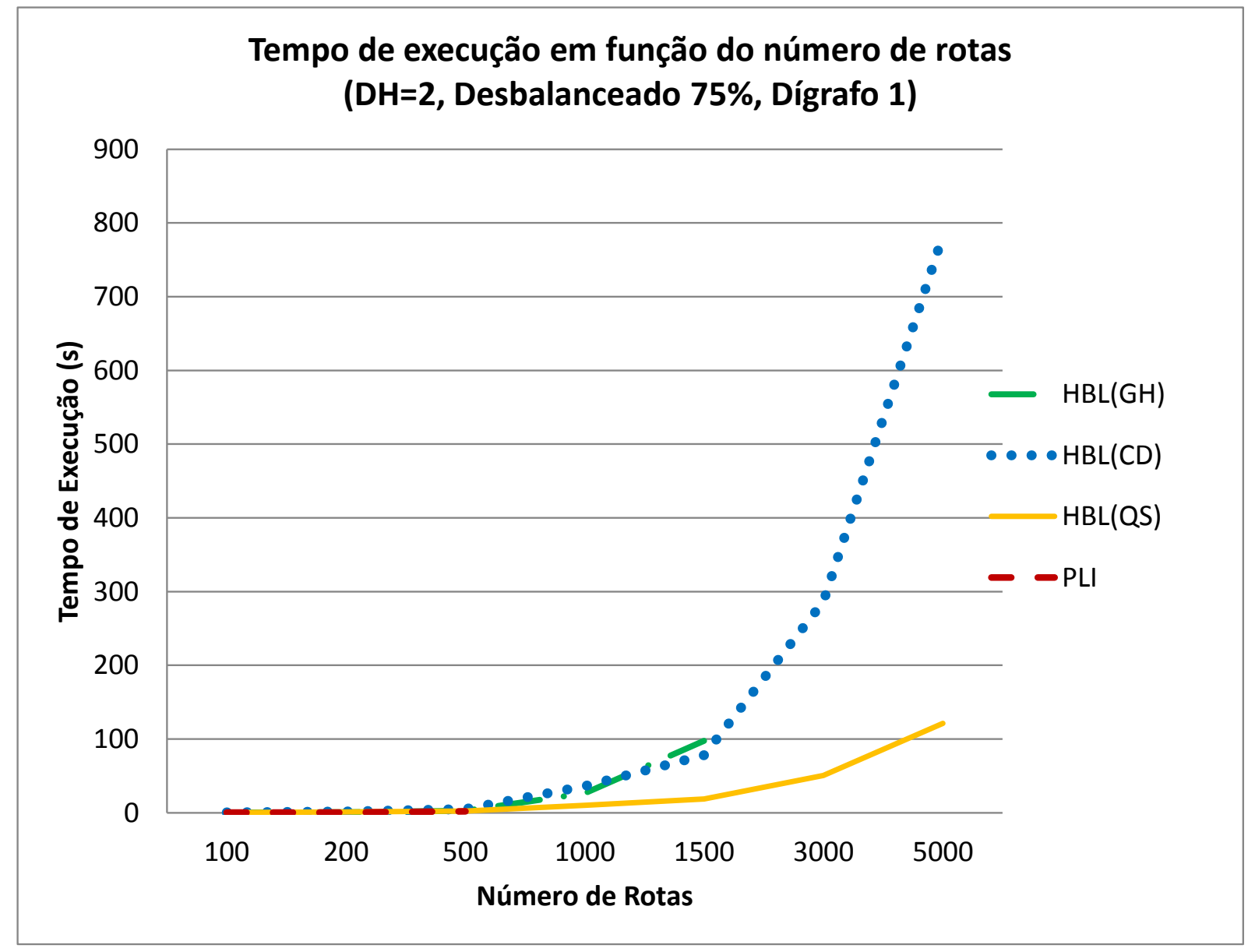

Figura 4-14: Gráfico dos tempos de execução para problemas desbalanceados (75\%) e com dois reposicionamentos (Dígrafo 1) 


\section{CONCLUSÕES E PERSPECTIVAS DE TRABALHOS FUTUROS}

Neste capítulo são apresentados os comentários sobre os resultados obtidos e propostas para trabalhos futuros.

\subsection{Comentários sobre os resultados obtidos}

No Capítulo anterior são apresentados os resultados da Heurística com Busca Local (HBL) quando aplicado a diferentes soluções iniciais (GH, CD e solução inicial QS proposta por este trabalho).

Na Tabela 5-1 é possível observar que a Heurística com Busca Local quando aplicada utilizando como solução inicial o Algoritmo Guloso (GH) reduz em 1,76\% o seu valor, sendo esta redução mais expressiva nos problemas com um reposicionamento, onde a redução é de 2,87\%. O Mesmo ocorre quando a Heurística com Busca Local é aplicada utilizando como solução inicial o Algoritmo Construtivo-Destrutivo (CD), reduzindo o seu valor em $1,56 \%$, sendo a redução mais expressiva nos problemas com um reposicionamento $(2,50 \%)$.

A solução inicial QS fornece resultados iniciais ruins, e por isso a Heurística com Busca Local ainda consegue reduzir em média 18,98\% o seu valor, sendo a redução mais expressiva nos problemas com dois reposicionamentos $(27,64 \%)$.

Problemas em que são permitidos dois reposicionamentos possuem um espaço de solução com maior grau de liberdade quando comparado aos problemas com um reposicionamento, e por isso a HBL quando aplicada à solução inicial QS permitindo-se dois reposicionamentos, esta apresenta uma redução mais expressiva. O mesmo não ocorre quando aplicada sobre GH ou $C D$, pois esta redução depende do quanto cada uma destas soluções iniciais já estava ou não distantes do ótimo. 
Tabela 5-1: Resumo da melhoria realizada pela Heurística com Busca Local (HBL) quando aplicada a diferentes soluções iniciais

\begin{tabular}{ccccc} 
DH & Desbal. & $\mathbf{H B L}_{(\mathbf{G H})} \mathbf{\times} \mathbf{G H}$ & $\mathbf{H B L}_{(\mathbf{C D})} \mathbf{X C D}$ & $\mathbf{H B L}_{(\mathbf{Q S})} \mathbf{\times Q S}$ \\
\hline 1 & $0 \%$ & $-4,69 \%$ & $-3,81 \%$ & $-15,82 \%$ \\
1 & $25 \%$ & $-3,76 \%$ & $-3,49 \%$ & $-13,12 \%$ \\
1 & $50 \%$ & $-2,32 \%$ & $-2,00 \%$ & $-8,68 \%$ \\
1 & $75 \%$ & $-0,73 \%$ & $-0,69 \%$ & $-3,63 \%$ \\
\hline \multicolumn{6}{c}{ Média } & $-2,87 \%$ & $-2,50 \%$ & $-10,31 \%$ \\
\hline 2 & $0 \%$ & $-0,65 \%$ & $-0,50 \%$ & $-32,24 \%$ \\
2 & $25 \%$ & $-0,64 \%$ & $-0,61 \%$ & $-30,73 \%$ \\
2 & $50 \%$ & $-0,68 \%$ & $-0,66 \%$ & $-26,86 \%$ \\
2 & $75 \%$ & $-0,63 \%$ & $-0,70 \%$ & $-20,75 \%$ \\
\hline \multicolumn{7}{c}{ Média } & $-0,65 \%$ & $-0,62 \%$ & $-27,64 \%$ \\
\hline \multicolumn{7}{c}{}
\end{tabular}

$\mathrm{Na}$ Tabela 5-2 pode-se observar como para problemas com dois reposicionamentos $(\mathrm{DH}=2)$ os resultados obtidos por $\mathrm{GH}$ e $\mathrm{CD}$ já estão próximos do ótimo, e por isso a HBL não permite uma redução maior do que apresentada na Tabela 5-1 quando aplicada sobre estas soluções iniciais. Para problemas com um reposicionamento ( $\mathrm{DH}=1)$, a Heurística com Busca Local utilizando como solução inicial QS foi a que apresentou os melhores resultados (apenas 2,42\% do ótimo).

Tabela 5-2: Resumo da comparação dos diferentes resultados obtidos pela Heurística com Busca Local (HBL) conforme solução inicial utilizada Diferenças PLI (\%) Diferenças HBL (\%)

\begin{tabular}{|c|c|c|c|c|c|c|c|}
\hline \multirow[b]{2}{*}{ DH } & \multirow[b]{2}{*}{ DESBAL. } & & \\
\hline & & $\mathrm{HBL}_{(\mathrm{GH})} \times \mathrm{PLI}$ & $\mathrm{HBL}_{(\mathrm{CD})} \times \mathrm{PLI}$ & $\mathrm{HBL}_{(\mathrm{QS})} \times \mathrm{PLI}$ & $\mathrm{HBL}_{(\mathrm{QS})} \times \mathrm{HBL}_{(\mathrm{GH})}$ & $\mathrm{HBL}_{(\mathrm{QS})} \times \mathrm{HBL}_{(\mathrm{CD})}$ & $\mathrm{HBL}_{(\mathrm{CD})} \times \mathrm{HBL}_{(\mathrm{GH})}$ \\
\hline 1 & $0 \%$ & $5,62 \%$ & $4,69 \%$ & $3,49 \%$ & $-2,01 \%$ & $-1,14 \%$ & $-0,88 \%$ \\
\hline 1 & $25 \%$ & $5,41 \%$ & $4,09 \%$ & $2,82 \%$ & $-2,46 \%$ & $-1,22 \%$ & $-1,26 \%$ \\
\hline 1 & $50 \%$ & $4,65 \%$ & $3,91 \%$ & $2,33 \%$ & $-2,21 \%$ & $-1,52 \%$ & $-0,71 \%$ \\
\hline 1 & $75 \%$ & $2,25 \%$ & $1,89 \%$ & $1,04 \%$ & $-1,18 \%$ & $-0,83 \%$ & $-0,36 \%$ \\
\hline \multicolumn{2}{|c|}{ Média } & $4,48 \%$ & $3,64 \%$ & $2,42 \%$ & $-1,97 \%$ & $-1,18 \%$ & $-0,80 \%$ \\
\hline 2 & $0 \%$ & $0,84 \%$ & $0,79 \%$ & $0,91 \%$ & $0,07 \%$ & $0,12 \%$ & $-0,05 \%$ \\
\hline 2 & $25 \%$ & $0,52 \%$ & $0,53 \%$ & $0,63 \%$ & $0,10 \%$ & $0,10 \%$ & $0,00 \%$ \\
\hline 2 & $50 \%$ & $0,31 \%$ & $0,33 \%$ & $0,35 \%$ & $0,04 \%$ & $0,03 \%$ & $0,01 \%$ \\
\hline 2 & $75 \%$ & $0,15 \%$ & $0,18 \%$ & $0,15 \%$ & $0,00 \%$ & $-0,03 \%$ & $0,03 \%$ \\
\hline \multicolumn{2}{|c|}{ Média } & $0,46 \%$ & $0,45 \%$ & $0,51 \%$ & $0,05 \%$ & $0,06 \%$ & $0,00 \%$ \\
\hline
\end{tabular}


Para problemas com dois reposicionamentos houve quase que um empate entre os resultados obtidos pela $\mathrm{HBL}$ conforme as diferentes soluções iniciais utilizadas.

Entretanto, a Tabela 5-3 mostra o tempo médio de execução das soluções HBL para problemas de 5.000 rotas. Verifica-se que os melhores resultados são obtidos por $\mathrm{HBL}_{(\mathrm{QS})}$, sendo que $\mathrm{HBL}_{(\mathrm{GH})}$ não fornece resultados para instâncias de grande porte (número elevado de rotas).

Diante dos resultados apresentados na Tabela 5-2 e Tabela 5-3, conclui-se que a Heurística $\mathrm{HBL}_{(\mathrm{QS})}$ é a que apresentou um melhor desempenho para o problema estudado quando observado resultados obtidos e tempo de processamento.

Na Tabela 5-4 é feita a comparação dos resultados totais obtidos para todos os grupos de problemas pela literatura (GH e CD) e pela Heurística com Busca Local utilizando a solução inicial QS. Verifica-se que os resultados obtidos por $H B L_{(Q S)}$ reduzem em $4,17 \%$ os resultados obtidos por $\mathrm{GH}$ e 3,19\% os resultados obtidos pela heurística CD.

Ainda na Tabela 5-4 percebe-se a diferença dos subtotais para as instâncias com um e dois reposicionamentos. Isso ocorre pois os subtotais representam a somatário dos resultados das instâncias em que encontramos resultados por todos os métodos. Assim, como não existe resultado para GH para problemas com mais de 1500 rotas e $\mathrm{DH}=2$, os subtotais deste grupo de instâncias ficou muito baixo quando comparados aos subtotais para $\mathrm{DH}=1$.

Tabela 5-3: Tempo médio de execução para instâncias de 5000 rotas

\begin{tabular}{ccccc} 
& & \multicolumn{3}{c}{ Tempo de execução (s) } \\
\cline { 3 - 5 } DH & Desbal. & HBL $_{(\mathrm{GH})}$ & HBL $_{(\mathrm{CD})}$ & HBL $_{(\mathrm{QS})}$ \\
\hline 1 & $0 \%$ & 516 & 95 & $\mathbf{6 3}$ \\
1 & $25 \%$ & 408 & 141 & $\mathbf{5 0}$ \\
1 & $50 \%$ & 226 & 236 & $\mathbf{4 2}$ \\
1 & $75 \%$ & 71 & 341 & $\mathbf{3 2}$ \\
\hline 2 & $0 \%$ & $\mathrm{n} / \mathrm{d}$ & 198 & $\mathbf{1 4 1}$ \\
2 & $25 \%$ & $\mathrm{n} / \mathrm{d}$ & 346 & $\mathbf{1 5 6}$ \\
2 & $50 \%$ & $\mathrm{n} / \mathrm{d}$ & 670 & $\mathbf{1 3 6}$ \\
2 & $75 \%$ & $\mathrm{n} / \mathrm{d}$ & 1.061 & $\mathbf{1 1 0}$ \\
\hline
\end{tabular}


Tabela 5-4: Comparação dos resultados obtidos pela HBL aplicada sobre a solução inicial QS com os resultados obtidos pela literatura

\begin{tabular}{|c|c|c|c|c|c|c|}
\hline \multirow[b]{2}{*}{ DH } & \multirow[b]{2}{*}{ DESBAL. } & \multicolumn{3}{|c|}{ Resultados } & \multicolumn{2}{|c|}{ Diferenças (\%) } \\
\hline & & GH & $C D$ & $\mathrm{HBL}_{(\mathrm{QS})}$ & $\mathrm{HBL}_{(\mathrm{QS})} \times \mathrm{GH}$ & $\mathrm{HBL}_{(\mathrm{QS})} \times \mathrm{CD}$ \\
\hline 1 & $0 \%$ & 10.818 .084 & 10.624 .473 & 10.103 .650 & $-6,60 \%$ & $-4,90 \%$ \\
\hline 1 & $25 \%$ & 11.275 .159 & 11.101 .844 & 10.583 .915 & $-6,13 \%$ & $-4,67 \%$ \\
\hline 1 & $50 \%$ & 13.080 .547 & 12.945 .662 & 12.493 .977 & $-4,48 \%$ & $-3,49 \%$ \\
\hline 1 & $75 \%$ & 15.033 .964 & 14.974 .081 & 14.748 .111 & $-1,90 \%$ & $-1,51 \%$ \\
\hline \multicolumn{2}{|c|}{ SUBTOTAL } & 12.551 .939 & 12.411 .515 & 11.982 .413 & $-4,54 \%$ & $-3,46 \%$ \\
\hline 2 & $0 \%$ & 1.121.241 & 1.119.015 & 1.114.782 & $-0,58 \%$ & $-0,38 \%$ \\
\hline 2 & $25 \%$ & 1.269 .214 & 1.268 .890 & 1.262 .383 & $-0,54 \%$ & $-0,51 \%$ \\
\hline 2 & $50 \%$ & 1.309 .623 & 1.309 .607 & 1.301 .315 & $-0,63 \%$ & $-0,63 \%$ \\
\hline 2 & $75 \%$ & 1.397.101 & 1.398 .449 & 1.388 .240 & $-0,63 \%$ & $-0,73 \%$ \\
\hline \multicolumn{2}{|c|}{ SUBTOTAL } & 1.274.295 & 1.273 .990 & 1.266 .680 & $-0,60 \%$ & $-0,57 \%$ \\
\hline \multicolumn{2}{|r|}{ TOTAL } & 13.826 .233 & 13.685 .505 & 13.249 .093 & $-4,17 \%$ & $-3,19 \%$ \\
\hline
\end{tabular}

Uma conclusão importante do trabalho é como uma solução inicial de boa qualidade (próxima do ótimo) pode não ser decisiva para a obtenção de melhores resultados após aplicação de Heurística baseada em busca local. Ao utilizar uma solução inicial de qualidade ruim (porém rápida) que já explorava rotas consecutivas foi possível obter, na maioria dos casos, melhores resultados do que quando aplicada a Heurística com Busca Local sobre a solução inicial obtida pelos algoritmos da literatura.

\subsection{Perspectivas de trabalhos futuros}

Ao longo do desenvolvimento deste trabalho observaram-se oportunidades de trabalhos futuros, tais como:

- Alteração na estrutura de Heurística com Busca Local de forma a tratar problemas com cardinalidade maior do que as tratadas neste trabalho e pelas referências anteriores.

- Profundidade da Busca Local não depender de um dado de entrada (parâmetro n) conforme o número de rotas, mas deixar com que o algoritmo decida qual deverá ser a profundidade da busca a cada iteração. 
- Estudar outras variações de critérios de parada da Busca Local.

- Aplicação desta heurística em um caso real

- Aplicação desta heurística em outras variações do PCR (PCRER, PCRJT e PCRMT).

- Estudar o problema PCRCR combinado com outras restrições além da cardinalidade (tal como tempo e extensão do ciclo). 


\section{BIBLIOGRAFIA}

AARTS, E.; LENSTRA, J. K. Local search in combinatorial optimization. New York: Wiley, 1997.

BALLOT, E.; FONTANE, F. Reducing transportation co2 emissions through pooling of supply networks: Perspectives from a case study in french retail chains. Production Planning \& Control. v.21, p.640-650, 2010.

BALLOU, R. H. Gerenciamento da cadeia de suprimentos/logística empresarial. 5. Ed. Porto Alegre: Bookman, 2006.

BERGER, S.; BIERWIRTH, C. Solutions to the request reassignment problem in collaborative carrier networks. Transportation Research Part E: Logistics and Transportation Review, v. 46, n. 5, p. 10, 2010.

BOTTER, R. C.; TACLA, D.; HINO, C. M. Estudo e aplicação de transporte colaborativo para cargas de grande volume. Revista Pesquisa Operacional. Rio de Janeiro: SOBRAPO. v.26, no.1, 2006.

BOURLAKIS, C.; BOURLAKIS, M. Information technology safeguards, logistics asset specificity and fourth-party logistics network creation in the food retail chain. Journal of Business \& Industrial Marketing, v. 20, p. 88-98, 2005.

BROWNING, B.; WHITE, A. Collaborative transportation management. Logility Inc. 2004. Disponível em: http://www.logility.com/library/white-papers.cfm. Acesso em 10/08/2010.

CARIS, A.; MACHARIS, C.; JANSSENS, G. K. Network analysis of container barge transport in the port of antwerp by means of simulation. Journal of Transport Geography, v. 19, p. 9, 2011.

CHAN, F. T. S.; ZHANG, T. The impact of collaborative transportation management on supply chain performance: A simulation approach. International Conference on Supply Chain Management and Information Systems, 2010. Hong Kong.

CHOPRA, S.; MEINDL, P. Gerenciamento da cadeia de suprimentos. São Paulo: Prentice Hall, 2003. 
CROES, G. A. A method for solving traveling-salesman problems. Operations Research, v. 6, n. 6, p. 791-812, 1958.

CUNHA, C. B.; BONASSER, U. D. O.; ABRAHÃO, F. T. M. Experimentos computacionais com heurísticas de melhorias para o problema do caixeiro viajante. Panorama Nacional de Pesquisa em Transportes - Anais do XVI ANPET. Rio de Janeiro: ANPET. v.1, p.105-117, 2002.

DAI, B.; CHEN, H. Mathematical model and solution approach for collaborative logistics in less than truckload (ItI) transportation. International Conference on Computers Industrial Engineering, 2009. Troyes.

EISELT, H. A.; GENDREAU, M.; LAPORTE, G. Arc routing problems, part 1: The chinese postman problem. Operations Research, v. 43, p. 231-242, 1995.

ERGUN, O.; KUYZU, G.; SAVELSBERGH, M. The lane covering problem. Georgia Institute of Technology, EUA. 2004.2 Disponível em: http://www2.isye.gatech.edu/ mwps/publications/ijoc030404.pdf. Acesso em 05/08/2010.

ERGUN, Ö.; KUYZU, G.; SAVELSBERGH, M. Reducing truckload transportation costs through collaboration. Georgia Institute of Technology, EUA. 2007a. Disponível em: http://www2.isye.gatech.edu/ gkuyzu/TCLCP.pdf. Acesso em 05/08/2010.

ERGUN, Ö.; KUYZU, G.; SAVELSBERGH, M. Shipper collaboration. Computers \& Operations Research, v. 34, p. 1551 - 1560, 2007b.

ESPER, T. L.; WILLIAMS, L. R. The value of collaborative transportation management (ctm): Its relationship to cpfr and information technology. Transportation Journal, v. 42, n. 4, p. 14, 2003. Disponível em: http://transplace.com/media/TheValueofCTM112002.pdf. Acesso em: 10/08/2010.

FERRI, E. B. Uma proposta de heurística para solução do problema de cobertura de rotas com cardinalidade restrita. 2009. 158 p. Dissertação (Mestrado). Departamento de Engenharia de Produção, Escola Politécnica da Universidade de São Paulo, São Paulo.

LIN, S. Computer solutions of the traveling salesman problem. Bell System Technical Journal, v. 44, p. 2245-2269, 1965. 
LIN, S.; KERNIGHAN, B. W. An effective heuristic algorithm for the traveling salesman problem. Operations Research, v. 21, p. 498-516, 1973.

ÖZENER, O. Ö. Collaboration in transportation. 2008. Tese (Doutorado). Georgia Institute of Technology, Estados Unidos.

ÖZENER, O. Ö.; ERGUN, Ö. Allocation costs in a collaborative transportation procurement network. Transportation Science. v.42, no.2, p.146-165, 2008.

ÖZENER, O. Ö.; ERGUN, Ö.; SAVELSBERGH, M. Lane-exchange mechanisms for truckload carrier collaboration. Transportation Science. v.45, no.1, p.1-17, 2011.

PAN, S.; BALLOT, E.; FONTANE, F. The reduction of greenhouse gas emissions from freight transport by pooling supply chains. International Conference on Industrial Engineering and Systems Management. Montréal, Canada, 2009.

SAVELSBERGH, M.; ERGUN, O.; KUYZU, G. Collaborative logistics. 35th Annual Conference of the Italian Operations Research Society, 2004. Lecce, Itália.

STRINGHER, F. G. Designação de rotas para frota dedicada em uma rede de distribuição de linha branca. 2004. 90 p. Dissertação (Mestrado). Departamento de Engenharia de Produção, Escola Politécnica da Universidade de São Paulo, São Paulo.

TYAN, J.; WANG, F. Applying collaborative transportation management models in global third-party logistics. International Journal of Computer Integrated Manufacturing, v. 16, p. 9, $2003 . \quad$ Disponível em: http://www.informaworld.com/smpp/title content=t713804665. Acesso em: 10/08/2010.

VIEIRA, J. G. V.; YOSHIZAKI, H. T. Y.; LUSTOSA, L. J. Um estudo exploratório sobre colaboração logística em um grande varejo supermercadista. Produção. v. 20, p.p. $135-147,2010$. 